\title{
LOS CURSOS DE AGUA COMPARTIDOS ENTRE MÉXICO Y LOS ESTADOS UNIDOS DE AMÉRICA Y LA VARIABLE MEDIOAMBIENTAL. UNA APROXIMACIÓN*
}

\author{
Marisol ANGLÉS HERNÁNDEZ**
}

RESUMEN: Este artículo analiza las relaciones de México y los Estados Unidos de América respecto de las aguas fronterizas. En la región semiárida de la frontera México-EUA las tensiones sobre el uso del agua, su contaminación y su distribución equitativa han aumentado. Aunque hay muchos obstáculos, gradualmente la cooperación en la gestión de los recursos compartidos y en el tratamiento de los problemas ambientales transfronterizos se ha consolidado. La autora muestra algunos de los éxitos y de las fallas de los ambiciosos programas de política y de los tratados de la frontera y enfatiza que México y los EUA enfrentan un gran desafío, al ser necesario considerar las implicaciones del cambio climático en la definición de las estrategias de la administración del agua y su distribución equitativa, desarrollo urbano y mejora del medio ambiente en la zona fronteriza.

ABSTRACT: This paper examines U.S.-Mexico relations regarding border waters. In the semi-arid border region from Mexico-U.S. the tensions about the use of water, its pollution, and its equitable distribution have increased. Even though there are many obstacles, the cooperation on management of shared resources and jointly addressing transboundary environmental problems has gotten strengthen gradually. The author shows some of the successes and failures of the ambitious border policy initiatives and treaties about the border and emphasizes that Mexico and the U.S. face a great challenge, certainly, it is necessary to consider climatic change to may define planning strategies for water management, and its equitable distribution; urban development, and improvement of the environment in the border area.

RÉSUMÉ: Cet article analyse les relations du Mexique et les Etats-Unis de l'Amérique en ce qui concerne les eaux frontalières. Dans la région semi-aride de la frontière Mexique-EUA les tensions sur l'utilisation de l'eau, sa pollution et sa distribution équitable ont augmenté. Bien qu'il y ait beaucoup d'obstacles, la coopération dans la gestion des ressources partagées et dans le traitement des problèmes environnementaux transfrontaliers a été consolidée progressivement. L'auteur montre certaines des succès et quelques échecs des ambitieux programmes de politique et des traités de la frontière et souligne que le Mexique et les EUA font face à un grand défi, étant nécessaire de considérer les implications du changement climatique dans la définition des stratégies de la gestion de l'eau et sa distribution équitable, le développement urbain et l'amélioration de l'environnement dans la zone frontalière.

* Agradezco las observaciones y comentarios del doctor Rodolfo Cruz Miramontes, ya que gracias a ellos este artículo tomó una nueva dirección y pudo enriquecerse.

** Académica del Instituto de Investigaciones Jurídicas de la UNAM, doctoranda del Programa "Derecho Ambiental", Universidad de Alicante, España; becaria de la Dirección General de Asuntos del Personal Académico de la UNAM, mangles@servidor.unam.mx

Anuario Mexicano de Derecho Internacional, vol. VI, 2006, pp. $89-166$ 
SUMARIO: I. Introducción. II. Características generales de la frontera México-EUA. III. Aspectos sociopolíticos y jurídicos de la frontera México-EUA. IV. Marco jurídico del agua en México. V. Las cuencas superficiales compartidas entre México y los EUA. VI. Disposiciones relevantes del Tratado de Aguas de 1944. VII. Incumplimiento del Tratado de Aguas por parte de México. VIII. Principios de derecho internacional ambiental. IX. Cooperación ambiental bilateral. X. Reflexiones finales. XI. Bibliohemerografía.

\section{INTRODUCCIÓN}

Por todos es sabido que el agua cubre el $70 \%$ de la superficie del planeta y que es el elemento que ha hecho posible la biosfera. ${ }^{1}$ Debido al ciclo hidrológico, la cantidad total de agua dulce ni aumenta ni disminuye desde hace miles de años. De los más de 1,400 millones de kilómetros cúbi$\cos \left(\mathrm{km}^{3}\right)$ de agua disponible en el planeta tan sólo el $0,05 \%$ es destinado a atender las condiciones básicas para la vida sobre la tierra firme, ${ }^{2}$ pues el $96.5 \%$ del volumen total se localiza en los océanos y solamente $2.5 \%$ es agua dulce, de este pequeño porcentaje las dos terceras partes se encuentra en las regiones polares y el resto forma los sistemas de agua subterránea. ${ }^{3}$

La historia de la civilización humana ha ido de la mano con la del aprovechamiento de los recursos hídricos. El agua permitió que el hombre pasara de ser nómada a sedentario mediante la práctica de la agricultura; actividad que consume las dos terceras partes del agua disponible en el mundo, pues aproximadamente el $40 \%$ de los alimentos se cosecha en campos de regadío. ${ }^{4}$

La escasez del agua es la peor amenaza contra la producción de alimentos para el futuro, ya que las estimaciones para el año 2025 muestran que harán falta $800 \mathrm{~km}^{3}$ más de agua (diez veces el caudal del río Nilo)

1 Cfr. Martín Mateo, Ramón, "Cultura y tecnología del agua", Revista Española de Derecho Administrativo, Madrid, núm. 62, 1988, pp. 173 y ss.

2 Véase Martín Mateo, Ramón, Tratado de derecho ambiental, Madrid, Trivium, 1991, vol. 2, p. 3.

3 Cfr. Mazari Hiriart, Marisa, "El agua como recurso", ¿Cómo ves?, México, año 5, núm. 54, mayo 2003, p. 10.

4 Cfr. Albright, Madelene, "An Alliance for Global Water Security in the 21st Century", International Rivers and Lakes Newsletter, New York, núm. 33, June 2000, p. 8. 
para satisfacer la demanda alimenticia de unos 7,200-8,000 millones de personas. ${ }^{5}$ Lo anterior plantea nuevos retos para el desarrollo de sistemas de riego que permitan un mejor aprovechamiento de los recursos hídricos y eviten su desperdicio.

Respecto de la disponibilidad del recurso, reportes de la Organización de las Naciones Unidas identificaron la existencia de más de 1,000 millones de personas que no cuentan con agua potable y unos $2,500 \mathrm{mi}-$ llones que no tienen saneamientos adecuados; debido a ello mueren al día entre 10 mil y 20 mil niños por enfermedades evitables vinculadas al agua. ${ }^{6}$

En consecuencia, el agua ha dejado de considerarse un elemento inagotable, al servicio incondicional de todos, para adquirir un valor económico e importancia significativa en los últimos años $;^{7}$ especialmente, desde que su escasez es abordada como un problema de carácter mundial y actual, ${ }^{8}$ por lo que el acceso a este recurso se erige como un derecho humano fundamental, ${ }^{9}$ pues de las reservas de agua dulce — ríos, lagos, lagunas y acuíferos subterráneos - depende el derecho a la vida recono-

5 Véase Postel, Sandra, "Aprovechamiento agrícola del agua", Investigación y Ciencia, Madrid, núm. 295, abril 2001, pp. 28-30.

6 Cfr. Gleick, Peter H., "La importancia de cada molécula", Investigación Cientifica, Madrid, núm. 295, abril 2001, p. 23.

7 Cfr. Loperena Rota, Demetrio, El derecho al medio ambiente adecuado, reimp., Madrid, Civitas, 1998, p. 160. En este sentido, el agua ha sido considerada como un elemento de seguridad nacional tanto en México como en los Estados Unidos de América, situación que la ubica entre los aspectos prioritarios en las políticas nacionales y bilaterales. Sobre la conceptualización del agua puede verse García-Acevedo, María Rosa, "The confluence of water, patterns of settlement, and constructions of the border in the Imperial and the Mexicali Valleys (1990-1999)", en Blatter, Joachim e Ingram, Helen (eds.), Reflections on water: New approaches to transboundary conflicts and cooperation, Cambridge, The MIT Press, 2001 y Gottlieb, Robert y Fitz Simmons, Margaret, Thirst for growth: Water agencies as hidden government in California, Tucson, University of Arizona Press, 1991, p. 75.

8 Cfr. Filho, Armando Gallo Yahn, "Aspectos jurídico-ambientais da utilização dos cursos d'água internacionais", en Benjamin, Antonio Herman (ed.), Direito, Água e Vida, São Paulo, Procuradoria Geral de Justiça do Estado de São Paulo-Instituto O Direito por um Planeta Verde, 2003, vol. 2, p. 52.

9 Por vez primera, en noviembre de 2002, el Pacto Internacional sobre Derechos Económicos, Sociales y Culturales reconoció el derecho al agua como un derecho humano fundamental, por lo que los 145 países que ratificaron este instrumento están obligados a asegurar progresivamente que todos tengan acceso al agua potable segura, de forma equitativa y sin discriminación. Cfr. United Nations, International Year of Freshwater 2003, "El derecho al agua como derecho humano", en http://www.wateryear2003.org/es/ev.php-URL_ID $=4087 \& U R L \_D O=D O \_T O P I C \& U R L \_S E C-I O N=2$ 01.html 
cido por el artículo 3o. de la Declaración Universal de los Derechos del Hombre. ${ }^{10}$

De cada dos ríos y lagos importantes en el planeta, uno está seriamente contaminado. En cada continente, se han dañado los ecosistemas de agua dulce; la mitad de los humedales del mundo ha desaparecido. Por otra parte, los estudios demuestran que la presión sobre los acuíferos se eleva tanto como las poblaciones crecen; así, aumenta la demanda, continúa y se incrementa la contaminación, y el cambio climático en el ámbito global se acelera. ${ }^{11}$

Así es que, como bien apunta el maestro Martín Mateo, la falta de una autoridad internacional del agua puede dar lugar, en un futuro no muy lejano, a importantes conflictos internacionales, ya que no es suficiente tener agua, ésta debe contar con determinados parámetros de calidad que permitan su utilización. ${ }^{12}$ Por ello debe atenderse el grave problema del deterioro de las aguas como resultado de los vertidos excesivos e incontrolados; ${ }^{13}$ así como la racionalización del uso de las reservas de agua dulce, a fin de permitir que los acuíferos se recuperen y con ello garantizar su disponibilidad y la estabilidad internacional. ${ }^{14}$

Aunque es claro que los Estados han decretado leyes ambientales y han tomado medidas para limpiar los acuíferos, prevenir la contaminación atmosférica, $y$, entre otros, conservar los recursos naturales y la biodiversidad, debe ponerse especial énfasis en un elemento que es la base

10 Véase el texto completo de la Declaración en Tapia Hernández, Silverio (comp.), Principales Declaraciones y Tratados Internacionales de Derechos Humanos Ratificados por México, México, Comisión Nacional de Derechos Humanos, 1999, pp. 27-32.

11 Las actividades humanas han modificado la composición de la atmósfera terrestre por el aumento de los gases de efecto invernadero (GEI), entre los que destaca el bióxido de carbono $\left(\mathrm{CO}_{2}\right)$ producido por la quema de combustibles fósiles — carbón, petróleo y gas natural- . De acuerdo con la Convención Marco de las Naciones Unidas sobre el Cambio Climático, los GEI son aquellos componentes gaseosos de la atmósfera, tanto naturales como antropogénicos, que absorben y remiten radiación infrarroja (artículo 1o., párrafo 5o.), cfr. United Nations, "The United Nations Framework Convention on Climate Change", en http://unfccc.int/essential_background/kyoto_protocol/status_of_ratification/items/2613.php

12 La calidad del agua significa que ésta debe mantener las aptitudes indispensables para satisfacer las distintas necesidades, tales como el consumo humano y de los animales, el riego, el uso industrial, el uso recreativo, etc. Cfr. Campos Díaz Barriga, Mercedes, La responsabilidad civil por daños al medio ambiente; El caso del agua en México, México, UNAM, Instituto de Investigaciones Jurídicas, 2000, p. 140.

13 Sobre el particular véase Martín Mateo, Ramón, Tratado..., cit., vol. 2, p. 5.

14 Cfr. Albright, Madelene, "An Alliance for Global Water..., cit., p. 7. 
para todos los demás: el agua, recurso imprescindible para la vida y desafío ambiental para la comunidad internacional de nuestra época.

En el contexto geopolítico en el que se ubica el tema de los cursos de agua compartidos entre México y los EUA se erige como una cuestión ineludible en la agenda diplomática binacional, la negociación relativa a su distribución equitativa y a la prevención de su contaminación; ${ }^{15}$ misma que debe basarse en el aparato normativo e institucional de ambos países, así como en el desarrollo de los mecanismos, de carácter internacional, establecidos para tal fin, los cuales deben fomentar la participación de los grupos ambientalistas y los usuarios tradicionales del agua. ${ }^{16}$

Nuestros países se beneficiarán de esta alianza al disminuir las tensiones bilaterales y al contribuir ambos a la mejora de las condiciones medioambientales del mundo.

En este trabajo analizamos el problema de los cursos de agua superficiales compartidos por México y los EUA, con especial énfasis en el Tratado de Distribución de Aguas de 1944 y en las condiciones que han complicado su cumplimiento; destacamos, sin embargo, la cooperación que ha caracterizado los procesos de negociación bilateral sobre la cuestión, así como la falta de atención a temas intrínsecos en la problemática.

\section{CARACTERÍSTICAS GENERALES DE LA FRONTERA MÉXICO-EUA}

La frontera entre México y los Estados Unidos de América (EUA) es una de las más largas del mundo, con una longitud de 3,141 km. Cuatro estados estadounidenses (California, Arizona, Nuevo México y Texas) y, seis estados mexicanos (Baja California Norte (BCN), Sonora, Chihuahua, Coahuila, Nuevo León y Tamaulipas) están situados a lo largo de esta línea fronteriza, donde catorce ciudades gemelas colindan, desde

15 De acuerdo con las Normas de Helsinki, el término contaminación del agua se refiere a todo cambio nocivo resultante de un acto humano en la composición, contenido o calidad naturales de las aguas de una cuenca hidrográfica internacional (artículo IX). Cfr. Székely, Alberto, Instrumentos fundamentales de derecho internacional público, México, UNAM, Instituto de Investigaciones Jurídicas, 1990, t. V, p. 3340, disponible en http://www.bibliojuridica.org/libros/libro.htm?l=356

16 Cfr. Du Mars, Charles T., "The New Federal Regulatory Water Rights and the Future of River Management: The Example of New Mexico", Utton Center Report, Albuquerque, New Mexico, vol. 1, núm. 1, spring, 2002, p. 3. Los boletines del "Utton Transboundary Resources Center", publicados por la Facultad de Derecho de la Universidad de Nuevo México, pueden consultarse en: http://uttoncenter.unm.edu/newsletter.html 
San Diego-Tijuana, en las costas del océano Pacífico, hasta Brownsville-Matamoros, en el Golfo de México. La línea fronteriza se conforma de la siguiente manera: 2,019 km están delimitados por el río Bravo; $1,084 \mathrm{~km}$ son cruzados por la línea divisoria terrestre al oeste de Ciudad Juárez, Chihuahua y, $38 \mathrm{~km}$ corresponden al segmento del río Colorado. ${ }^{17}$

Esta frontera une dos grandes países, dos culturas con marcadas diferencias económicas, políticas y sociales, y soporta una ineludible interdependencia regional. ${ }^{18}$ En la actualidad, se encuentra habitada por 10.6 millones de personas, con una población de 4.8 millones en la parte mexicana y de 5.8 millones en la estadounidense. Se estima que para el año 2020 la población podría llegar a alcanzar los 24 millones en ambos lados de la frontera. ${ }^{19}$

La región presenta una diversidad de climas que varía entre el muy seco y el templado subhúmedo. Con excepción de una porción equivalente a menos del 3\% de la franja fronteriza, en su extremo noreste, en donde predomina el clima subhúmedo, la frontera binacional es dominada en un $96 \%$ por los climas seco y muy seco.

Las principales cuencas hidrológicas superficiales de la región son el río Bravo y el Colorado. La disponibilidad general de agua superficial y subterránea en la franja fronteriza es escasa, debido principalmente a la sobreexplotación, uso inadecuado, excesiva demanda y, entre otros, a los severos problemas de sequía, que con cierta frecuencia se presentan. ${ }^{20}$

17 Secretaría de Relaciones Exteriores, "Comisión Internacional de Límites y Aguas entre México y los Estados Unidos", en http://www.sre.gob.mx/cila

18 Davila, Guillermo H., "Air pollution control on the United States-Mexico Border: International considerations", Natural Resources Journal, Albuquerque, New Mexico, vol. 12, núm. 4, October, 1972, p. 545.

19 Cfr. Bennett, Vivienne y Herzog, Lawrence A., "U.S.-Mexico borderland water conflicts and institutional change: A commentary", Natural Resources Journal, Albuquerque, New Mexico, vol. 40, núm. 4, fall 2000, p. 974; y Peach, James y Williams, James, "Borderlands Demographic Trends", Borderlines 58, New Mexico, vol. 7, núm. 7, August 1999, p. 4. Borderlines es una publicación realizada por el Interhemispheric Resource Center del International Relations Center, ubicado en Silver City, New Mexico, disponible en http://americas.irc-online.org/borderlines/index.html

20 Véase Food Agriculture Organization, "Sistema de Información sobre el Uso del Agua en la Agricultura y el Medio Rural de la FAO; Estado del Agua en México", en http://www.fao.org/ landandwater/aglw/aquastat/countries/mexico/indexesp.stm. En los últimos años la comunidad internacional ha trabajado sobre el problema de la desertificación, es decir, la extensión de los desiertos a tierras anteriormente productivas, por ello, a partir de 1994, la ONU proclamó el 17 de junio como Día Mundial de Lucha contra la Desertificación y Sequía, con objeto de sensibilizar a la opinión pública sobre la importancia de controlar la extensión del desierto, así como valorar y cuidar 
Además de lo anterior, los problemas de contaminación complican el manejo y abasto del agua de la zona. De manera más específica, las descargas de aguas municipales e industriales; los residuos agrícolas y los pesticidas han contribuido también a la degradación de la calidad de las aguas de la cuenca del río Conchos. Por su parte, el río Pecos tiene un alto nivel de sólidos disueltos totales, por lo que es inadecuado para usos domésticos y municipales, en consecuencia su caudal es utilizado para la irrigación de algunas ciudades rurales por las que atraviesa. ${ }^{21} \mathrm{La}$ calidad del agua en las presas la Amistad y Falcón, también se ha visto afectada por las aguas residuales industriales y domésticas provenientes de las ciudades de Nuevo Laredo y Laredo; así como por los niveles de salinidad elevados, provenientes del Golfo de México; estos cambios también han alterado la diversidad de las especies acuáticas, ya que muchas de ellas han sido reemplazadas por otras con mayor tolerancia salina. ${ }^{22}$

Aunado a lo anterior, tenemos que, en general, las zonas con mayor densidad de población son deficitarias en su balance oferta-demanda de agua, en consecuencia las nuevas fuentes de abastecimiento se ubican cada vez a mayor distancia de los centros de consumo. ${ }^{23}$

En ambos lados de la frontera existen importantes áreas naturales protegidas o parques nacionales con diversas categorías de manejo, en las que se hallan ecosistemas tan diversos como bosques templados, zonas áridas, marinas y humedales, entre otros. ${ }^{24}$

los recursos hídricos en los cinco continentes. Por su parte, la Convención Marco de las Naciones Unidas sobre Cambio Climático incluye consideraciones especiales con relación a los países más vulnerables y también sobre aquellos países que podrían verse afectados por las medidas que se tomaran por los países industrializados (artículos 4.8 y 4.9).

21 Kelly, Mary, Solís, Arturo y Kourous, George, "The Border's Troubled Waters", Borderlines 83, New Mexico, vol. 9, núm. 10, November 2001, p. 5.

22 Idem.

$23 C f r$. Herrera Ramos, M. J. (ed.), Desarrollo regional e infraestructura, México, Fundación Mexicana Cambio XXI, 1994, p. 78. Datos interesantes pueden consultarse en Romero Lankao, Patricia, "Uso social y gestión gubernamental del agua en México", en Barba Pirez, Regina (coord.), La guía ambiental, México, Unión de Grupos Ambientalistas, 1998, pp. 207-214.

24 Secretaría de Medio Ambiente y Recursos Naturales, Centro de Educación y Capacitación para el Desarrollo Sustentable, "Programa para la Frontera Norte", en http://cecadesu.semarnat.gob. $m x /$ programa_fronteranorte/index.shtml\#_ftn 1 


\section{ASPECTOS SOCIOPOLÍTICOS Y JURÍDICOS DE LA FRONTERA MÉXICO-EUA}

Las tensiones bilaterales entre México y los EUA se remontan al establecimiento de los límites fronterizos entre ambos países. En ese contexto se celebraron: el Tratado del 12 de enero de 1828 en el que se fijaron las líneas fronterizas; ${ }^{25}$ el Tratado de Paz, Amistad y Límites, ${ }^{26}$ suscrito en Guadalupe Hidalgo, el 2 de febrero de 1848 y, años más adelante, el Tratado de Límites la Mesilla, ${ }^{27}$ firmado en 1853, por virtud de los cuales México perdió más de la mitad de su territorio original. ${ }^{28}$ Con el paso de los años, otro motivo de tensión fue el uso de los cursos de agua compartidos - el Tijuana, el Colorado y el Bravo-. En relación a los ríos Colorado y Bravo, en ese entonces, ambos países sólo dispusieron que no debería menoscabarse su navegabilidad. Al parecer, no se pensó en ninguna otra utilización de las aguas y, menos aún, en su preservación y distribución.

Como puede imaginarse, la consolidación de esta región binacional es producto de un largo proceso de integración que la ha transformado en uno de los sitios de mayor movimiento de personas y mercancías en el mundo; ello, debido al impulso que ambos países dieron a la zona. Por un lado, el gobierno estadounidense realizó grandes inversiones para la

25 Este tratado vino a ratificar el Tratado Adams-Onís, signado en 1819, que señalaba los límites territoriales entre, la entonces, Nueva España y los Estados Unidos de América. Cfr. Bosch García, Carlos, “1819-1836: la expansión norteamericana”, Revista Secuencia, México, núm. 20, mayo-agosto, 1991, pp. 25-34.

26 Un estudio sobre el origen y la negociación de este pacto puede encontrarse en Sepúlveda, César, "Historia y problemas de los límites de México; I. La frontera Norte", Historia Mexicana, México, vol. VIII, núm. 1, julio-septiembre, 1958, pp. 1-34. En este instrumento, las cláusulas V a VII abordan las cuestiones fluviales y reconocen como ríos fronterizos al Bravo/Grande, al Gila y al Colorado, cfr. Secretaría de Relaciones Exteriores, Algunos Documentos sobre el Tratado de Guadalupe y la situación de México durante la invasión americana, México, SRE, Archivo Histórico Mexicano, 1930, p. 139.

27 Sobre el tema véase Diego-Fernández, Salvador, Los pactos de Bucareli; El Tratado de la Mesilla, México, Editorial Polis, 1937. Por virtud de este convenio, el río Gila dejó de ser fronterizo y el Colorado continuó siéndolo en un tramo mínimo. Véase Casasús, Joaquín D., El Chamizal. Demanda, réplica, alegato e informes ante el Tribunal de Arbitraje y sentencia, México, Eusebio Gómez de la Puente, Editor, 1911, pp. 66-70.

28 La Convención Respecto a la Línea Divisoria entre los Dos Países en la Parte que sigue el Lecho del Río Grande y el Río Colorado, celebrada el 14 de noviembre de 1884, dio respuesta definitiva a los cambios naturales de la cuenca del río Bravo, consistentes en mudar su cauce, arrancar bordes y trasladar los pueblos de un lado de la frontera al otro, lo cual alteraba el límite establecido y provocaba constantes y recurrentes problemas. Cfr. Sepúlveda, César, "Historia y problemas de los límites...", cit., p. 24. 
industria manufacturera y la agricultura; mientras que el gobierno mexicano implementó diversos programas para alentar las inversiones en la infraestructura ${ }^{29} \mathrm{y}$ fortalecer a la industria maquiladora, lo que creó nuevos empleos y tuvo un efecto indirecto sobre las actividades comerciales y de servicios. ${ }^{30}$ Entre los factores que han impulsado la migración mexicana hacia el norte del país, se encuentran el desempleo y la proximidad con los EUA, que es vista como la posibilidad de alcanzar empleo y mejores niveles de vida. ${ }^{31}$

Es innegable que la industrialización ha traído beneficios económicos importantes a la región fronteriza, especialmente a la de México que se ha convertido en la zona de mayor intercambio de capital. Sin embargo, no deben perderse de vista los conflictos y contradicciones producto de las asimetrías económicas, sociales, culturales y políticas entre ambos países; fundamentalmente, la migración, el narcotráfico y la contaminación transfronteriza; ${ }^{32}$ así como la dinámica poblacional que ha incrementado, entre otros, la demanda del uso y consumo del agua; la utilización industrial del agua del río Bravo como insumo y su cauce como receptor, con capacidad ilimitada, de aguas residuales, sustancias y residuos peligrosos, ${ }^{33}$ lo que ha contaminado su caudal y, por ende, limitado su aprovechamiento, amén de alterar los mantos freáticos a través de las

29 Cfr. Brown, Christopher P. y Mumme, Stephen, "Applied and theoretical aspects of Binational Watershed Councils (Consejos de Cuencas) in the US-Mexico Borderlands", Natural Resources Journal, Albuquerque, New Mexico, vol. 40, núm. 4, fall, 2000, p. 896.

30 Véase Victoria Mascorro, Edmundo, "Características del desarrollo económico de la franja fronteriza norte de México", Natural Resources Journal, Albuquerque, New Mexico, vol. 22, núm. 4, October, 1982, pp. 823-845.

31 Véase Enriquez, Bill, "International legal implications of industrial development along the Mexican-U.S. border", Natural Resources Journal, Albuquerque, New Mexico, vol. 12, núm. 4, October, 1972, pp. 570-571.

32 La contaminación transfronteriza es aquella que se origina en un Estado y produce efectos dañinos sobre el medio ambiente de otro Estado, cfr. Kiss, Alexandre y Shelton, Dinah, International environmental law, New York, Transnational Publishers, Inc., 1991, p. 115. Por su parte, la OCDE ha definido a este tipo de contaminación como la introducción por el hombre, directa o indirectamente, de sustancias o energía en el medio ambiente que origina efectos dañinos a la naturaleza y pone en riesgo la salud humana, daña a los recursos vivos y a los ecosistemas y deteriora o interfiere con el esparcimiento y los usos legítimos del medio ambiente, $c f r$. Recomendación C (74) 224 de noviembre 14, 1974.

33 Cfr. García Moreno, Víctor Carlos, "Derecho internacional, ecología, desechos peligrosos y otros temas", Lex; Difusión y Análisis, México, 3a. época, año II, núm. 10, abril 1996, p. 43 y Piñero, Daniel (comp.), La ecología, las ciencias ambientales y la situación ambiental en México, México, Secretaría Ejecutiva del Consejo Consultivo de Ciencias, Presidencia de la República, 1994, p. 22. 
infiltraciones. ${ }^{34}$ Todas estas acciones ponen en riesgo la salud de los habitantes de la zona fronteriza binacional y evidencian la insuficiencia de las políticas públicas para prevenir y restaurar los daños ambientales. ${ }^{35}$

\section{MARCO JURÍDICO DEL AGUA EN MÉXICO}

Las bases legales para el aprovechamiento del agua en México provienen de la Constitución de los Estados Unidos Mexicanos, que decreta en su artículo 27 que son propiedad de la nación, entre otros, las aguas de los ríos y sus afluentes directos o indirectos, los lagos interiores de formación natural, los manantiales y el subsuelo. Asimismo, la nación ejerce un dominio inalienable e imprescriptible sobre el agua y compete al Ejecutivo federal otorgar concesiones y asignaciones para su aprovechamiento. ${ }^{36}$ En lo referente al aspecto institucional, en 1989 se creó la Comisión Nacional del Agua (CNA), como autoridad única en la materia. ${ }^{37}$

A partir de la promulgación en 1988 de la Ley General del Equilibrio Ecológico y la Protección al Ambiente (LGEEPA); así como del establecimiento del cobro de derechos por descargas regulado por la Ley Federal de Derechos de 1991 y reformas de 1996 y 1997, se han iniciado importantes proyectos para dar tratamiento a las aguas residuales y reducir los niveles de contaminación de los cuerpos receptores de descargas de agua en el país. Sin embargo, aun cuando se reconoce un importante avance, la evaluación de los logros alcanzados muestra que es necesario un mayor esfuerzo en la planeación y ejecución de estos programas.

34 Véase Sánchez, Roberto A., "Health and environmental risk of the maquiladora in Mexicali”, Natural Resources Journal, Albuquerque, New Mexico, vol. 30, núm. 1, winter 1990, pp. 163-186 y Kiss, Alexandre y Shelton, Dinah, International..., cit., p. 224.

35 Cfr. Kelly, Mary, Solís, Arturo y Kourous, George, "The Border's Troubled..., cit., p. 4 y Gasca Zamora, José, "Desarrollo regional y medio ambiente en la frontera de México-Estados Unidos", en Delgadillo Macías, Javier (coord.), Los terrenos de la política ambiental en México, México, UNAM, Instituto de Investigaciones Económicas-Miguel Ángel Porrúa, Librero-Editor, 2001, pp. 195-200.

36 Véase Carbonell, Miguel (coord.), Constitución Política de los Estados Unidos Mexicanos; Comentada y concordada, México, Porrúa-UNAM, Instituto de Investigaciones Jurídicas, 2003, t. I, pp. 407-422.

37 La CNA es un órgano desconcentrado que en sus orígenes dependió de la Secretaría de Agricultura y Recursos Hidráulicos y que a partir de diciembre de 1994 se integró a la Secretaría de Medio Ambiente, Recursos Naturales y Pesca, hoy Secretaría de Medio Ambiente y Recursos Naturales. 
El agua subterránea, uno de los recursos naturales más importantes, constituye a escala mundial una gran proporción del agua que puede y que ha sido utilizada. En México obtenemos aproximadamente $30 \mathrm{mil}$ millones de $\mathrm{m}^{3}$ de agua al año de los acuíferos subterráneos, utilizándose $63 \%$ para riego, $19 \%$ para satisfacer las necesidades de las poblaciones urbanas, $13 \%$ para abastecer a la industria y $5 \%$ para aprovechamiento rural. ${ }^{38}$

El problema de la disponibilidad efectiva del agua es aún mayor por la deficiente infraestructura hidráulica, la ineficiencia de su uso y el aumento de los niveles de contaminación. ${ }^{39}$ Aunado a ello, tenemos la sobreexplotación de estos acuíferos que provoca el abatimiento de sus niveles y la concentración de sustancias como el arsénico y sus compuestos, los cuales impiden su utilización como agua potable. ${ }^{40}$

En este sentido, corresponde a la Comisión Nacional del Agua publicar en el Diario Oficial de la Federación la disponibilidad de las aguas nacionales, determinada con base en la norma oficial mexicana: "NOM011-CNA-2000, Conservación del Recurso Agua". ${ }^{41}$ Por tanto, el 31 de enero de 2003 fue publicada la disponibilidad de 188 acuíferos de los 654 identificados. De estos 188 acuíferos, 102 están en condiciones de sobreexplotación (la extracción es superior a la recarga al menos en un $10 \%$ ) y los otros 47 se encuentran cerca de la condición de sobreexplotación. ${ }^{42}$ En el ámbito mundial, México ocupa el lugar 74 con $57.5 \%$ del índice de pobreza de agua (IPA). ${ }^{43}$

38 Cfr. Mazari Hiriart, Marisa, "El potencial de contaminación del agua subterránea”, Gaceta Ecológica, México, nueva época, núm. 36, septiembre, 1995, pp. 54-56 y Escolero, O., Panorámica del agua subterránea en México; El agua recurso vital, Oaxaca, Universidad Tecnológica de la Mixteca, 1993, p. 17.

39 Cfr. Ortiz Rendón, Gustavo, “Aspectos relevantes de la política del agua en México en el marco del desarrollo sustentable", en http://www.oieau.fr/ciedd/contributions/at2/contribution/rendon.htm, p. 1 .

40 Cfr. Mazari Hiriart, Marisa, "El potencial...", cit., pp. 54-56 y Sánchez, Vicente, Castillejos, Margarita y Rojas Bracho, Leonora, Población, recursos y medio ambiente en México, México, Fundación Universo Veintiuno, 1989, pp. 88-89.

41 Comisión Nacional del Agua, "NOM-011-CNA-2000. Conservación del recurso agua. Establece las especificaciones y el método para determinar la disponibilidad media anual de las aguas nacionales", Diario Oficial de la Federación, México, 17 de abril de 2002.

42 Cfr. Comisión Nacional del Agua, Estadísticas del Agua en México, México, CNA, 2003, p. 33 .

43 Cfr. World Water Council, "Indicadores de disponibilidad, acceso y calidad del agua", en http://www.worldwaterforum.net 
Por lo que respecta a la Ley de Aguas Nacionales, promulgada en 1992 y reformada en 2004, entre sus objetivos fundamentales encontramos: ${ }^{44}$ la administración integral del agua; la mayor participación usuaria y privada en el financiamiento, construcción y operación; la seguridad jurídica sobre los aprovechamientos y el desarrollo integral sostenible del agua, sus bienes y servicios. Dicha ley contiene un procedimiento para constituir "Consejos de Cuenca", los cuales pretenden mejorar la coordinación intergubernamental para el ordenamiento de los recursos hidráulicos y consolidar la cooperación entre las entidades gubernamentales y los usuarios del agua, entre otros.

Este ordenamiento privilegia el uso doméstico y el público urbano, y señala expresamente las condiciones de variabilidad de la fuente de agua de la cual se realizará la extracción respectiva para el otorgamiento de concesiones y asignaciones; así como las restricciones a las que se sujetará la extracción de agua ante sequías y otros fenómenos, lo que permitirá tomar en consideración los volúmenes aprovechables en las fuentes señaladas (artículo 22). Asimismo, el Ejecutivo federal podrá expedir decretos para fundar zonas de veda para la explotación, uso o aprovechamiento de aguas, en casos de sobreexplotación, sequía, escasez extrema o situaciones de emergencia o urgencia, motivadas por contaminación de las aguas o por la explotación, uso o aprovechamiento de las aguas nacionales (artículo 39 bis).

Sin embargo, esta ley no define ninguno de los conceptos aludidos ante los cuales podrán dictarse decretos para establecer zonas de veda, algo similar a lo que sucede con algunas nociones que se incluyen en el Tratado de Aguas de 1944, analizado en el punto VI infra, y que han dificultado su aplicación satisfactoria.

En tanto se cumple con lo dispuesto en el párrafo tercero del artículo 22 de esta ley, ${ }^{45}$ se observará el siguiente orden de prelación para la con-

44 Secretaría de Medio Ambiente y Recursos Naturales, "Decreto por el que se Reforman, Adicionan y Derogan Diversas Disposiciones de la Ley de Aguas Nacionales", Diario Oficial de la Federación, México, 29 de abril de 2004.

45 Artículo 22, Párrafo 3o. El Consejo de Cuenca en coordinación con el Organismo de Cuenca que corresponda, propondrá a la CNA el orden de prelación de los usos del agua para su aprobación, el cual se aplicará en situaciones normales, para el otorgamiento de concesiones y asignaciones de la explotación, uso o aprovechamiento de aguas nacionales, superficiales y del subsuelo, atendiendo a lo dispuesto en los artículos 13 bis 3, y 14 bis 5 de esta ley. El uso doméstico y el uso público urbano siempre serán preferentes sobre cualquier otro uso. El artículo 13 bis 3 
cesión y asignación de la explotación, uso o aprovechamiento de aguas nacionales, superficiales y del subsuelo, aplicable en situaciones normales: 1. Doméstico, 2. Público urbano, 3. Pecuario, 4. Agrícola, 5. Uso para la conservación ecológica o uso ambiental, 6. Generación de energía eléctrica para servicio público, 7. Industrial, 8. Acuacultura, 9. Generación de energía eléctrica para servicio privado, 10. Lavado y entarquinamiento de terrenos, 11. Uso para turismo, recreación y fines terapéuticos, 12. Uso múltiple, y 13. Otros. Lo anterior se aplicará sin perjuicio de lo dispuesto en el artículo 29 bis 5 y en el título quinto, de esta ley. ${ }^{46}$

Entre los distintos planes estratégicos que se han puesto en práctica en el sector hidráulico mexicano, destacan: el Programa de Modernización de Manejo del Agua (Promma), el cual plantea una estrategia integral de reforma de la administración del agua con tres metas fundamentales: a) Asignación equitativa y eficiente del recurso; b) Uso sostenible y eficiente del agua; $\mathrm{y}, c)$ Acciones para la reducción de accidentes y pérdidas relacionadas con los fenómenos meteorológicos y climatológicos por la operación ineficiente de la infraestructura hidráulica. Uno de los lineamientos estipulados en el Programa Nacional Hidráulico 2001-2006 considera como prioridad promover el desarrollo financiero del sector a fin de contribuir a mantener e incrementar la calidad de los servicios de agua potable, alcantarillado y saneamiento; así como la prevención de los riesgos y la atención del impacto económico, político y social que generará el cambio climático extremo en México, todo ello, a través de los consejos de cuencas y el fomento en la eficiencia y productividad de las zonas de riego. ${ }^{47}$

En 1994 se creó un consejo para la cuenca del río Bravo, con inclusión del río Conchos, el cual empezó a sesionar recientemente a consecuencia del adeudo de agua de México a los EUA. Dicho adeudo tiene sustento en el Tratado de Aguas que analizamos en el inciso VI, mismo que, como veremos, actualmente no coincide con las circunstancias actuales imperantes, pues estudios científicos han demostrado que la precipitación pluvial en la cuenca del río Bravo es extremadamente variable, hecho que ha dado lugar a un fenómeno de "sequía severa" afectándose

establece las facultades de los Consejos de Cuenca y el artículo 14 bis 5 detalla los principios que sustentan la política hídrica nacional.

46 Artículo 15 transitorio de la Ley de Aguas Nacionales.

47 Véase Comisión Nacional del Agua, Programa Nacional Hidráulico 2001-2006, México, CNA, 2000, pp. 17 y ss. 
la región por más de diez años. ${ }^{48}$ Este es un problema multifactorial, que va desde la estructura geológica de la región hasta aspectos meteorológi$\cos ,{ }^{49}$ y que constituye un reto para quienes diseñan políticas, ya que sus causas y manifestaciones se presentan a nivel local, regional e internacional. ${ }^{50}$

La finalidad de este Consejo de Cuenca reside en tratar los aspectos relativos a la equidad en la distribución del recurso mediante una política coordinada que incluya acciones para la conservación. ${ }^{51}$

Paralelamente, las prácticas del Programa de Acciones de Saneamiento (PAS) coadyuvan a cumplir la norma NOM-001-Semarnat$1996^{52}$ que establece los límites máximos permisibles de contaminantes en las descargas de aguas residuales en aguas y bienes nacionales. Por su parte, el Programa de Modernización de Organismos Operadores de Agua (Promagua) se dirige preferentemente a las 178 localidades con más de 50,000 habitantes, las cuales representan el 54\% de la población actual del país; su objetivo es funcionar como fuente adicional de recursos y respaldar técnica y financieramente a estos organismos con ayuda de la iniciativa privada para incrementar su eficiencia, mejorar la calidad de los servicios, ampliar las coberturas, facilitar el acceso a tecnología de punta y apoyar la preservación ambiental. ${ }^{53}$

\section{LAS CUENCAS SUPERFICIALES COMPARTIDAS ENTRE MÉXICO Y LOS EUA}

Como producto de la constitución de la frontera México-EUA surge la necesidad natural de compartir algunos recursos como cuencas hidrológicas, atmosféricas y regiones de flora y fauna. En lo concerniente a los cursos de agua superficiales, ya señalamos que ambos países compar-

48 Houston Advanced Research Center, "Water and Sustainable Development in the Binacional Lower Rio Grande", en http://www.harc.edu/mitchellcenter/mexico/downloads.html

49 Hernández, John W., "Analysis of the drought of 1996 in the Middle Río Grande Valle of New Mexico", Natural Resources Journal, Albuquerque, New Mexico, vol. 39, núm. 1, winter 1999, pp. 133-134.

50 Cfr. Linares, Mireille, "La sequía en la cuenca del río Bravo: principios de política", Gaceta Ecológica, México, núm. 70, 2004, p. 57.

$51 C f r$. Brown, Christopher P. y Mumme, Stephen, "Applied and theoretical aspects of Binational Watershed ..., op. cit., pp. 904-905.

52 Publicada en Diario Oficial de la Federación, México, 6 de enero de 1997.

53 Comisión Nacional del Agua, "Programa de Modernización de Organismos Operadores de Agua", en http://www.cna.gob.mx/portal/publica/doctos/publicaciones/promma/promagua.pdf 
ten tres -el Tijuana, el Colorado y el Bravo-, cada uno con una complejidad diversa debido a sus condiciones particulares (véase el mapa en la página siguiente).

a) Río Tijuana. Esta corriente, cuya una extensión es de $152 \mathrm{~km}$, nace en el estado de Baja California Norte y desemboca en la bahía de San Diego, California. La cuenca del río es de 4,424 km²; de los cuales en México se encuentran aproximadamente tres cuartas partes de su total $\left(3,203 \mathrm{~km}^{2}\right)$, y en los EUA un tramo pequeño $\left(1,221 \mathrm{~km}^{2}\right)$. El uso y aprovechamiento de esta corriente transfronteriza, en general, ha sido conveniente para ambos países. ${ }^{54}$

b) Río Colorado. Este afluente nace en los EUA y su cuenca comprende los estados de Wyoming, Colorado, Utah, Nuevo México, Arizona, Nevada y California; tiene una longitud de 2,730 km, localizándose únicamente $160 \mathrm{~km}$ en nuestro territorio. ${ }^{55} \mathrm{La}$ aportación anual de la cuenca estadounidense es de 22,203,000,000 m³ ; mientras de la cuenca mexicana es realmente mínima.

El delta del río Colorado ha tenido distintos usos, ha servido de sustento a los nativos de la zona; se ha destinado a la navegación con fines comerciales; a la generación de electricidad y a la irrigación tierras cultivables, tanto en México como en los EUA, además ha abastecido a más de 30 millones de personas en ambos lados de la frontera. ${ }^{56}$

En materia de biodiversidad, el río Colorado desempeña un papel muy importante al permitir el desarrollo de una amplia variedad de vida silvestre, entre la que se incluyen muchas especies endémicas y en peligro de extinción listadas en ambos países. ${ }^{57}$ Sin embargo, los elevados niveles de salinidad que ha llegado a presentar su caudal, provenientes del aporte natural de selenio, así como de los residuos de tipo agrícola; ha provocado, como veremos más adelante, numerosos incidentes en ambos lados de la frontera.

54 Cfr. Secretaría de Relaciones Exteriores, El Tratado de Aguas Internacionales Celebrado entre México y los Estado Unidos el 3 de febrero de 1944, México, SRE, Oficina de Límites y Aguas Internacionales, 1947, pp. 13-14.

55 Cfr. Secretaría de Recursos Hidráulicos, Salinidad del Río Colorado (Recopilación), México, SRH, 1975, pp. 1-2.

56 Cfr. Pitt, Jennifer et. al., "Two nations, One river: Managing ecosystem conservation in the Colorado River Delta”, Natural Resources Journal, Albuquerque, New Mexico, vol. 40, núm. 4, fall, 2000, pp. 826-827.

57 Ibidem, pp. 825 y 829 . 
Mapa. Acuíferos superficiales transfronterizos México-EUA

ESTADOS UNIDOS DE AMÉRICA

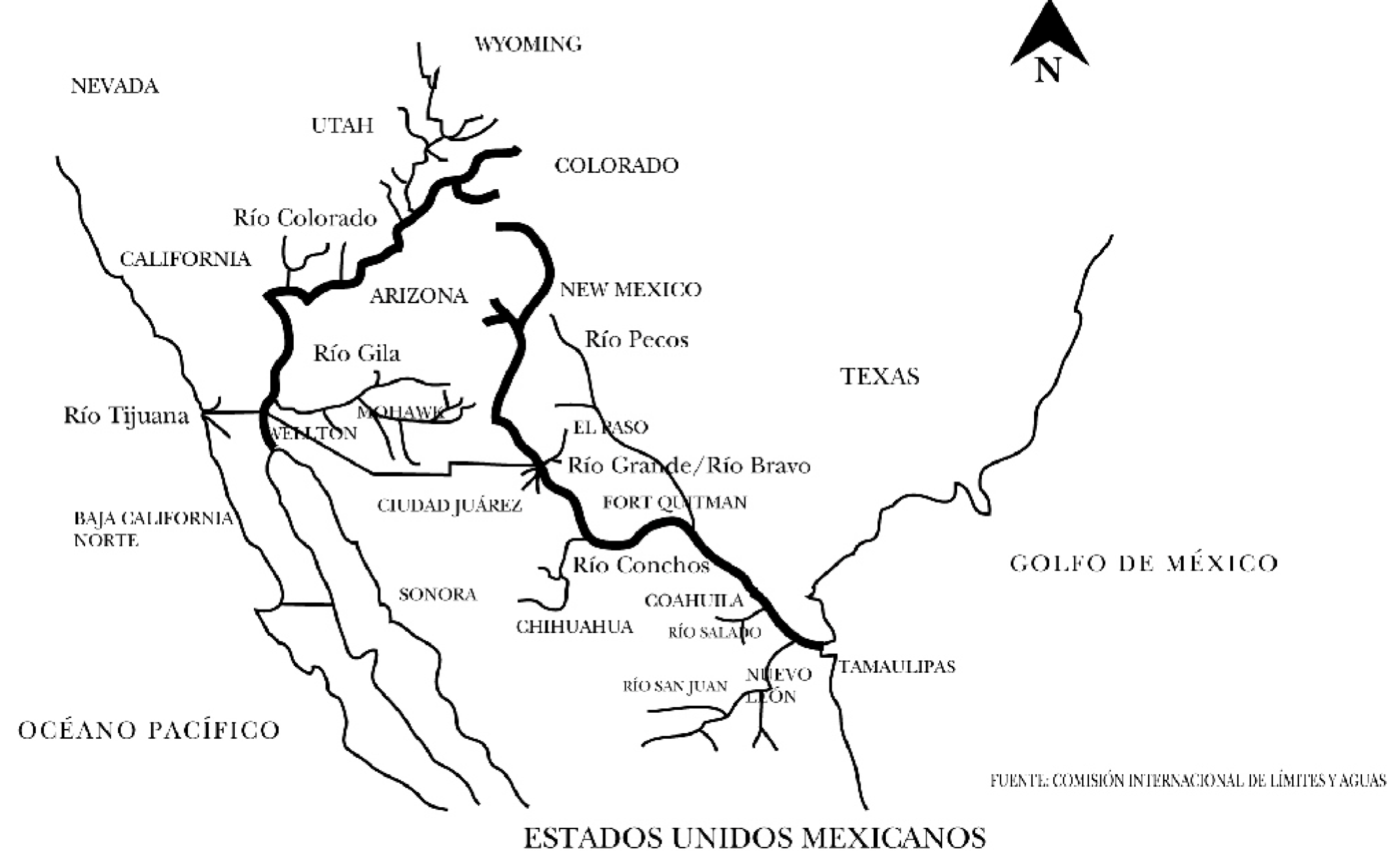


c) Río Bravo. Este río, que también nace en los EUA, en la parte meridional del estado de Colorado, corre por dicho país, donde es llamado Río Grande, a través de Nuevo México hacia el sur, marca la frontera de Texas y desemboca en el Golfo de México (aproximadamente 3,000 $\mathrm{km}$ ), es el río de mayor importancia política tanto para los EUA como para México, ya que a partir de Ciudad Juárez, Chihuahua, hasta el Golfo de México $(2,053 \mathrm{~km})$, sirve como límite fronterizo entre ambos países. Las entidades federativas del lado mexicano de la cuenca del río Bravo son Chihuahua, Coahuila, Nuevo León y Tamaulipas; y las del lado estadounidense son Colorado, Nuevo México y Texas. La aportación anual de agua de la cuenca estadounidense es de 6,325,000,000 $\mathrm{m}^{3}$ (el 52.1\% del total), y de la mexicana es de 5,810,000,000 $\mathrm{m}^{3}$ (el $47.9 \%$ restante).

Al tratarse de tres ríos compartidos, por tener su curso y cuenca en ambos países, los dos gobiernos deben de común acuerdo y basados en el principio de buena vecindad, ${ }^{58}$ planear el mejor y mayor aprovechamiento de sus aguas de conformidad con las circunstancias presentes y, previa consideración, en la medida de lo posible, de las futuras.

A continuación revisamos el marco jurídico aplicable a los cursos de agua superficiales compartidos por México y los EUA, el cual está integrado, fundamentalmente, por las Actas de la Comisión Internacional de Límites y Aguas; la Convención para la Distribución Equitativa de las Aguas del Río Bravo de 1906, y el Tratado para la Distribución de las Aguas de los Ríos Bravo, Tijuana y Colorado de 3 de febrero de 1944; de este último nos ocuparemos de manera específica, aunque existen también, como veremos, otros esfuerzos internacionales binacionales, que involucran a estos cuerpos de agua.

Téngase en cuenta que desde 1889, con base en la doctrina Harmon "de la soberanía absoluta", ${ }^{59}$ que permite al Estado ribereño aguas arriba utilizar libremente las aguas de una corriente internacional dentro de su

58 Este principio fue establecido tanto en el preámbulo como en el artículo 74 de la Carta de las Naciones Unidas el 26 de junio de 1945, Cfr. Arnaud, Vicente Guillermo, Derecho Internacional Ambiental; La contaminación de los ríos en el Derecho Internacional Público, Buenos Aires, Centro de Tecnología del Agua, 1975, pp. 17 y ss.

59 En 1895 el procurador general de los EUA, señor Harmon, al dictaminar una reclamación hecha por agricultores del Valle de Juárez fundada en la salinidad de las aguas del río Colorado, eximió de responsabilidad a su gobierno basándose en la doctrina de la soberanía absoluta, $c f r$. Cruz Miramontes, Rodolfo, "El problema limítrofe fluvial entre México y los Estados Unidos; La Doctrina Harmon, el Tratado de Aguas de 1944 y algunos problemas derivados de su aplicación", Revista de Derecho Público, Santiago, Chile, núm. 4, septiembre, 1965, pp. 85-89. 
territorio; ${ }^{60}$ los agricultores estadounidenses utilizaron abusivamente las aguas de los ríos Colorado y Bravo para riego, lo cual produjo una disminución considerable en su caudal en la parte correspondiente a Ciudad Juárez, hecho que causó graves perjuicios a los agricultores mexicanos, quienes interpusieron una reclamación ante el gobierno de los EUA.

Asimismo, nuestro país manifestó su inconformidad a través de un dictamen elaborado por dos reconocidos jurisconsultos mexicanos - José M. Gamboa e Ignacio L. Vallarta - el cual, basado en las reglas fundamentales de derecho internacional concluyó que: "Ningún Estado puede, en virtud de su soberanía, independencia, libertad o facultad de autodeterminación aplicada a su supremacía territorial, usar su territorio fluvial, si altera las condiciones naturales de éste o las aprovecha en forma que impida a otro Estado hacer, a su vez, un uso natural y legítimo de su propio territorio fluvial o que le produzca algún otro daño". ${ }^{61}$

Toda esta situación dio origen a la celebración, el 1o. de marzo de ese mismo año, de una convención entre ambos países para crear la Comisión Internacional de Límites encargada de conocer y decidir todas las diferencias o cuestiones suscitadas en la parte de la frontera entre México y los EUA en que sirven de límite los ríos Bravo y Colorado, ya sea que provengan de alteraciones o cambios en el lecho de los ríos mencionados, o de obras que se construyan en los mismos (artículo 1o.); 62 la convención entró en vigor dos años más tarde y aunque su duración estuvo planeada por un lapso de cinco años, su vigencia se renovó por períodos iguales hasta la celebración de la convención del 21 de noviembre de 1900, misma que resolvió su permanencia indefinida.

A pesar de ello, los abusos continuaron, así es que el 21 de mayo de 1906 fue celebrada la Convención para la Equitativa Distribución de las Aguas del Río Bravo, que comprende el tramo del río desde Ciudad Juárez, Chihuahua, hasta Fort Quitman, Texas, que es de $125 \mathrm{~km} .{ }^{63}$ A través de este tratado, los EUA se obligó a entregar a México, sin costo alguno, un volumen anual de 74 millones de $^{3}$ de agua distribuidos conforme a

60 Cfr. Secretaría de Relaciones Exteriores, El Tratado de Aguas...”, cit., p. 48.

61 Ibidem, pp. 11-12.

62 Véase Mumme, Stephen P., "La Comisión Internacional de Límites y Aguas, los Estados Unidos y México. La protección del ambiente en la frontera entre los Estados Unidos y México", Revista de la Facultad de Derecho de México, México, tomo XXXV, núms. 142-144, julio-diciembre 1985, pp. 630-635.

63 Cfr. Secretaría de Relaciones Exteriores, El Tratado de Aguas...", cit., p. 19. 
una tabla de entregas; y México renunció a las reclamaciones pasadas y futuras de los usuarios de Ciudad Juárez.

Cabe señalar, que este instrumento, aún basado en la doctrina Harmon, fue muy criticado por su inequidad, ya que muestra una actitud prepotente por parte de los EUA; ejemplo de ello es el contenido de su artículo IV al mandar que la entrega del agua a México no implica reconocimiento alguno por los EUA de ningún derecho por parte de nuestro país a dichas aguas; y el artículo $\mathrm{V}$ preceptúa que al celebrar el tratado, los EUA no otorgan ni explícita ni implícitamente ningún fundamento legal para reclamaciones de cualesquiera pérdidas sufridas por los propietarios de tierras en México. Pero aún a su pesar, el hecho de que los EUA hayan negociado la entrega de agua a México implica un reconocimiento del derecho que a este último le asiste. No obstante, en la actualidad, debemos admitir que la dotación de agua para nuestro país es insuficiente, ${ }^{64}$ por lo que este instrumento también es digno de revisión, a fin de evitar conflictos binacionales en un futuro no muy lejano.

Después de muchos años de negociación diplomática se logró revertir la doctrina Harmon para que los EUA aceptara lo que actualmente es un principio de derecho internacional, ${ }^{65}$ que los Estados ribereños aguas arriba en un río internacional deben usar las aguas de las corrientes internacionales dentro de sus respectivos territorios siempre y cuando no se modifiquen las condiciones naturales de la cuenca en perjuicio de otro Estado, además el volumen de agua deberá distribuirse en forma proporcional entre los Estados ribereños.

Debido al problema constante de la distribución justa de las aguas internacionales se tomó la decisión de fortalecer, el 5 de agosto de 1927, el mandato de la Comisión Internacional de Límites para darle atribuciones específicas en materia de aguas; por tanto cambió su nombre a Comisión Internacional de Límites y Aguas (CILA) entre México y los EUA. ${ }^{66}$

La CILA, que está integrada por representantes de ambos gobiernos, permite la aplicación de los diversos tratados y acuerdos sobre límites y

64 Véase Sepúlveda, César, "Los recursos hidráulicos en la zona fronteriza México-Estados Unidos. Perspectiva de la problemática hacia el año 2000; Algunas recomendaciones", Natural Resources Journal, Albuquerque, New Mexico, vol. 22, núm. 4, October, 1982, pp. 1083 y 1087.

65 Véase punto VIII, infra, el uso equitativo y razonable.

66 Recordemos que la CILA cuenta con atribuciones que provienen de los distintos convenios que la han regulado, en de 1889, 1944 y el de 1970. Véase Cruz Miramontes, Rodolfo, "Las Comisiones Fluviales ..., op. cit., pp. 118-119. 
aguas, en donde la solución técnica a un problema puede ser desarrollada de manera conjunta, lo que facilita la toma de decisiones de las partes. La competencia de la comisión se refiere fundamentalmente a los puntos siguientes: a) La aplicación del tratado de 1944; b) La reglamentación y el ejercicio de los derechos y el cumplimiento de las obligaciones que los dos gobiernos adquirieron en virtud del mismo, y c) La resolución de todos los conflictos que originen su observación y ejecución. ${ }^{67}$

La forma de actuar de la CILA es a través de la elaboración de actas, instrumentos oficiales preparados por representantes, tanto de la sección mexicana como estadounidense, por virtud de las cuales se busca solucionar los problemas dentro de su jurisdicción, que comprende los tramos limítrofes del río Bravo y del río Colorado, sobre la línea divisoria terrestre entre los dos países y sobre las obras construidas en aquéllos y en ésta. ${ }^{68}$ Cada acta negociada es enviada a la Secretaría de Relaciones Exteriores, en México, y al Departamento de Estado, en Washington, para su autorización; una vez aprobada por ambos gobiernos, el acta se convierte en una obligación para cada país, siendo éstos responsables de su implementación, ya sea directamente o por medio de dependencias de un país o del otro, bajo la supervisión de la CILA. ${ }^{69}$

El objetivo inicial de la CILA se ha ampliado y en la actualidad también colabora con ambos gobiernos en la mejoría y conservación del medio ambiente de la región fronteriza, a través del desarrollo de soluciones internacionales, tales como proyectos de infraestructura sanitaria así como de control, conservación y utilización de agua; diseñados de manera conjunta y construidos y operados por los dos países bajo su control. ${ }^{70}$ A lo largo de su existencia, esta comisión ha alentado y coordinado el establecimiento de relaciones de cooperación con otras dependencias federales, estatales y locales en México y los EUA para llevar a cabo sus proyectos fronterizos y sus actividades. ${ }^{71}$

67 Becerra Ramírez, Manuel, "Nota introductoria al Tratado sobre Distribución de Aguas Internacionales entre los Estados Unidos Mexicanos y los Estados Unidos de América", Anuario Mexicano de Derecho Internacional, México, vol. III, 2003, p. 544. El texto íntegro del tratado está disponible en http://www.juridicas.unam.mx/publica/rev/derint/cont/3/cin/cin32.htm

68 Artículo 2o. del Tratado de Aguas de 1944.

69 Sepúlveda, César, "Los recursos hidráulicos...", cit., p. 1085.

70 Las facultades de la CILA están comprendidas en los artículos 2o. y 24 del Tratado de Aguas de 1944.

71 Una reseña de algunos de los resultados positivos de esta comisión puede verse en Cruz Miramontes, Rodolfo, "Las comisiones fluviales internacionales y la Comisión Internacional de 
Así, una de las primeras cuestiones planteadas a la comisión fue el problema que provocaba el río Bravo en el tramo ubicado entre Texas y Chihuahua, lugar en el que las inundaciones causaban graves perjuicios a los agricultores de la región en general. La situación fue atendida parcialmente con la construcción de la presa El Elefante y con la negociación del Acta 129,72 del 31 de julio de 1930, la cual dio lugar a la celebración de la Convención para la Rectificación del Río Bravo del Norte (Grande) en el Valle de Juárez-El Paso, firmada el 1o. de febrero de 1933, en la que se planteó la canalización del cauce del río en el tramo de conflicto; la construcción de una presa para regular las aguas de las nuevas crecientes; así como la apropiación de las tierras necesarias por cada uno de los gobiernos para llevar a cabo las obras que previeran contrariedades posteriores con los particulares. ${ }^{73}$

No obstante, fue hasta noviembre de 1943, después de muchos años de discusiones y arreglos diplomáticos, cuando se elaboró el Tratado de Distribución de Aguas Internacionales entre México y los EUA.

\section{DiSPOSICIONES RELEVANTES DEL TRATADO DE AGUAS DE 1944}

La negociación del Tratado sobre Distribución de Aguas Internacionales entre México y los EUA, a diferencia de lo que sucedió en los anteriores tratados bilaterales entre ambos países, tuvo como basamento a la teoría del derecho internacional de vecindad. ${ }^{74}$ Así, desde el preámbulo

Límites y Aguas" Natural Resources Journal, Albuquerque, New Mexico, vol. 18, núm. 1, January 1978, pp. 115-116.

72 El texto completo de esta y todas las actas que mencionamos en el documento pueden verse en Secretaría de Relaciones Exteriores, "Comisión Internacional de...", cit., en http://www. sre.gob.mx/cila

73 Véase Secretaría de Relaciones Exteriores, Tratados y Convenciones Vigentes entre los Estados Unidos Mexicanos y otros países, México, SRE, 1938, t. VI, Tratados y Convenciones Bilaterales, pp. 79-102.

74 Véase, entre otros, Andrassy, Juraj, "Les Relations Internationales de Voisinage", Recueil des Cours, Leyde, t. 79, vol. II, 1951, pp. 77-181 y Sauser-Hall, George, "L'utilisation industrielle des fleuves internationaux", Recueil des Cours, Leyde, t. 83, vol. II, 1953, p. 555. Esta teoría trata de explicar la limitación al ejercicio de la soberanía de los Estados sobre las aguas comunes, a través del reconocimiento de la institución del derecho de vecindad como un derecho de gentes. En consecuencia, el Estado ribereño de una corriente fluvial tendrá el derecho de realizar todos aquellos actos que no impliquen para sus co-ribereños más inconvenientes que las incomodidades propias e inseparables a la vecindad, absteniéndose de aquellos que excedan aquéllos. Cfr. Cruz Miramontes, 
se deja claro el espíritu franco de cordialidad y de cooperación amistosa para su celebración. El tratado, firmado en la ciudad de Washington el 3 de febrero de 1944, fija y delimita claramente los derechos de ambos países sobre los ríos Colorado, Tijuana y Bravo, desde Fort Quitman, Texas, EUA, hasta el Golfo de México, contemplándose los intereses de ambos países de ampliar el aprovechamiento de las aguas implicadas en el tratado en otros usos y consumos distintos a los de la navegación; siempre con el fin de obtener la utilización más completa y satisfactoria de las aguas superficiales internacionales. ${ }^{75}$

Este instrumento consta de 28 artículos y de un protocolo, considerado parte integral del tratado, el cual aborda con detalle las cuestiones inherentes a la construcción de las obras estipuladas en el tratado.

El artículo 3o. del tratado dispone un orden de preferencia para el uso común de las aguas internacionales (1. Usos domésticos y municipales, 2. Agricultura y ganadería, 3. Energía eléctrica, 4. Otros usos industriales, 5. Navegación, 6. Pesca y caza y, 7. Cualesquiera otros usos benéficos determinados por la CILA).

Al respecto, cabe destacar que, debido a la insuficiencia de los abastecimientos del recurso para atender todos los usos, México ha privilegiado el uso agrícola, por ello, ha puesto especial énfasis en la calidad de las aguas recibidas. En consecuencia, uno de los problemas más importantes surgió cuando el distrito Wellton-Mohawk de Arizona (véase supra mapa) empezó a drenar aguas de desecho con alto contenido salino. Situación que se tradujo en la contaminación del agua que México recibía como parte de la dotación fijada en el tratado, pues los niveles de salinidad pasaron de 800 partes por millón (ppm) a 2,500 ppm, lo cual impedía su utilización para fines agrícolas. ${ }^{76}$

Sobre este punto las autoridades estadounidenses sostuvieron que a la firma del tratado, México aceptó recibir el agua sin especificarse su calidad, puesto que los artículos 10 y 11 hacen referencia a las aguas "cualquiera que sea su fuente", lo que significa que los EUA cumplen su obligación al entregar a México la cantidad de agua estipulada, indepen-

Rodolfo, "Las Comisiones Fluviales ..., op. cit., p. 111 y del mismo autor, "El conflicto de las aguas del río Colorado", Lecturas Jurídicas, Chihuahua, México, núm. 10, 1962, pp. 73-74.

75 Preámbulo del tratado, cfr. Diario Oficial de la Federación, México, 30 de marzo de 1946, tomo CLV, núm. 26, sección segunda.

76 Reynolds, S. E., "The water quality problem on the Colorado River", Natural Resources Journal, Albuquerque, New Mexico, vol. 12, núm. 4, October, 1972, p. 480. 
dientemente de su calidad; bien puede tratarse de aguas salinas, residuales, contaminadas, etc. ${ }^{77}$ En respuesta a ello las autoridades mexicanas argumentaron que la referencia a la calidad de las aguas en el tratado puede legítimamente ser extraída del artículo 3o. del mismo, el cual establece los usos benéficos citados; así como de su preámbulo, que hace alusión a la "utilización más completa y satisfactoria" de las cuencas para ambos países, ${ }^{78}$ pues al determinarse en el preámbulo su objeto, quedó estipulado el principio que deberá normar la entrega de las aguas de las cuencas superficiales transfronterizas. ${ }^{79}$ Por si esto no fuera suficiente, los artículos 8o. y 16, párrafo segundo, ponen énfasis en la utilización más benéfica de las aguas, así como en el mayor aprovechamiento de ellas por cada uno de los Estados.

Además, es inconcebible la celebración de un tratado que contenga en su texto la posibilidad de causar daño o perjuicio al territorio de otro Estado a través de la entrega de aguas contaminadas. Esto simplemente es contrario al sentido común y al principio de celebración de buena fe de los tratados ${ }^{80}$ así como al espíritu de cordialidad y de amistosa cooperación sobre los cuales fue negociado el tratado en cuestión. ${ }^{81}$ Concretamente, si la calidad de las aguas asignada a México cuenta con un alto grado de salinidad (2,500 ppm), ello es contrario a los fines del tratado,

77 Cfr. Anderson, Kirsten J., "A History and interpretation of The Water Treaty of 1944”, Natural Resources Journal, Albuquerque, New Mexico, vol. 12, núm. 4, October, 1972, pp. 603-604.

78 Véase Sobarzo, Alejandro, "Salinity in the Colorado: An interpretation of the Mexican-American Treaty of 1944", Natural Resources Journal, Albuquerque, New Mexico, vol. 12, núm. 4, October 1972, pp. 511-512.

79 Cfr. Cruz Miramontes, Rodolfo, "Comentarios al Acta 218 de la Comisión Internacional de Límites y Aguas", Lecturas Jurídicas, Chihuahua, México, núm. 27, abril-junio, 1966, p. 90. Actualmente, las reglas de interpretación fijadas en la Convención de Viena sobre Derecho de los Tratados, disponen en su artículo 31, que un "tratado deberá interpretarse de buena fe conforme al sentido corriente que haya de atribuirse a los términos del tratado en el contexto de éstos y teniendo en cuenta su objeto y su fin". Convención de Viena sobre el Derecho de los Tratados de 1969, México, Secretaría de Relaciones Exteriores, 1976, p. 17.

80 Cfr. Sepúlveda, César, "Mexican-American International Water Quality Problems: Prospects and Perspectives", Natural Resources Journal, Albuquerque, New Mexico, vol. 12, núm. 4, October, 1972, p. 488.

81 Ahora bien, si acudimos a los medios de interpretación complementarios comprendidos en el artículo 32 de la Convención sobre Derecho de los Tratados, tenemos que, deberán considerarse los trabajos preparatorios del tratado y las circunstancias de su celebración para determinar el sentido, cuando éste sea ambiguo u oscuro, o cuando conduzca a un "resultado manifiestamente absurdo o irrazonable", que sería justamente el caso planteado. Véase Convención de Viena..., cit., p. 18 . 
en virtud de impedir el destino del agua a la agricultura, como está estipulado en el artículo 3o. del instrumento.

En definitiva, compartimos la opinión del maestro Cruz Miramontes al sostener que, las aguas que los EUA debe entregar a nuestro país provenientes de los ríos superficiales internacionales deben ser aptas para el riego, de lo contrario se estaría ante el incumplimiento de una obligación internacional emanada de un tratado, lo que a su vez daría lugar a la configuración de un delito internacional. ${ }^{82}$

En consecuencia, después de una serie de negociaciones bilaterales, se firmó el Acta 218, el 22 de marzo de 1965, por virtud de la cual, tanto el gobierno de México como el de los EUA consideraron procedente adoptar las medidas necesarias encaminadas a: a) Aislar las aguas de alcantarillado procedentes de Wellton-Mohawk con el fin de poder manejarlas separadamente de los demás volúmenes de agua, y b) Controlar el grado de salinidad de las aguas que México deriva para su utilización por el Canal del Álamo. Para ello se acordó construir un canal de desvío que condujera las aguas de alcantarillado de Wellton-Mohawk para su descarga en el lecho del río Colorado en el punto que México determinara. Con lo cual, podrían descargarse directamente en el Golfo de California o aguas arriba de la presa Morelos para mezclarse con el agua que México deriva por el Canal del Álamo cuando, a juicio de los técnicos y de los agricultores de la región, sea conveniente y pueda mantenerse la salinidad en un máximo de 1,500 ppm. ${ }^{83}$ De igual forma, se firmaron las actas 223 , en 1965, y 224, en 1967, relativas a la calidad de las aguas del río Bravo. ${ }^{84}$

82 La responsabilidad internacional constituye uno de los aspectos más importantes del derecho internacional público; su perfeccionamiento es constante y de carácter fundamentalmente consuetudinario, y se ha conformado como una institución eminentemente reparadora, lo cual ha quedado reconocido desde el 13 de septiembre de 1928, fecha en la que la entonces Corte Permanente de Justicia Internacional resolvió en el caso de la fábrica Chorzow que es un principio de derecho internacional que toda violación de un compromiso implica el deber de reparar en forma adecuada. Citado por Besné Mañero, Rosario, El crimen internacional; Nuevos aspectos de la responsabilidad internacional de los Estados, Bilbao, Universidad de Deusto, 1999, p. 103 y Cruz Miramontes, Rodolfo, "Comentarios al Acta 218...", cit., p. 91.

83 Véase Gantz, David A., "United States approaches to the salinity problem on the Colorado River", Natural Resources Journal, Albuquerque, New Mexico, vol. 12, núm. 4, October, 1972, pp. 500-507 y Secretaría de Relaciones Exteriores, Convenio con Estados Unidos acerca de la salinidad de las aguas del río Colorado que se entregan a México, México, SRE, 1965, pp. 37-42.

84 Cfr. Mumme, Stephen P., "La Comisión Internacional...", cit., p. 630. 
Más adelante, el Acta 241, signada en julio de 1972, determinó que se dejarían correr las aguas salobres provenientes de Wellton-Mohawk hasta el Golfo de California y que la mitad de los volúmenes de agua no aprovechables serían sustituidos por cantidades iguales de aguas útiles suministradas en el río Colorado. Con ello se lograba reducir la salinidad en forma aceptable, aunque se sacrificaba una gran parte del agua correspondiente a México. ${ }^{85}$

Después de años de trabajo, el 30 de agosto de 1973 ambos gobiernos firmaron el Acta 242 de la CILA intitulada, "Solución permanente y definitiva al problema internacional de la salinidad del Río Colorado", en la cual se establece que las aguas recibidas por México deberán tener "una salinidad media anual que no sobrepase en más de $121 \mathrm{ppm} \pm 30$ ppm a la salinidad media anual de las aguas del río Colorado que lleguen a la presa Imperial". ${ }^{86}$

También por razón de esta acta se buscaron puntos de acuerdo entre ambos países para el manejo de las aguas subterráneas transfronterizas; consistentes en limitar el bombeo de esta agua, en su propio territorio, dentro de los $8 \mathrm{~km}$ de la línea divisoria entre Sonora y Arizona a $193,358,000 \mathrm{~m}^{3}$ anuales.

Ambos países acordaron consultarse recíprocamente antes de emprender en la zona fronteriza de sus respectivos territorios cualquier obra o modificación respecto de las aguas superficiales o subterráneas que pudieran afectar adversamente al otro país. ${ }^{87} \mathrm{Sin}$ embargo, EUA decidió unilateralmente revestir el Canal Todo Americano para recuperar el agua que ahora se infiltra desde el canal y transferirla al área urbana de San Diego. El recubrimiento del canal se traducirá en daños para México, ya que el acuífero Mesa Arenosa de San Luis experimenta una recarga anual total de 700 millones de $\mathrm{m}^{3}$, de los cuales 80 millones de $\mathrm{m}^{3}$, es decir, el 11\%, son aportados por las infiltraciones del Canal Todo Ameri-

85 Cfr. Sepúlveda, César, "La contaminación de los ríos internacionales y el derecho; El conflicto México-Estados Unidos sobre el río Colorado 1961-1973 y sus lecciones", Anuario de Derecho Internacional, Pamplona, núm. 1, 1974, pp. 311-312.

86 Secretaría de Relaciones Exteriores, Comisión Internacional de Límites y Aguas entre México y los Estados Unidos, Sección Mexicana, "Salinidad de las Aguas que Recibe México del Río Colorado en el Valle de Mexicali, B.C.", en http://www.sre.gob.mx/cila

87 Cfr. Mumme, Stephen P., "Minute 242 and beyond: Challenges and opportunities for managing transboundary groundwater on the Mexico-U.S. border", Natural Resources Journal, Albuquerque, New Mexico, vol. 40, núm. 2, spring 2000, pp. 341-378. 
cano. ${ }^{88}$ Nuevamente esta es una manifestación de la prepotencia con la que se conduce nuestro vecino del norte.

Si retomamos el artículo 3o., último párrafo del tratado, veremos que existe referencia a las medidas y obras sanitarias que convengan ambos gobiernos a fin de resolver "preferentemente los problemas fronterizos de saneamiento". Con esta base, la CILA, inicialmente dio solución a un gran número de problemas sanitarios y de drenaje transfronterizo; no obstante, empezaron a presentarse alteraciones en la calidad del agua derivadas de fuentes industriales y agrícolas. Tales como descargas de residuos peligrosos y pesticidas, entre otros. Esta situación llevó a los gobiernos de México y los EUA a firmar el Acta 261, en septiembre de 1979, para ampliar el mandato ambiental de la CILA y solucionar los problemas sanitarios fronterizos.

De acuerdo con la sección 1 del acta en cuestión, los dos gobiernos reconocen que un problema fronterizo de sanidad es aquél en el que las aguas que atraviesan la frontera, incluidas las aguas de las costas y las que fluyan a los límites del río Bravo y del río Colorado, tienen condiciones sanitarias que constituyen un riesgo para la salud y bienestar de los habitantes de ambos lados de la frontera o impiden una utilización benéfica de esta corriente de agua. La consecuencia más importante del acta es hacer que la cláusula del artículo 3o. del tratado se aplique a todas las formas de contaminación del agua. ${ }^{89}$

A través de esta acta, la jurisdicción de la CILA rebasa las partes limítrofes de los ríos Bravo y Colorado, al referirse a los tributarios de estos, entre los que se encuentran los ríos mexicanos: San Juan, Salado y Conchos; y los afluentes estadounidenses: Pecos y Gila, cuyos niveles de contaminación pueden llegar a impactar la región fronteriza. ${ }^{90}$ Asimismo, la sección 3 del acta insta a las agencias competentes de cada gobierno a

88 García, G., López, A., Navarro, J., "El impacto del revestimiento del canal "Todo americano" sobre la calidad del agua del acuífero y el rendimiento de los cultivos del Valle de Mexicali", en Sánchez Munguía, Vicente (coord.), El revestimiento del Canal Todo Americano. ¿Competencia o cooperación por el agua en la frontera México Estados Unidos?, México, El Colegio de la Frontera Norte-Plaza y Valdés, 2004, p. 94 y Székely, Alberto, "Emerging boundary environmental challenges and institutional issues: Mexico and the United States", Natural Resources Journal, Albuquerque, New Mexico, vol. 33, núm. 1, winter 1993, p. 36.

89 Cfr. Mumme, Stephen P., "La Comisión Internacional...", cit., p. 632 y Arnaud, Vicente Guillermo, Derecho internacional ambiental..., cit., pp. 17 y ss.

90 Utton, Albert E., "An assessment of the management of U. S.-Mexican water resources: Ancicipating the year 2000", Natural Resources Journal, Albuquerque, New Mexico, vol. 22, núm. 4, October, 1982, p. 1105. 
proveer a la comisión de la información y avances técnicos que requiera a fin de dar un seguimiento y atención a la calidad de las aguas fronterizas. $^{91}$

A partir de la aceptación del Acta 242, se han elaborado distintos proyectos en los que se analiza la calidad de las aguas del río Colorado, sobre todo en lo que a concentraciones salinas se refiere. ${ }^{92}$

Por lo que se refiere a la utilización de las aguas del río Bravo entre México y los EUA, los artículos 4o. al 9o. del tratado se encargan de reglamentar y detallar los compromisos para la construcción de las presas internacionales necesarias para el almacenamiento y regularización del escurrimiento del río. Se plantea la posibilidad del aprovechamiento de las aguas superficiales internacionales a favor de los agricultores de ambos lados de la frontera; la generación de energía eléctrica y, en su caso, su reparto.

De manera particular, el artículo 4o. del tratado distribuye las aguas del río Bravo entre ambos países, entre Fort Quitman, Texas, y el Golfo de México. La asignación quedó establecida de la siguiente manera:

1) A México: a) La totalidad de las aguas que lleguen a la corriente principal del río Bravo (Grande), de los ríos San Juan y Álamo; comprendiendo los retornos procedentes de los terrenos que rieguen estos dos últimos ríos; b) La mitad del escurrimiento del cauce principal del río Bravo abajo de la presa inferior principal internacional de almacenamiento, siempre que dicho escurrimiento no esté asignado expresamente en este tratado a alguno de los dos países; c) Las dos terceras partes del caudal que llegue a la corriente principal del río Bravo (Grande) procedente de los ríos Conchos, San Diego, San Rodrigo, Escondido, Salado y Arroyo de Las Vacas, en concordancia con lo acordado en el inciso c) del párrafo $\mathrm{B}$ de este artículo; $\mathrm{y}, d$ ) La mitad de cualquier otro escurrimiento en el cauce principal del río Bravo (Grande), no asignado específicamente en este artículo, y la mitad de las aportaciones de todos los afluentes no aforados — que son aquellos no denominados en este artículo- entre Fort Quitman y la presa inferior principal internacional.

91 Idem.

92 Cfr. Utton, Albert E., "Problems and successes of international water agreements: The example of the United States and Mexico", en Carroll, John E. (ed.), International environmental diplomacy; The management and resolution of transfrontier environmental problems, Cambridge, Cambridge University Press, 1990, pp. 70-72. 
2) A los Estados Unidos: a) La totalidad de las aguas que lleguen a la corriente principal del río Bravo procedentes de los ríos Pecos, Devils, manantial Goodenough y arroyos Alamito, Terlingua, San Felipe y Pinto; b) La mitad del escurrimiento del cauce principal del río Bravo abajo de la presa inferior principal internacional de almacenamiento, siempre que dicho escurrimiento no esté asignado expresamente en este tratado a alguno de los dos países; $c$ ) Una tercera parte del agua que llegue a la corriente principal del río Bravo procedente de los ríos Conchos, San Diego, San Rodrigo, Escondido, Salado y Arroyo de Las Vacas; tercera parte que no será menor en conjunto, en promedio y en ciclos de cinco años consecutivos, de $431.721,000 \mathrm{~m}^{3}$ anuales.

Al aceptar fijar esta cantidad en el tratado, en lugar de señalar un porcentaje, el cual puede depender de la disponibilidad del recurso, México se obligó a cumplir con ella, con independencia de si tiene, en un futuro, capacidad para hacerlo. ${ }^{93} \mathrm{Si}$ el fundamento para establecer la cantidad citada fue, como se ha llegado a afirmar, la consideración técnica de que existen regiones mexicanas a lo largo de la cuenca del río Bravo que no necesitan agua, ${ }^{94}$ fue muy aventurada esta reflexión, ya que no consideró las circunstancias futuras, que dependen de las variables, tanto hidrometeorológicas como geológicas y ambientales, mismas que escapan al mero control y negociación bilateral.

El mismo artículo 4o., inciso b), en su parte final prevé que, en casos de sequía extraordinaria o de accidente grave en los sistemas hidráulicos de los afluentes mexicanos aforados que hagan difícil para México dejar escurrir los 431,721,000 $\mathrm{m}^{3}$ anuales asignados a los EUA como aportación mínima de los afluentes mexicanos citados, los faltantes que existieren al final del ciclo aludido de cinco años se repondrán en el ciclo siguiente con agua procedente de los mismos tributarios.

Sin embargo, el tratado no brinda una precisión del término "sequía extraordinaria"; laguna que ha servido como punto de partida para las últimas controversias dirimidas por ambos países. Además, tampoco se alude a la definición de "accidente en los sistemas hidráulicos", ni de

93 Véase Cruz Miramontes, Rodolfo, "El conflicto de las aguas ..., op. cit., p. 79.

94 Cfr. Enríquez Jr., Ernesto, "Defensa del Tratado México-Norteamericano sobre Ríos Internacionales", Revista de la Escuela Nacional de Jurisprudencia, México, t. VIII, núm. 30, abril-junio, 1946, pp. 229-230. 
"accidente en los sistemas de irrigación", omisiones, todas ellas, ${ }^{95}$ de carácter conceptual que dan margen a la subjetividad y dejan abierta la posibilidad a interpretaciones diversas y, con ello, a diferencias que pueden tener consecuencias importantes.

Por virtud del artículo 9o., inciso b), se convino que ambos países podrán derivar y usar en cualquier lugar del cauce principal del río Bravo, desde Fort Quitman, Texas, hasta el Golfo de México, el agua que les pertenezca y podrán construir, para ello, las obras necesarias. Sin embargo, no podrán hacer ninguna derivación o uso fuera de los existentes en la fecha en que entre en vigor este tratado, ni construir obra alguna con aquel fin, hasta que la sección de la CILA del país en que se intente hacer la derivación o uso verifique que hay el agua necesaria para ese efecto, dentro de la asignación de ese mismo país, a menos que la CILA haya convenido, de acuerdo con lo estipulado en el inciso d) de este artículo, en una derivación o uso en mayor cantidad. ${ }^{96}$

Más adelante, inciso f) del mismo precepto dispone que de presentarse una sequía extraordinaria en uno de los dos países y un abastecimiento de agua abundante en el otro, el agua de éste almacenada en las presas internacionales podrá cederse al país que experimente la sequía, siempre y cuando la CILA lo autorice.

La distribución de las aguas del río Colorado entre ambos países y el desarrollo de las instalaciones necesarias para ello, se hallan en el artículo 10 del instrumento, el cual dispone que de las aguas del río Colorado, cualquiera que sea su fuente, se asignan a México un volumen garantizado de 1,850,234,000 $\mathrm{m}^{3}$ anuales, mismos que serán entregados conforme al artículo 15 del propio tratado. ${ }^{97}$ Además de esta garantía, se convino que cuando exista agua en exceso en el río Colorado, a juicio de la sección de los EUA, éste se obliga a entregar a México cantidades adicionales de agua.

95 Respecto de las omisiones en el marco conceptual véase Sepúlveda, César, "Instituciones para la solución de problemas de aguas de superficie entre México y los Estados Unidos", Natural Resources Journal, Albuquerque, New Mexico, vol. 18, núm. 1, January 1978, p. 133.

96 Inciso d) La comisión podrá autorizar que se deriven y usen aguas que no correspondan completamente al país que pretenda hacerlo, cuando el agua que pertenezca al otro país pueda ser derivada y usada sin causarle perjuicio y le sea repuesta en algún otro lugar del río.

97 La distribución de las aguas provenientes de esta corriente, constituye un hito en la historia de las relaciones diplomáticas, pues debido a la dificultad para construir presas de almacenamiento y regulación en la parte correspondiente a México, se optó por una solución técnica consistente en unir el sistema de riego mexicano al estadounidense, lo que garantiza la entrega regular del recurso. Véase Cruz Miramontes, Rodolfo, "El conflicto de las aguas...", cit., p. 70. 
En cuanto a la construcción de infraestructura relativa al río Colorado, México se obligó a edificar — en el tramo limítrofe del río Colorado o dentro del territorio nacional-, una presa de derivación de las aguas provenientes de la corriente del río Colorado; y los EUA se comprometió a construir la presa Davis para regularizar las aguas destinadas a México.

Ahora veamos lo que determina el tratado para los casos de extraordinaria sequía o de serio accidente al sistema de irrigación de los EUA que haga difícil a éste entregar la cantidad anual garantizada proveniente del río Colorado; según el inciso b) último párrafo del mismo artículo 10 , el agua asignada a México, se reducirá en la misma proporción en que se reduzcan los consumos en los EUA.

Como vemos, son totalmente diferentes los criterios aplicables a México y a los EUA en caso de sequía extrema o de accidente en los sistemas de irrigación; ya que este último no tiene la obligación de ceder los faltantes de agua en el siguiente ciclo de entrega, es decir, para los estadounidenses no son acumulativos dichos faltantes, lo cual evidencia la desigualdad en las obligaciones de cada parte en el tratado, misma que requiere de un replanteamiento urgente basado en los principios de equidad y cooperación en la distribución del recurso ${ }^{98}$ con criterios de sostenibilidad. ${ }^{99}$

Asimismo, es necesario tomar acciones binacionales orientadas a asumir los problemas de la degradación ambiental en la región, a través del reconocimiento del principio de interdependencia ecológica, el cual obliga a los Estados a asegurar que las actividades realizadas dentro de su jurisdicción respeten el ambiente de otros Estados o de las zonas más allá de su jurisdicción. ${ }^{100}$

Por su parte, el artículo 16 del tratado, alude al reparto de las aguas del río Tijuana y faculta a la CILA para realizar las investigaciones, los estudios y los proyectos que estime convenientes para atender la distribu-

98 Véase González Aninat, Raimundo, "Principios generales del derecho ambiental internacional", Revista de Derecho, Chile, año LX, núm. 191, enero-junio, 1992, pp. 109 y ss; Bogdanovic, Slavko (ed.), International Law of Water Resources: Contribution of the International Law Association (1954-2000), The Netherlands, Kluwer Law International, 2001, pp. 252 y 412 y Hohmann, Harald, Precautionary Legal Duties and Principles of Modern International Environmental Law. The Precautionary Principle: International Environmental Law between Exploitation and Protection, London, Graham \& Trotman, 1994, pp. 189-190.

99 Cfr. International Court of Justice, Case concerning Gabcikovo-Nagymaros Project (Hungary/Slovakia), Judgment of 25 September 1997, The Netherlands, ICJ, 1997, p. 78.

$100 C f r$. International Court of Justice, "Legality of the Threat or Use of Nuclear Weapons, Advisory Opinion of 8 July 1996", en http://www.icj-cij.org/icjwww/icases/iunan/iunanframe.htm 
ción, aprovechamiento y almacenamiento de esta corriente; así como lo tocante a la ejecución de las obras pertinentes y su mantenimiento.

\section{INCUMPLIMIENTO DEL TRATADO DE AGUAS POR PARTE DE MÉXICO}

Independientemente de las disposiciones injustas del tratado para México y de las distintas anomalías regularizadas por los EUA a la celebración del mismo; lo cierto es que este instrumento bilateral ha funcionado razonablemente bien y las disputas entre ambos países en torno al reparto de las aguas fronterizas han encontrado soluciones satisfactorias hasta fecha reciente. ${ }^{101}$

Entre los factores que han reducido la posibilidad de disposición y, por ende, generado la sobreexplotación de los cuerpos de agua subterráneos en la región fronteriza, se halla, sin duda, la degradación del agua; aunado a ello, la persistente sequía en el sureste de Texas y el noreste de México ha hecho que una cantidad significativamente menor del recurso llegue al caudal principal del río Bravo, en particular, proveniente del río Conchos, ubicado en Chihuahua, el cual durante los años de precipitación pluvial normal constituye la cuenca que más agua aporta al río Bravo abajo de El Paso. De hecho, se han reducido los caudales a tal grado que desde 1992 México empezó a verse impedido para cumplir con sus obligaciones internacionales en materia de agua. ${ }^{102}$

Ante este panorama, México declaró una emergencia nacional e instauró un programa para atender la sequía; sin embargo nada podía hacerse para mejorar las condiciones meteorológicas, por lo que tuvo que negociarse, en octubre de 1995, ${ }^{103}$ el Acta 293, por virtud de la cual, los EUA realizó un préstamo a México de 100 millones de $\mathrm{m}^{3}$ del recurso para aliviar la insuficiencia que las comunidades mexicanas río abajo de la Presa de la Amistad padecían, atendiéndose, principalmente los usos

$101 C f r$. Kourous, George, "The Border's Troubled Waters, Second in a two-part series", Borderlines 84, New Mexico, vol. 9, núm. 11, December 2001, p. 6.

102 United Nations, "Mexican desert state and US farmers fight for water", International Rivers and Lakes Newsletter, New York, núm. 36, December 2001, p. 7 y Mumme, Stephen, "Managing acute water scarcity on the U.S.-Mexico border: Institutional issues raised by the 1990's drought", Natural Resources Journal, Albuquerque, New Mexico, vol. 39, núm. 1, winter 1999, p. 157.

103 Cfr. Chávez, Octavio E. "The 1994-95 drought, what did we learnt from it?: The Mexican perspective", Natural Resources Journal, Albuquerque, New Mexico, vol. 39, núm. 1, winter 1999, pp. 37-38. 
domésticos y municipales, conforme a lo establecido en el artículo 30. del tratado. Las características principales de este acuerdo incluyen la delimitación cuidadosa de los términos del préstamo, un énfasis en la recuperación rápida del agua prestada, atención especial binacional a los datos que comparten en prácticas de la disponibilidad y gestión del agua en el río Bravo, y una comisión económica para Texas por la asistencia técnica para mejorar la conservación del agua en México. ${ }^{104}$

Como las cuestiones hidrometeorológicas no tuvieron variaciones importantes; al cierre del ciclo de cinco años que concluyó el 2 de octubre de 1997, México adeudaba a los EUA aproximadamente 1,200 millones de $\mathrm{m}^{3}$ de agua. ${ }^{105}$ Esta cantidad superó más de dos veces el déficit contraído por México durante la sequía de los años cincuenta, primera ocasión en que nuestro país no cumplió con los requisitos mínimos de entrega de agua durante un ciclo de cinco años; según cifras de la CILA, el adeudo de agua por parte de México a los EUA llegó a incrementarse en 1,800 millones de $\mathrm{m}^{3}$.

El incumplimiento citado fue atendido el 16 de marzo de 2001 a través del refrendo del Acta 307 de la CILA, denominada: "Cobertura Parcial del Déficit en la Aportación de los Tributarios Mexicanos del Río Bravo entre Fort Quitman y la Presa Falcón"; por la que México se comprometió a liberar 740 millones de $\mathrm{m}^{3}$ de agua proveniente del escurrimiento de los tributarios aforados y no aforados del río Bravo. De acuerdo con un mecanismo de contingencia detallado en dicha acta, el esquema debía prorrogarse hasta septiembre si México no efectuaba el pago que vencía el 31 de julio del mismo año. ${ }^{106}$ Sin embargo, el 21 de julio, México suspendió la entrega de ese escurrimiento a los EUA debido al amparo que un tribunal mexicano concedió a agricultores mexicanos por haber entregado, el Estado mexicano, agua de afluentes no aforados a los EUA, cuestión no incluida en el tratado. ${ }^{107}$

104 Cfr. Mumme, Stephen, "Managing acute water scarcity...", cit., pp. 157-164.

105 Véase Kelly, Mary E., "The drought in Texas: Its impact and consequences", Natural Resources Journal, Albuquerque, New Mexico, vol. 39, núm. 1, winter 1999, pp. 129-131.

106 García-Acevedo, María Rosa, "Agua: cooperación y conflicto en la frontera México-Estados Unidos", Cuadernos Americanos, nueva época, vol. 3, núm. 87, mayo-junio del 2001, p. 212 y Marin, Carlos, "Mexican water debt coming due", International Rivers and Lakes Newsletter, New York, núm. 35 June 2001, p. 6.

107 Kourous, George, "Las Aguas Turbulentas de la Frontera", Boderlines 84, New Mexico, vol. 9, núm. 11, diciembre 2001, p. 4. 
Otro punto planteado en el acta es el trabajo conjunto de México y de los EUA para identificar las medidas de cooperación en materia de manejo sostenible de la cuenca del río Bravo que logren una distribución equitativa del recurso entre ambos países y que permitan redefinir la condición de sequía extrema para ajustar los pagos de agua a su disponibilidad mediante el mismo criterio que opera para el río Colorado.

A fin de dar cumplimiento a las obligaciones de México estipuladas en el tratado se suscribió, en el seno de la CILA, el 28 de junio de 2002, el Acta 308, intitulada: "Asignación a los EUA de Aguas del Río Bravo durante el último Año del Ciclo Actual" para proporcionar una asignación a los EUA de aguas provenientes del río Bravo antes del 26 de octubre de ese mismo año. De esta manera, los dos gobiernos acordaron: a) Que la Comisión Nacional del Agua (CNA) presentaría a la CILA un informe del avance de los trabajos sobre sus estudios referentes a la planeación del manejo de la sequía, a fin de que las autoridades competentes en cada país puedan coordinar sus planes respectivos sobre el tema y b) Convocar una reunión binacional de expertos y de usuarios del agua de cada país con el fin de proporcionar a las autoridades competentes la información referente a la administración sostenible de la cuenca del río Bravo. ${ }^{108}$

Con esta base, y a fin de contribuir al manejo sostenible de las aguas superficiales del río Conchos, la CNA certificó en 2002 ante la Comisión de Cooperación Ecológica Fronteriza (COCEF) el Programa de Tecnificación en Distritos de Riego del río Conchos, para lo cual se dispuso de 40 millones de dólares provenientes de recursos no reembolsables del recientemente creado Fondo de Conservación del Agua del Banco de Desarrollo de América del Norte, con el que se pretende ahorrar 395 millones de $\mathrm{m}^{3}$ de agua. De la misma manera, la CNA realiza acciones en los distritos de riego de Tamaulipas, con el fin de lograr tener mayor certidumbre en la disponibilidad del agua, rendimientos e ingresos para los productores. ${ }^{109}$

El Acta 309, aprobada el 3 de julio de 2003, se refiere a los volúmenes de agua ahorrados con los proyectos de modernización y tecnifica-

$108 C f r$. Mumme, Stephen, "Despite shortcomings, promising potential for improved protection NAFTA's Environmental Side Agreement: Almost Green?", Borderlines 60, New Mexico, vol. 7, núm. 9, October 1999, pp. 5-6.

109 Presidencia de la República, "Plan Nacional de Desarrollo", en pnd.presidencia.gob.mx/ pdf/2003/pag_234-246.pdf 
ción de los distritos de riego en la cuenca del río Conchos y las medidas para su conducción hacia el río Bravo; acciones que contribuyeron a disminuir, al cierre de 2003, el déficit acumulado de agua en 1,537,405 millones $\mathrm{m}^{3}$, ya que pudieron asignarse 645,378 millones $\mathrm{de}^{3}$. A finales del 2003 y principios del 2004, se registraron escurrimientos extraordinarios que permitieron asignar a los EUA, al 21 de febrero de 2004, un total de 493,586 millones de $\mathrm{m}^{3}$ de agua, con lo cual el déficit a esa fecha disminuyó a 1,253,803 millones de $\mathrm{m}^{3} .{ }^{110}$

La disminución de las reservas de abastecimiento de agua en Tijuana y los problemas en la red de distribución de agua potable de la ciudad, permitieron pronosticar periodos de escasez de agua en los cinco años subsecuentes; situación que motivó la suscripción del Acta 310, el 28 de julio de 2003, en la que se acordó que los EUA entregara de emergencia a México, agua del río Colorado para ser utilizada en Tijuana; esto en tanto se concluyeran las obras para mejorar la infraestructura y llevar a cabo los trabajos para el abastecimiento de agua a largo plazo para cubrir las necesidades de población creciente en Tijuana.

La última acta firmada en el seno de la CILA es la número 311, del 20 de febrero de 2004, la cual puntualiza las recomendaciones para construir en México una planta de tratamiento secundario de las aguas residuales generadas en el área del río Tijuana en México, las cuales fluyen sin tratamiento hacia los EUA o son parcialmente tratadas en la Planta de Tratamiento de Aguas Residuales ubicada en San Isidro, California; el proyecto prevé la participación pública y privada.

Estos esfuerzos tienen lugar en medio de una realidad demográfica y económica que ejerce una presión constante sobre los recursos ambientales de los cursos de agua transfronterizos, especialmente la disponibilidad de agua limpia. Según informes de la CILA, aproximadamente 13 millones de personas dependen del agua del río Bravo. ${ }^{11}$ Por ello, es necesario atender los problemas básicos de la cuenca, identificados por el maestro Sepúlveda: ${ }^{112}$ 1) La distribución equitativa de las aguas conforme al corpus juridicus que la regula; 2) La escasez futura del líquido;

110 Idem y United Nations, "April rains reduce Mexico water debt to Texas", International Rivers and Lakes Newsletter, New York, núm. 1, June 2004, pp. 6-7.

111 Cfr. Aguilar, Ricardo, “Los ríos: ¿Patrimonio de la humanidad?”, en http://www.guaso.com/ríos_ara_jornadas00_mesa3_01.htm

112 Sepúlveda, César, "Los recursos hidráulicos...", cit., p. 1087. 
3) La contaminación del recurso, y 4) Las aguas subterráneas, su distribución y contaminación. ${ }^{113}$

Si bien el tratado omitió el tema de la asignación de las aguas subterráneas, la CILA ha creado un mandato parcial para explorar los mecanismos de cooperación binacional en la materia desde finales de los años sesenta, cuando la crisis de la salinidad atrajo atención al problema. ${ }^{114}$ Aunque ha resultado difícil alcanzar un acuerdo integral sobre aguas subterráneas, la CILA tomó medidas en la década pasada para empezar a levantar mapas de las áreas críticas de aguas subterráneas a lo largo de la frontera y monitorearlas; pues estos acuíferos pueden servir como reserva para emplearse en tiempos de sequía, por ello su correcta administración y la prevención de su contaminación son puntos que deben atenderse urgentemente. ${ }^{115}$

El grave problema del agua en México, que según los expertos internacionales ya es calificado como de "estrés hídrico" en el norte del país, se tradujo en una cuestión de vulnerabilidad en esta región, la cual exige desarrollar y poner en práctica acciones coordinadas en ambos lados de la frontera.

113 A iniciativa conjunta de Albert Utton y César Sepúlveda se formó un Grupo de Estudio sobre Recursos Transfronterizos México-Estados Unidos; el cual se reunió por primera vez en Oaxtepec, México, en 1977. Conforme a esa iniciativa se encomendó a un grupo de trabajo la tarea de examinar los crecientes problemas de los acuíferos transfronterizos a lo largo de la extensa frontera entre los dos países. El grupo se amplió y las reuniones subsecuentes se celebraron en Ixtapa y Puerto Vallarta, en México. Después de considerar diversos aspectos y propuestas, el estudio culminó con un borrador de acuerdo provisional no oficial entre los dos países. El "Borrador de Ixtapa" se puso a discusión y se publicó en the Natural Resources Journal, cfr. Rogers, Ann Berkley y Utton, Albert E., "The Ixtapa Draft Agreement relating to the Use of Transboundary Ground waters", Natural Resources Journal, Albuquerque, New Mexico, vol. 25, núm. 3, July 1985, pp. 715-722; también se ha analizado la necesidad de dotar a la CILA, o a otro órgano intergubernamental confiable, de atribuciones sobre la identificación y designación de cuencas internacionales subterráneas fronterizas, su protección contra la contaminación y su distribución. Así como para promulgar las normas y reglamentos sobre calidad del agua; establecer planes y programas para administrar el recurso y resolver los conflictos que sobre el tema se susciten. Entre otros, véase Sepúlveda, César, "Los recursos hidráulicos...”, cit., pp. 1089-1091 y Utton, Albert E., "An assessment of the management...", cit., pp. 1110-1113.

114 El Acta 242, firmada en 1973, encargó a la CILA el monitoreo de la extracción de aguas subterráneas en el área de San Luis río Colorado-Yuma y requirió que los dos gobiernos se informaran mutuamente sobre cualquier nueva circunstancia que pudiera afectar a la otra parte. Dicha acta también contempló la necesidad de un acuerdo integral que abordara la cuestión de las aguas subterráneas. Véase Mumme, Stephen P., "La Reinvención de la Comisión Internacional de Límites y Aguas", Borderlines 79, New Mexico,vol. 9, núm. 6, June 2001, p. 8.

115 Cfr. Utton, Albert E., "Doping with drought on an International River under stress: The case of the Río Grande/Río Bravo", Natural Resources Journal, Albuquerque, New Mexico, vol. 39, núm. 1, winter 1999, p. 34. 
Lo anterior pone de manifiesto que el problema se ha agravado por la escasez del recurso tanto en la cuenca del río Bravo como en el resto de la región; es claro que la crisis por el líquido vital ha iniciado, esta realidad se expresa en un conflicto binacional con dimensiones políticas y económicas que México y los EUA deben atender con urgencia y prioridad. ${ }^{116}$ Con un enfoque positivo, esta crisis puede verse como la oportunidad para ambos países ${ }^{117}$ de renegociar el tratado o de crear alternativas que permitan la solución de conflictos de manera objetiva, clara y pacífica.

\section{PRINCIPIOS DE DERECHO INTERNACIONAL AMBIENTAL}

Se entiende por "principio" (del latín principium) aquella "norma no legal supletoria de ella y constituida por doctrina o aforismos que gozan de general y constante aceptación de jurisconsultos y tribunales". ${ }^{118}$ Son principios generales por su naturaleza y subsidiarios por su función, porque suplen las lagunas de las fuentes formales del derecho. Como señala el maestro Sepúlveda, son la sustancia misma de los sistemas jurídicos, comunes a todos ellos, con un valor muy elevado, pues proporcionan la base jurídica de tratados y costumbres, gobiernan su interpretación y aplicación. ${ }^{119}$

Con esta base, los Estados han incluido en sus sistemas jurídicos internos o en los distintos instrumentos internacionales que suscriben una serie de principios de no contaminar, de prevenir, de cooperar, de consultar, de informar, etc., todos ellos encaminados a regular la utilización del medio ambiente. ${ }^{120}$

116 Debe analizarse el cambio fundamental de las circunstancias, imprevisible al momento de la celebración del tratado (artículo 62, Convención de Viena sobre Derecho de los Tratados).

117 Así lo ha visualizado el profesor Mumme, Stephen P., "Strengthening Binational Drought Management”, Utton Center Report, Albuquerque, New Mexico, vol. 2, núm. 1, winter 2003, p. 7.

118 Real Academia Española, Diccionario de la Lengua Española, 20a. ed., Madrid, Espasa-Calpe, t. II, H-Z, 1984, p. 1114.

119 De acuerdo con el artículo 38 del Estatuto de la Corte Internacional de Justicia son fuentes del derecho internacional: a) Los tratados; b) La costumbre; c) Los principios generales del derecho; d) Las decisiones judiciales; e) La doctrina; f) Las resoluciones de los órganos internacionales; y $g$ ) La codificación del derecho internacional, Cfr. Sepúlveda, César, Derecho Internacional, 18a. ed., actualizada, México, Porrúa, 1997, pp. 93-94 y 105-106.

120 Cfr. Jaquenod de Zsögön, Silvia, El derecho ambiental y sus principios rectores, Madrid, Dykinson, 1991, p. 366. Además, véase el Resumen de los Proyectos de Principios Jurídicos para la Protección del Medio Ambiente y el Desarrollo Duradero adoptado por la Comisión Mundial sobre 
Los principios que analizamos enseguida nacieron en el seno del derecho internacional consuetudinario general, son reconocidos por la jurisprudencia internacional y, más frecuentemente, incluidos en la práctica convencional de los Estados que rige las relaciones de amistad y cooperación entre ellos.

\section{La debida diligencia}

Se trata de una norma consuetudinaria de carácter general que obliga a todo Estado a comportarse diligentemente para evitar que actividades (suyas, de particulares o, eventualmente de otros sujetos de derecho internacional), llevadas a cabo en zonas bajo su jurisdicción o control, ocasionen daños graves, apreciables, al medio ambiente de otros Estados.

Los orígenes de este principio se hallan en máxima del derecho romano (sic utere iure tu out alterum no laedas), la cual fue observada en la sentencia arbitral del Caso de la Fundidora Trail Smelter, EUA contra Canadá, del 11 de marzo de 1941, ${ }^{121}$ en la que se reconoce que, ningún Estado tiene derecho a permitir que se produzca un daño que afecte o pueda afectar a otro Estado o a los bienes de personas de otro Estado, o zonas que estén fuera de su jurisdicción. En 1949, también se hizo referencia a esta directriz en la sentencia de la Corte Internacional de Justicia (CIJ) que resolvió el Caso del Estrecho de Corfú. ${ }^{122}$ De igual forma,

el Medio Ambiente y el Desarrollo, presentado por el Grupo Internacional de Expertos en Derecho, que enumera: I. Principios, Derechos y Deberes Generales: Derecho humano fundamental; Igualdad entre las generaciones; Conservación y utilización duradera; Normas para el medio ambiente y vigilancia; Evaluaciones previas del medio ambiente; Notificación previa; Igualdad de acceso y proceso imparcial; Desarrollo duradero y asistencia; Obligación general de cooperar. II. Principios Derechos y Deberes Relativos a los Recursos Naturales y a las Interferencias Ambientales que Traspasan las Fronteras: Utilización equitativa y razonable; Prevención y supresión; Responsabilidad estricta; acuerdos previos cuando los costos de prevención sean notablemente superiores a los daños; No discriminación; Obligación general de cooperar en problemas ambientales transfronterizos; Intercambio de informaciones; Evaluación y notificación previas; Consultas previas; acuerdos de cooperación para la evaluación y protección del medio ambiente; Situaciones de emergencia; Igualdad de acceso y trato. III. Responsabilidad de los Estados, y IV. Arreglo Pacífico de las Controversias, en Székely, Alberto, (comp.), Instrumentos fundamentales ..., op. cit., t. V, pp. 3117-3121.

121 El caso completo puede consultarse en Ojeda, Ramón y Loperena, Demetrio (eds.), Cases and materials on international and comparative environmental law, México, Editora Laguna, 2001, pp. 27-54.

122 Véase el caso en Gómez-Robledo Verduzco, Alonso, Responsabilidad internacional por daños transfronterizos, México, UNAM, Instituto de Investigaciones Jurídicas, 1983, pp. 50-52. Cabe destacar que jurisprudencia de la CIJ, en su dictamen consultivo del 8 de julio de 1996, afirmó 
el principio ha sido adoptado por importantes convenios e instrumentos internacionales, como las Declaraciones de Estocolmo, ${ }^{123}$ Río $^{124} \mathrm{y}$, últimamente, Johannesburgo. ${ }^{125}$

En fecha más reciente, la Comisión de Derecho Internacional decidió en su 54o. periodo de sesiones, celebrado en 2002, incluir en su programa de trabajo el tema de los recursos naturales compartidos, entre los que destaca el tema de las aguas subterráneas confinadas transfronterizas y la posible aplicación de la Convención Internacional sobre el Derecho de los Usos de los Cursos de Agua Internacionales para Fines Distintos de la Navegación, ${ }^{126}$ la cual estipula que los Estados del curso de agua internacional, al utilizarlo en sus territorios, adoptarán todas las medidas apropiadas para impedir que se causen daños sensibles a otros Estados del curso de agua. Cuando a pesar de ello otro Estado sufra los daños, el Estado cuyo uso los cause deberá, a falta de acuerdo con respecto a ese uso, adoptar todas las medidas apropiadas para eliminar o mitigar esos daños y, cuando proceda, examinar la cuestión de la indemnización (artículo 7o.).

Para poder cumplir con el contenido de esta máxima es necesario que los Estados cuenten con el aparato jurídico y material suficiente que les permita, como afirma Quentin-Baxter, "velar porque los derechos de otros Estados no resulten lesionados por los efectos perjudiciales de ac-

que "la existencia de una obligación general a cargo de los Estados de asegurarse de que las actividades que se llevan a cabo bajo su jurisdicción y control respeten el medio ambiente de otros Estados o zonas no sometidas a control nacional forma ya parte del corpus del Derecho internacional del medio ambiente", cfr. United Nations, Summaries of Judgments, Advisory Opinions and Orders of the International Court of Justice, 1992-1996, New York, United Nations, 1998, p. 96.

123 La Declaración de Estocolmo sobre el Medio Humano de 1972 puede consultarse en Adede, Andrónico O., Digesto de Derecho Internacional Ambiental, trad. de Diana L. Ponce Nava, México, Secretaría de Relaciones Exteriores, 1995, pp. 466-468.

124 La Declaración de Río sobre el Medio Ambiente y el Desarrollo, adoptada el 14 de junio de 1992, es el instrumento que ha condensado una serie de máximas aceptadas de manera aislada en diversos instrumentos de carácter internacional ambiental. Véase la Declaración de Río en Ibidem, pp. 479-483.

125 Véase United Nations, Department of Economic and Social Affairs, "Declaración de Johannesburgo sobre el Desarrollo Sostenible", en http://www.un.org/esa/sustdev/documents/WSSD_POI_ PD/Spanish/WSSDsp_PD.htm

126 Véase el texto completo del Convenio en Naciones Unidas, Asamblea General, Convención Internacional sobre el Derecho de los Usos de los Cursos de Agua Internacionales para Fines Distintos de la Navegación, A/RES/51/229, 21 de mayo de 1997, disponible en http://www.un.org/ spanish/documents/ga/res/51/list51.htm 
ciones u omisiones realizadas en su territorio o bajo su jurisdicción". ${ }^{127}$ Esto requiere de una conducta activa a cargo del Estado para consolidar en su sistema interno la adaptación de su legislación a los compromisos internacionales adquiridos, con la inclusión de los medios de control necesarios para lograr su respeto y evitar su violación.

\section{El uso equitativo y razonable}

La Declaración sobre el Uso Industrial y Agrícola de los Ríos Internacionales, aprobada el 24 de diciembre de 1933, dispone que "Los Estados tienen el derecho exclusivo de aprovechar, para fines industriales o agrícolas, la margen que se encuentra bajo su jurisdicción, de las aguas de los ríos internacionales. Ese derecho, sin embargo, está condicionado en su ejercicio por la necesidad de no perjudicar el igual derecho que corresponde al Estado vecino en la margen de su jurisdicción". ${ }^{128}$

Por su parte, las Reglas de Helsinki de 1966 establecieron este principio, el cual ha sido aplicado principalmente a los ríos internacionales y, por ende, entre Estados fronterizos; sin embargo, también puede aplicarse a otros recursos. En materia de aguas, las reglas establecen que todo Estado ribereño de una cuenca tiene derecho, dentro de los límites de su territorio a una participación razonable y equitativa de los usos benéficos de las aguas de una cuenca hidrográfica internacional (artículo IV). Para tal efecto, deberán considerarse, entre otros, la hidrología y el clima de la cuenca; su utilización pasada y, en particular, actual, así como el grado en que pueden satisfacerse las necesidades de un Estado ribereño sin causar perjuicio notable a un Estado co-ribereño (artículo V). Y sobre todo, no se puede negar a un Estado de la cuenca, con fines de reservar el aprovechamiento futuro de las aguas, el uso razonable presente de las aguas de una cuenca hidrográfica internacional. Asimismo, los Estados deben evitar cualquier forma de contaminación del agua o aumento del grado de contaminación existente en una cuenca internacional que pudiera causar perjuicio notable en el territorio de un Estado co-ribereño. ${ }^{129} \mathrm{La}$ prevención comprende tanto el hecho de no contaminar en perjuicio del

127 Véase la opinión de Quentin-Baxter, R., en Anuario de la Comisión de Derecho Internacional, 1981, New York, Naciones Unidas, 1983, vol. 2, 1a. parte, p. 123.

128 Székely, Alberto, Instrumentos fundamentales..., cit., t. V, p. 3303.

129 Véase Anuario de la Comisión de Derecho Internacional, 1974, New York, Naciones Unidas, 1976, vol. 2, 2a. parte, pp. 385-391. 
vecino, como la necesidad de hacer compatibles los distintos usos del recurso, de acuerdo a los fines que tengan proyectados los Estados involucrados.

En definitiva, el uso equitativo de los recursos naturales pone de manifiesto la interdependencia existente entre los distintos elementos integrantes del medio ambiente. Las actividades realizadas en un Estado pueden repercutir no sólo en el medio ambiente del Estado vecino, sino también en el de Estados más alejados geográficamente. No obstante, es mucho más fácil articular la cooperación entre los Estados que comparten un recurso natural y, de manera más integral, un sistema ambiental.

La Declaración de Estocolmo reconoce que el agua como elemento básico del medio ambiente debe gestionarse desde una perspectiva de conservación con estándares de cantidad y calidad idóneos para el desarrollo sostenible. Por ello, los usos económicos de este recurso deben subordinarse a su conservación. ${ }^{130}$ Con este argumento, el principio 6 de este instrumento dispone que debe ponerse fin a la descarga de sustancias tóxicas y de otras materias y a la liberación de calor, en cantidades o concentraciones tales que el medio no pueda neutralizarlas, para que no se causen daños graves o irreparables a los ecosistemas. Debe apoyarse la justa lucha de los pueblos de todos los países contra la contaminación.

La Convención sobre el Derecho de los Usos de los Cursos de Agua Internacionales Distintos de la Navegación de 1997,131 pacta que los Estados deben utilizar, en sus respectivos territorios, un curso de agua internacional de manera equitativa y razonable, lo cual implica la preservación del río para que otros Estados por él bañados también puedan valerse de los beneficios que proporciona, así como, garantizar a otras poblaciones el acceso al agua y el desarrollo económico (artículo 5o.).

De la lectura de los artículos 7.2 y 10.1 de la convención que aquí se comenta, ${ }^{132}$ se deduce que el daño en sí mismo no infringe las normas de derecho internacional, pues para ello se requiere que el uso no haya sido equitativo y razonable, ya que realmente se trató de privilegiar el enten-

130 Sobre el particular Loperena afirma que su conservación descansa en su consideración como elemento fundamental para lograr el equilibrio de la biosfera. Véase Loperena Rota, Demetrio, El derecho al medio ambiente..., cit., p. 107.

131 United Nations, Yearbook of the International Law Commission, 1990, Summary Records of the Meetings of the Forty-Second Session, 1 May 1-20 July 1990, New York, United Nations, 1993, vol. II, part 2, pp. 46-52.

132 Idem. 
dimiento entre los Estados que comparten un curso de agua, el cual es utilizado, a través del ejercicio soberano, por cada uno de ellos de distinta manera.

\section{La buena fe}

La Resolución 34/186, del 18 de diciembre de 1979, reafirma que los Estados deben conducirse siempre sobre la base de la buena fe y con espíritu de buena vecindad, en tal forma que se beneficie y no perjudique el desarrollo y los intereses de todos los países, en particular de los países en desarrollo. ${ }^{133}$

La actuación de buena fe es aplicable a la obligación de prevención de los Estados, no sólo en el cumplimiento de sus compromisos internacionales, sino también en la utilización del medio ambiente sobre el que se tiene jurisdicción. Este principio entraña una pauta de conducta que los Estados deben adoptar para impedir los daños medioambientales.

Así, el principio 21 de la Declaración de Estocolmo, señala que de conformidad con la Carta de las Naciones Unidas y con los principios del derecho internacional, los Estados tienen el derecho soberano de explotar sus propios recursos en aplicación de su propia política ambiental y la obligación de asegurar que las actividades que se lleven a cabo dentro de su jurisdicción o bajo su control no perjudiquen al medio de otros Estados o de zonas situados fuera de toda jurisdicción nacional.

Como puede notarse, en esta máxima convergen los tres principios eje del comportamiento de los Estados en el ámbito internacional ambiental - el uso equitativo y razonable de los recursos, la debida diligencia y la buena fe-.

Por su parte, el artículo 2, elaborado por la Asociación de Derecho Internacional en la 59a. Conferencia celebrada en 1980, señala: "En consonancia con el principio de utilización equitativa, los Estados de las cuencas cooperarán con espíritu de buena fe y buena vecindad en la evaluación de sus necesidades y posibilidades en la preparación en los pla-

133 Véase United Nations, General Assembly, Resolución 34/186, Cooperación en el campo del medio ambiente en materia de recursos naturales compartidos por dos o más Estados", en http:/ /www.un.org/spanish/documents/ga/res/34/ares34.htm 
nes de regulación. Cuando proceda, la regulación se emprenderá de manera conjunta". 134

\section{Obligación general de cooperar}

La Resolución 3129 de las Naciones Unidas estima que la cooperación entre países que comparten recursos naturales debe realizarse mediante el establecimiento de normas internacionales adecuadas para su conservación y explotación armoniosa. ${ }^{135}$ Dicha cooperación deberá realizarse sobre la base de igualdad, soberanía e integridad territorial de los Estados de conformidad con el principio 21 de la Declaración de Estocolmo. ${ }^{136}$

Asimismo, las recomendaciones 51 a 55 del Plan de Acción de Estocolmo conminan a la cooperación internacional para proteger las aguas interiores y los recursos de agua contra la contaminación. Más adelante, la Conferencia de las Naciones Unidas sobre el Agua, ${ }^{137}$ celebrada en Mar de Plata, Argentina, en 1977, recomendó estudiar los métodos que puedan emplearse para el manejo de los recursos de agua, así como elaborar programas comunes e implementar los mecanismos e instituciones necesarias para la utilización coordinada de los recursos de agua, con un énfasis especial en la cooperación para dar protección al medio ambiente.

De acuerdo con la Declaración de Río, los Estados deben cooperar efectivamente para desalentar o evitar la reubicación y la transferencia a otros Estados de cualesquiera actividades y sustancias que causen degradación ambiental grave o se consideren nocivas para la salud humana (principio 14).

Los recursos de agua transfronterizos y su utilización revisten gran importancia para los Estados ribereños. A ese respecto, puede ser conveniente la cooperación entre esos Estados de conformidad con los acuerdos existentes y otros mecanismos pertinentes, teniendo en cuenta los in-

134 Cfr. Anuario de la Comisión de Derecho Internacional, 1982, New York, Naciones Unidas, 1984, vol. 2, 1a. pte., p. 201.

135 Resolución sobre Cooperación en el Campo del Medio Ambiente en Materia de Recursos Naturales Compartidos por Dos o Más Estados, Asamblea General de la ONU, 13 de diciembre de 1973, en Székely, Alberto, Instrumentos fundamentales de derecho internacional público, México, UNAM, Instituto de Investigaciones Jurídicas, 1990, t. V, p. 2908.

136 Recomendaciones de la Conferencia de las Naciones Unidas sobre Aguas Internacionales, en Székely, Alberto, Instrumentos fundamentales..., cit., t. V, p. 3313.

137 Ibidem, pp. 3313-3321. 
tereses de todos los Estados ribereños interesados (Agenda 21, capítulo 18.4)..$^{138}$

\section{Principio quien contamina paga $(P P P)^{139}$}

Este principio fue adoptado mediante una Recomendación de la OCDE en 1974. ${ }^{140}$ Sus principales objetivos son: ${ }^{141}$ promover la eficiencia en el manejo de los recursos, a través de la internalización de los costos de las medidas de prevención y control de la contaminación mediante la intervención de las autoridades públicas de cada país. ${ }^{142}$ Es decir, el que contamine deberá cubrir los gastos generados por la contaminación y tomar las medidas de control impuestas por las autoridades para que la situación del medio ambiente sea aceptable; el mecanismo puede ser a través de la imposición de normas, cargas o impuestos; y abolir las distorsiones al comercio y a la inversión, internalizar los costos detectables en los subsidios. ${ }^{143}$

El principio ha sufrido diversas modificaciones en el transcurso del tiempo. Así, aparece a principios de los años ochenta el tema de la conta-

138 También conocida como Programa 21, constituye uno de los instrumentos aprobados en la Conferencia de las Naciones Unidas sobre Medio Ambiente y Desarrollo, celebrada en junio de 1992. Cfr. United Nations, Department of Economic and Social Affairs, Division for Sustainable Development, "Programme 21", en http://www.un.org/esa/sustdev/documents/agenda21/spanish

139 Por sus siglas en inglés "Polluter Pays Principle”.

140 Organización internacional, creada el 30 de septiembre de 1961, que busca compartir valores y experiencias económicas que permitan a los países miembros identificar problemas comunes y encontrar soluciones adecuadas a los mismos mediante la formalización, coordinación y comparación de sus políticas económicas. Inicialmente su aplicación se dio en la Comunidad Económica Europea pero actualmente opera para todos los miembros de la organización. Cfr. González, Ana Karina, La OCDE y el medio ambiente; La OMC y el medio ambiente, México, Centro Mexicano de Derecho Ambiental-National Wildlife Federation, 1998, pp. 21 y ss. Además debe advertirse que la Organización ha elaborado distintos instrumentos que involucran a los acuíferos, entre ellos: la Declaración sobre Política Ambiental; la Declaración sobre Políticas Ambientales Preventivas, y la Declaración sobre Medio Ambiente y Recursos para el Futuro. México ingresó a la organización en 1994, cfr. Secretaría de Relaciones Exteriores, Declaración del Gobierno de los Estados Unidos Mexicanos sobre la Aceptación de sus Obligaciones como miembro de la Organización para la Cooperación y el Desarrollo Económico, México, SRE, 1994, p. 48.

141 Cfr. Gaine, Sanford E., "The polluter pays principe: From economic equity to environmental ethos", Texas International Law Journal, Austin, vol. 26, núm. 3, 1991, pp. 463-470.

142 Para un estudio específico sobre este principio véase García López, Tania, Quien contamina paga; principio regulador del derecho ambiental, México, Porrúa, 2001.

143 Puntualmente, en materia medioambiental, Jordano Fraga ha dicho que el PPP debe designarse como el principio de quien daña el medio ambiente, responde y lo restaura, $c f r$. Jordano Fraga, Jesús, La protección del derecho a un medio ambiente adecuado, Barcelona, Bosch, 1995, p. 138. 
minación accidental, toda vez que si se consideraba que existía una obligación de pago por daño, fundamentada en la responsabilidad objetiva, este tipo de contaminación no estaba prevista. Por tanto, en 1988 se relacionó el $P P P$ con el análisis y la responsabilidad de los daños causados por accidentes vinculados con sustancias peligrosas. En este orden de ideas, podemos afirmar que, nos enfrentamos a nuevas modalidades del principio las cuales están íntimamente ligadas a la globalización comercial y a la devastación global del planeta. ${ }^{144}$

La falta de incorporación de los costos ambientales en los costos productivos obedece a fallas de política y de mercado con serias repercusiones medioambientales, pues la existencia de estas externalidades causa uno de los conflictos que median entre comercio y medio ambiente y para superarlos es necesario introducir medidas económicas y políticas, ya que la cuestión fundamental es lograr que el sistema productivo incluya el costo total de producción, inclusive el medioambiental, lo cual evitará que la sociedad y el entorno asuman las consecuencias de las externalidades.

\section{Obligación de información y asistencia mutua}

A raíz del accidente de Chernobyl, URSS, los Estados advirtieron la necesidad de tratar las amenazas del daño ambiental transfronterizo; con esa base se han desarrollado importantes instrumentos internacionales ${ }^{145}$ y se ha aceptado la obligación de los Estados de notificar inmediatamente a otros Estados de los desastres naturales u otras situaciones de emergencia que puedan producir efectos nocivos súbitos en el medio ambiente de esos Estados.

De acuerdo con la Declaración de Río, la comunidad internacional deberá hacer todo lo posible por ayudar a los Estados que resulten afectados (principio 18). Asimismo, los Estados se comprometen a proporcionar la información pertinente, y a notificar previamente y en forma oportuna, a los Estados que posiblemente resulten afectados por actividades

144 Cfr. Plascencia Rodríguez, José Francisco, "Principios de tributación ambiental”, Trimestre Fiscal, Guadalajara, Jal., México, año 17, núm. 55, julio-septiembre de 1996, pp. 219-221.

145 Sobresalen la Convención sobre la Pronta Notificación de Accidentes Nucleares y la Convención sobre Asistencia en caso de Accidente Nuclear o Emergencia Radiológica, ambos celebrados en 1986 y disponibles, respectivamente, en http://www.iaea.org/worldatom/Documents/Legal/cenna.shtml y http://www.iaea.org/worldatom/Documents/Legal/cacnare.shtml. 
que puedan tener considerables efectos ambientales transfronterizos adversos, y deberán celebrar consultas con esos Estados en una fecha temprana y de buena fe (principio 19).

Como Soares lo ha afirmado, las formas más perfectas del deber de cooperación entre los Estados, en materia de preservación del medio ambiente, se refieren a la obligación de prestarse asistencia ante una emergencia o un accidente, ${ }^{146}$ misma que puede darse directamente entre los Estados o por medio de organizaciones internacionales.

\section{Principio de prevención}

De conformidad con el principio 2 de la Declaración de Río, los Estados tienen el derecho soberano de aprovechar sus recursos según sus propias políticas ambientales y de desarrollo, y la responsabilidad de velar por que las actividades realizadas dentro de su jurisdicción o bajo su control no causen daños al medio ambiente de otros Estados o de zonas que estén fuera de los límites de la jurisdicción nacional.

Como se observa, este principio, actualmente conocido como "de prevención" se configura sobre la base de otras máximas bien definidas y reconocidas con anterioridad - del uso equitativo y razonable de los recursos, de la debida diligencia y de la buena fe-; lo cual se traduce, en el caso que nos ocupa, en la obligación de no causar daños transfronterizos por la utilización de un curso de agua internacional por parte de un Estado, de forma soberana en su territorio.

\section{Principio de precaución}

La elaboración de este principio responde al reconocimiento de la incertidumbre científica respecto de los daños al medio ambiente que determinadas actividades pueden causar, pues ha quedado demostrado que, aunque en muchos de los casos la ciencia ha proporcionado respuesta a muchas preguntas y ha marcado la pauta a seguir; existen otros tantos en los que plantea una serie de interrogantes cuya respuesta aún no ha dado. ${ }^{147}$ De tal suerte, y con la finalidad de proteger el medio ambiente,

146 Cfr. Soares, Guido Fernando da Silva, Direito Internacional do Meio Ambiente, São Paulo, Atlas, 2001, p. 567.

147 Sobre el tema véase Juste Ruiz, José, Derecho internacional del medio ambiente, Madrid, McGraw-Hill, 1999, pp. 78-81. Algunos autores identifican el origen de este principio en el punto 9, 
los Estados deben aplicar ampliamente el criterio de precaución conforme a sus capacidades. Cuando haya peligro de daño grave o irreversible, la falta de certeza científica absoluta no deberá utilizarse como razón para postergar la adopción de medidas eficaces en función de los costos para impedir la degradación del medio ambiente (principio 15, Declaración de Río).

\section{Equidad intergeneracional}

A través de este postulado se pretende garantizar que las generaciones presentes usen los bienes ambientales de forma tal, que también puedan hacerlo en un futuro las generaciones venideras. En consecuencia, el derecho al desarrollo debe ejercerse de manera que responda equitativamente a las necesidades de desarrollo y ambientales de las generaciones presentes y futuras (principio 3, Declaración de Río).

\section{Principio de responsabilidad e indemnización}

Mediante esta máxima se admite que los Estados son responsables del cumplimiento de sus obligaciones internacionales sobre preservación y restauración del medio ambiente; en consecuencia, deben garantizar que sus sistemas jurídicos cuenten con los medios adecuados que permitan la reparación, en caso de incumplimiento. Para ello, deberán cooperar en el desarrollo y aplicación del derecho internacional ambiental (principios 22 y 13, Declaración de Estocolmo y de Río, respectivamente).

Así, el capítulo 18 de la Agenda 21 señala que los recursos de agua dulce son un componente esencial de la hidrosfera de la Tierra y parte indispensable de todos los ecosistemas terrestres. El medio de agua dulce se caracteriza por el ciclo hidrológico, que incluye las inundaciones y sequías, cuyas consecuencias se han vuelto en algunas regiones más extremas y dramáticas durante los últimos años. El cambio climático mundial

de la Declaración sobre Política Ambiental, preparada por la OCDE, el 14 de noviembre de 1974, el cual señala que a fin de prevenir el futuro deterioro ambiental, la evaluación previa de las consecuencias ambientales de las actividades, tanto públicas como privadas, que puedan causar un impacto, debería ser un elemento esencial de políticas, aplicada a nivel nacional, regional y local. Cfr. Hohmann, Harald, The precautionary legal..., cit., p. 141. Asimismo, véase Organisation for Economic Co-operation and Development, Declaration on environmental Policy, C/M(74)26, disponible en http:/webdomino1.oecd.org/horizontal/oecdacts.nsf/Display/C5E33AAD694E04E0C 1257052007C6AC9?OpenDocument 
y la contaminación atmosférica podrían también tener consecuencias para los recursos de agua dulce y su disponibilidad y, con la elevación del nivel del mar, poner en peligro las zonas costeras bajas y los ecosistemas de las islas pequeñas (18.1).

Si consideramos que debido a la permanencia del $\mathrm{CO}_{2}$ en la atmósfera las concentraciones actuales de este gas son el resultado de su acumulación desde los últimos 150 años, ${ }^{148}$ identificamos una gran responsabilidad pasada, presente y futura de los países industrializados que desarrollaron sus economías, y actualmente las sostienen, con base en la sobreexplotación de los recursos naturales de propiedad común, pues han considerado a la atmósfera como un recurso libre e ilimitado. ${ }^{149}$

\section{Resolución pacífica de controversias}

Este principio rige actualmente las relaciones de la comunidad internacional, por ello, la Carta de las Naciones Unidas prohíbe, tanto la amenaza como el uso de la fuerza, pues la idea es que los miembros de la organización arreglen sus controversias internacionales por medios pacíficos, de forma tal que no se pongan en peligro ni la paz y la seguridad internacionales ni la justicia.

Por ende, las partes en una controversia cuya continuación sea susceptible de poner en peligro el mantenimiento de la paz y la seguridad internacionales tratarán de buscarle solución, ante todo, mediante la negociación, la investigación, la mediación, la conciliación, el arbitraje, el

148 En el ámbito internacional, México se ubica dentro de las 15 naciones con mayores emisiones de $\mathrm{CO}_{2}$ a la atmósfera; sin embargo, en atención al volumen, aporta menos del $2 \%$ de las emisiones globales, aunque en términos de eficiencia energética tiene niveles menores que los alcanzados por los países industrializados, ello debido a su insuficiente desarrollo tecnológico. Por su parte, los EUA es responsable del $25 \%$ de la emisiones de $\mathrm{CO}_{2}$ acumuladas entre 1950 y 1990 , y del $36 \%$ de las emisiones globales de todos los GEI; por si fuera poco, sus emisiones de $\mathrm{CO}_{2}$ en el año 1995 aumentaron en 11\% respecto de las de 1990, lo que muestra su falta de convicción por atender el problema. Véase Peñalver, Eduardo M., "Acts of god or toxic torts? Applying tort principles to the problem of climate change", Natural Resources Journal, Albuquerque, New Mexico, vol. 38, núm. 4, fall, 1998, pp. 563-564. Aunado a ello, cabe destacar que, el Protocolo de Kyoto, acuerdo jurídicamente vinculante que dispuso los compromisos de limitación y reducción de GEI, entró en vigor el 16 de febrero de 2005, aún sin la ratificación de los EUA. Sobre el particular véase Lopez, Todd M., "A look at climate change and the evolution of the Kyoto Protocol", Natural Resources Journal, Albuquerque, New Mexico, vol. 43, núm. 1, winter 2003, pp. 299-300.

$149 C f r$. Anglés Hernández, Marisol, "Hacia la consolidación del Protocolo de Kioto y el control de los gases de efecto invernadero", Anuario Mexicano de Derecho Internacional, México, vol. II, 2002 , p. 233. 
arreglo judicial, el recurso a organismos o acuerdos regionales u otros medios pacíficos de su elección (artículo 33.1 de la Carta de las Naciones Unidas). ${ }^{150}$

Sin duda, la comunicación entre los Estados que comparten un curso de agua es fundamental para encontrar soluciones pacíficas a sus necesidades mutuas respecto de esa cuenca.

A continuación planteamos la construcción y avances de la cooperación bilateral entre México y los EUA tendente a afrontar y resolver la problemática vinculada a las aguas fronterizas de la región.

\section{COOPERACIÓN AMBIENTAL BILATERAL}

Desde la perspectiva ambiental, puede afirmarse que la zona fronteriza de México y los EUA constituye un sistema con características muy específicas, en el que los recursos naturales, principalmente el agua y el aire, son comunes y limitados en ambos lados de la frontera. Por tanto, la utilización de estos elementos beneficia a los habitantes de toda el área; mientras que su deterioro, afecta a la comunidad entera. ${ }^{151}$

Debido al crecimiento de la región, las áreas metropolitanas experimentan una expansión vertiginosa $\mathrm{y}$, en proporción a ella, la demanda sobre el medio ambiente se incrementa. Los elevados niveles de contaminación se deben, fundamentalmente, a las emisiones de monóxido de carbono, hidrocarburos y óxidos de nitrógeno de los vehículos automotores (los cuales del lado mexicano tienen una antigüedad que supera los diez años y malas condiciones de mantenimiento); ${ }^{152}$ al incremento de las fuentes industriales que son potencialmente contaminantes; a los procesos agrícolas y pesticidas que también emiten partículas peligrosas; al tránsito vehicular a través de calles sin pavimento, lo cual genera partículas suspendidas; a las operaciones mineras; a las emisiones generadas por las

150 Cfr. Naciones Unidas, "Carta de las Naciones Unidas", 26 de junio de 1945, disponible en http://www.un.org/spanish/aboutun/charter.htm

151 Cfr. Dávila, Guillermo H., "Air pollution control...", cit., pp. 545 y 546.

152 Ello responde a las características del subdesarrollo en el que nos encontramos — pobreza, ignorancia, tecnología obsoleta, mala administración, dependencia económica-, factores que generan un importante impacto ambiental en la zona fluvial fronteriza. Sobre el particular véase la opinión de Kiss, Alexandre, Droit International de l'Environnement, Paris, Pedone, 1989, pp. 36 y 37, así como la de Gutiérrez Baylón, Juan de Dios, "El septentrión fluvial y marítimo de México en el derecho internacional general", Anuario Mexicano de Derecho Internacional, México, vol. III, 2003, pp. 229-235. 
plantas termoeléctricas, y, entre otras, al influjo de barcos petroleros mexicanos y a los complejos petroquímicos. ${ }^{153} \mathrm{Sin}$ duda, la capacidad de la infraestructura existente ha sido rebasada, lo que ha conducido a insuficiencias en el abastecimiento de agua, manejo inadecuado de las aguas residuales e impacto negativo en el hábitat y en la biodiversidad de la zona.

La contaminación de las aguas superficiales por agentes industriales y productos químicos agrícolas, representa un grave problema; por ello, es fundamental el establecimiento de infraestructura para el manejo de los residuos sólidos y peligrosos que evite su disposición inadecuada, ya que genera degradación ambiental y pone en riesgo la salud de la población.

El mantenimiento de las condiciones ambientales en la frontera de México-EUA requiere de un acuerdo internacional que permita preservar sus características adecuadas en ambos países. Nuestros gobiernos tienen que encarar la realidad inminente, ya que aproximadamente en 25 años la población de la región sobrepasará los 30 millones de habitantes, los cuales, por el simple hecho de vivir y realizar sus actividades cotidianas, impactarán negativamente el medio ambiente.

Como hemos visto a lo largo de este estudio, la cooperación se erige como un factor determinante para alcanzar las metas en la región fronteriza, y la cuestión ambiental no puede dejarse del lado. Es así como gran parte de los problemas ambientales fronterizos se han tratado de resolver a través de acuerdos institucionales como la Comisión de Salud Fronteriza México-EUA, el Acuerdo de la Paz, el Acuerdo de Cooperación Ambiental del América del Norte; la Comisión de Cooperación Ambiental Fronteriza y el Banco de Desarrollo para América del Norte, entre otros.

Dentro de las actividades conjuntas llevadas a cabo por la CILA en materia de observación de la calidad de las aguas a lo largo de la región fronteriza, sobresalen las siguientes. ${ }^{154}$

El Acta 279, firmada el 28 de agosto de 1989, la cual dispone medidas conjuntas para mejorar la calidad de las aguas del río Bravo en el

153 Cfr. Applegate, Howard G., "Transboundary air quality: Problems and prospects from El Paso to Brownsville", Natural Resources Journal, Albuquerque, New Mexico, vol. 22, núm. 4, October, 1982, pp. 1133-1138.

154 Todos los esfuerzos de cooperación binacional realizados en el marco de la CILA pueden consultarse en Secretaría de Relaciones Exteriores, "Comisión Internacional de Límites...”, cit., en http://www.sre.gob.mx/cila 
área de Nuevo Laredo-Laredo; entre las que destaca un programa de monitoreo de la calidad de las mismas en el área antes mencionada. Ello a su vez, dio lugar a la elaboración del Estudio Binacional sobre el Monitoreo Intensivo de la Calidad de las Aguas del Río Bravo en el Tramo de Nuevo Laredo, Tamaulipas-Laredo, Texas, entre México y los EUA, del 6 al 16 de noviembre de 2000 .

Más adelante, el Acta 289, aprobada el 13 de noviembre de 1992, estableció las acciones para la Observación de la Calidad de las Aguas a lo largo de la Frontera entre México y los EUA. Esas actividades comprenden diversos programas de monitoreo cuyos resultados se presentan en los siguientes trabajos: Estudio Binacional sobre la Presencia de Sustancias Tóxicas en el Río Bravo-Río Grande y sus Afluentes, en su Porción Fronteriza entre México y los EUA (al cual se le dio seguimiento a través de tres fases consecutivas); Estudio Binacional de Monitoreo de las Aguas Subterráneas en el Acuífero Fluvial del Arroyo los Nogales, en la Zona de ambos Nogales, y Estudio Binacional sobre la Presencia de Sustancias Tóxicas en las Aguas del Bajo Río Colorado y del Río Nuevo.

En abril de 2002, la Comisión Estatal de Servicios Públicos de Mexicali y la Agencia de Protección Ambiental del Estado de California, con la participación de ambas secciones de la CILA, acordaron realizar un Programa de Monitoreo y Pretratamiento de aguas residuales de la ciudad de Mexicali, BCN, con el objetivo principal de desarrollar e implementar un programa de muestreo y análisis de laboratorio de aguas residuales, a fin de obtener información básica referente a la calidad de las aguas del sistema de colectores de Mexicali. Los resultados del Programa se describen el estudio denominado Wastewater Characterization Study, City of Mexicali, Baja California, Mexico (January-July 2003). ${ }^{155}$

No podemos pasar por alto los temas relacionados con la administración de los recursos naturales en ambos lados de la frontera entre los dos países, misma que ha iniciado en la región comprendida entre Fort Quitman y la Presa Internacional La Amistad con la realización del Simposio Binacional del Río Bravo de Fort Quitman y la Presa Internacional La Amistad, el cual estuvo coordinado por la CILA, y contó con la asistencia de representantes de los tres niveles de gobierno, además de organizaciones no gubernamentales y académicas de ambos países. En el sim-

155 Secretaría de Relaciones Exteriores, "Comisión Internacional de Límites...", cit., en http://www.sre.gob.mx/cila 
posio se trataron asuntos relativos a los cambios de calidad y cantidad de los flujos hidráulicos en el tramo del río Bravo indicado, y en particular lo relacionado a oportunidades para fomentar y proteger la biodiversidad del sitio, utilizando los recursos existentes y disponibles.

El Acta 306 de la CILA, intitulada: "Marco conceptual entre México y los EUA para el desarrollo de estudios que permitan emitir recomendaciones respecto a la ecología ribereña y el estuario del tramo limítrofe del río Colorado y su delta", permitió la constitución de un marco de trabajo para la cooperación de ambos países, a través del desarrollo de estudios conjuntos y la formulación de recomendaciones para proyectos que aseguren el uso de agua para propósitos ambientales de la ecología ribereña y del estuario del tramo limítrofe del río Colorado y su delta, con base en el principio de una distribución equitativa de los recursos. Como parte de las prácticas realizadas para alcanzar ese objetivo, se efectuó el Simposio Binacional del Delta del Río Colorado, el 11 y 12 de septiembre de 2001 en Mexicali, con los siguientes objetivos: 1 . Mejorar el nivel de conocimientos de los expertos y de las personas con injerencia en la toma de decisiones sobre aspectos institucionales y legales, de distribución y conducción de las aguas y sobre estudios científicos y ecológicos en relación al Delta, y 2. Identificar las necesidades y obstáculos del sistema del delta del río Colorado a fin de buscar la forma de superarlos.

Un antecedente importante de la gestión ambiental binacional es el Memorando de Entendimiento Secretaría de Mejoramiento del Ambiente (SMA)-Environmental Protection Agency (EPA) firmado en agosto de 1979 por los gobiernos de México y los EUA, respectivamente. Se trata de un documento que vislumbra todos los aspectos ambientales de la zona fronteriza, sin embargo, ha centrado su atención en el tema del control de la contaminación atmosférica; ya que se ha considerado que la contaminación de acuíferos o de suelos es técnicamente factible de resolver; mientras que es más complicado atender la situación de contaminación atmosférica, ya que el movimiento de las masas de aire contaminado no puede detenerse. ${ }^{156}$

Se han instalado en la frontera de ambos países redes de monitoreo de la calidad del aire, lo cual ha permitido tener información completa,

$156 C f r$. Tolivia, Enrique, "Problemas y perspectivas de la calidad del aire en la frontera", Natural Resources Journal, Albuquerque, New Mexico, vol. 22, núm. 4, October, 1982, pp. 1141-1145. 
actualizada y científicamente válida para establecer programas de prevención y control de la contaminación atmosférica.

La voluntad política de ambos países para resolver de manera conjunta los problemas ambientales en la franja fronteriza de $3141 \mathrm{~km}$ de longitud y $100 \mathrm{~km}$ de amplitud en cada uno de los territorios, quedó plasmada, el 14 de agosto de 1983, en el Convenio para la Protección y Mejoramiento del Medio Ambiente en la Región Fronteriza entre México y los EUA, conocido como Convenio de La Paz. ${ }^{157}$

Para la atención del convenio, fueron organizados seis grupos técnicos de trabajo: agua, aire, suelo, residuos sólidos y peligrosos, prevención de la contaminación y, prevención de contingencias y respuesta a emergencias.

A través del Grupo de Trabajo del Agua - que ahora forma parte de Frontera XXI - se atienden los aspectos de la contaminación provocada por los residuos peligrosos provenientes de las maquiladoras, empacadoras y zonas urbanas; así como de la construcción de plantas de tratamiento de aguas residuales. La CILA ha participado en discusiones de asuntos nacionales e internacionales con una gama de dependencias federales y estatales de ambos países. ${ }^{158}$

De igual forma, se crearon las bases normativas que enmarcan los esfuerzos de cooperación ambiental en cinco anexos técnicos: Anexo I, se refiere a la construcción y operación de las instalaciones de tratamiento de aguas residuales en Tijuana y San Diego (18 de julio de 1985); Anexo II, autoriza el establecimiento de un equipo local de respuesta conjunta, para atender los derrames accidentales de petróleo y sustancias peligrosas (18 de julio de 1985); Anexo III, instituye los procedimientos que regulan los movimientos transfronterizos de desechos y sustancias peligrosas (12 de noviembre de 1986); Anexo IV, negoció el Acuerdo de Cooperación sobre Contaminación Transfronteriza del Aire, Causada por las Fundidoras de Cobre a lo Largo de la Frontera Común, adoptado el 29 de enero de 1987 y, Anexo V, determina la evaluación de las causas y soluciones a los problemas de calidad del aire en las ciudades vecinas del área (13 de octubre de 1989).

157 Véase "Convenio entre los Estados Unidos Mexicanos y los Estados Unidos de América sobre Cooperación para la Protección del Medio Ambiente en la Zona Fronteriza", Diario Oficial de la Federación, México, 22 de marzo de 1984.

158 Cfr. Mumme, Stephen P., "La Reinvención de la comisión ..., op. cit., p. 5. 
En lo referente al control de la contaminación atmosférica, es importante señalar que las emisiones procedentes de procesos de fundición y refinación de cobre han sido controladas en ambos lados de la frontera. Además, se efectuaron veinticuatro visitas por el personal administrativo de la entonces Semarnap y de la EPA a lo largo de la frontera. El personal de la Semarnap recibió un entrenamiento técnico en los sistemas de incineración, manejo, transporte y almacenamiento de residuos peligrosos y quedaron conformados grupos de trabajo conjunto con el fin de mejorar la cooperación en el intercambio de conocimientos y experiencias. ${ }^{159}$

Por lo que respecta a la industria maquiladora de exportación en nuestro país existen 4,310 maquiladoras registradas ante la Secretaría de Economía, ${ }^{160}$ localizándose el $89 \%$ en la frontera norte del país. ${ }^{161} \mathrm{De}$ ellas, y de acuerdo con su giro, 1,855 generan residuos peligrosos y sólo doscientas cumplen con la obligación de manifestar sus residuos.

Debemos señalar algunas de las deficiencias propias del Convenio de La Paz: La subordinación del convenio a la existencia de las diferentes leyes y reglamentos ambientales ya existentes; la insuficiencia, por parte de los dos países, de fondos necesarios para mejorar los resultados del mismo, y una cuestión determinante, la falta de poder para exigir su cumplimiento.

El Plan Integral Ambiental Fronterizo (PIAF) formulado en febrero de 1992, tuvo entre sus metas: proporcionar protección a la salud de la población fronteriza, así como a los ecosistemas de la zona a través de diversos grupos de trabajo.

Para el caso de repatriación de residuos peligrosos que se importan o exportan ilegalmente, en 1992 se crearon en forma conjunta las Guías de Repatriación por Industria, que permiten devolver los residuos peligrosos al país exportador. ${ }^{162}$ Asimismo, las autoridades mexicanas y estadouni-

159 Cfr. McGee, Henry W. y Ortiz Nagle, Luz Estella, "TLC y el control de residuos tóxicos en la guerra contra la contaminación transfronteriza", Revista de Derecho Puertorriqueño, Ponce, vol. 35, núm. 1, 1996, pp. 75-76.

160 Cfr. Secretaría de Economía, "Sistema de Información de la Industria Maquiladora", en http://www.siem.gob.mx/siem2000/spyme/maquila_intranet.asp

161 Véase Instituto Nacional de Estadística, Geografía e Informática, Industria maquiladora de exportación, México, INEGI, 2003, pp. 4-5.

162 Como ejemplo tenemos la identificación de 173 tibores con residuos peligrosos exportados ilegalmente por la empresa $A \& W$ Smelters de los EUA a la mina "La Unión" ubicada en Guerrero Negro, México; de acuerdo al procedimiento establecido, estos residuos fueron repatriados a los 
denses, con fundamento en el Anexo III del Convenio de la Paz, la LGEEPA, el PIAF y la Resource Conservation and Recovery Act (RCRA), desarrollaron el Hazardous Waste Tracking System (Haztraks), cuyo objetivo consiste en generar información que coadyuve al control y rastreo de los movimientos transfronterizos de residuos peligrosos, así como a la identificación de su manejo adecuado por parte de las empresas involucradas. ${ }^{163}$

El Acuerdo de Cooperación Ambiental (ACA), por virtud del cual, intentaron paliarse las diferencias entre las políticas comerciales y medioambientales planteadas por las coaliciones ambientalistas ${ }^{164}$ durante la negociación del Tratado de Libre Comercio de América del Norte (TLCAN) entre México, los EUA y Canadá, ${ }^{165}$ que entró en vigor el 10. de enero de 1994, estipuló la creación de una Comisión para la Cooperación Ambiental (CCA), ${ }^{166}$ cuyo consejo posee varias funciones, entre ellas, la supervisión de la aplicación del acuerdo y la elaboración de futuras recomendaciones en lo técnico y en lo científico. De tal suerte, cuando una parte considere que otra falta de manera persistente, sistemática e injustificada en la aplicación efectiva de su legislación medioambiental y

EUA. Cfr. Cortinas de Nava, Cristina y Vega Gleason, Sylvia, Residuos peligrosos en el mundo y México, México, Secretaría de Desarrollo Social-Instituto Nacional de Ecología, 1993, pp. 124-125.

163 Kourous, George, "Availability of Information on the Border Environment: An Introductory Assessment”, Borderlines 59, New Mexico, vol. 7, núm. 8, September 1999, pp. 2-5.

$164 C$ Crr. Secretaría de Comercio y Fomento Industrial, Tratado de Libre Comercio de América del Norte. Acuerdos Paralelos. Conclusión de las Negociaciones, México, SECOFI-Miguel Ángel Porrúa, 1993, pp. 35-59 y Gallardo, Sofía C., "El debate sobre el Acuerdo de Cooperación Ambiental", Estados Unidos, México, vol. III, núm. 4, invierno de 1993, p. 38.

165 Aunque se trata de un tratado comercial, entre sus disposiciones señala que, de existir incongruencia de acuerdos previos al TLCAN con éste, prevalecen sobre él, las obligaciones ambientales; mandato aplicable, entre otros, al Protocolo de Montreal Relativo a las Sustancias Agotadoras de la Capa de Ozono de 1990; a la Convención de Basilea sobre el Control de los Movimientos Transfronterizos de los Desechos Peligrosos y su Eliminación de 1989 y al Convenio entre México y los Estados Unidos sobre Cooperación para la Protección y Mejoramiento del Medio Ambiente en la Zona Fronteriza de 1983 (artículo 104 y Anexo 104.1). Asimismo, reconoce el derecho de cada país para normar la protección de la vida, la salud humana, animal y vegetal, la seguridad del medio ambiente y la protección a los consumidores; así como para establecer los niveles de protección idóneos para lograr los objetivos legítimos en esta materia; y prohíbe la imposición de normas que produzcan obstáculos innecesarios al comercio (artículos 904.1 y 904.2). Empero, las partes no pueden minimizar sus normas en materia de salud, seguridad y medio ambiente para alentar las inversiones; no obstante, podrán tomar las medidas tendentes a asegurar que las mismas se efectúen bajo la consideración de los factores medioambientales (artículo 1114). Cfr. Secretaría de Comercio y Fomento Industrial, "Tratado de Libre Comercio de América del Norte", Diario Oficial de la Federación, México, 21 de diciembre de 1993.

166 Con sede en Montreal, Canadá. La comisión está integrada por un consejo, una secretaría y un Comité Público de Consulta. 
esto afecte bienes o servicios comerciables entre ellas, la primera podrá solicitar consultas.

Ahora bien, los ciudadanos y las organizaciones no gubernamentales deben seguir una serie de pasos, algunos muy costosos, para solicitar a la CCA la investigación y dictamen sobre una violación persistente de una de las partes a sus leyes ambientales; amén de que, como era de esperarse, en el contexto del TLCAN se han privilegiado las cuestiones comerciales.

Como parte de los trabajos realizados por la CCA se preparó el documento denominado "El Mosaico de América del Norte", en el que se advierte, entre otras, la urgente necesidad de instrumentar estrategias binacionales coordinadas y equitativas entre los gobiernos de los EUA y México, pues "la falta de un manejo integral y de cooperación en cuanto a los recursos transfronterizos de aguas subterráneas será sin duda uno de los retos más apremiantes del nuevo siglo". ${ }^{167}$

Las tareas de la CCA podrían realizarse con mayor eficiencia si se asegurara la difusión y transparencia con respecto a la ciudadanía. Por tanto, es necesario crear nuevos mecanismos para fomentar la participación de las comunidades en la obtención y manejo de información. ${ }^{168}$

Una cuestión que debemos resaltar, es que a partir de la adopción del TLCAN, nuestro país desarrolló una legislación medioambiental cuya aplicación correcta exigió una infraestructura gubernamental con autoridades competentes y mecanismos de control adecuados. ${ }^{169}$ Esta situación ha obligado al país a trabajar en el fortalecimiento e implementación de su marco jurídico medioambiental, ${ }^{170}$ en el que se incluye el agua, a través de distintos organismos gubernamentales, aunque ello no siempre ha alcanzado los resultados esperados.

167 Cfr. Comisión de Cooperación Ambiental, "El Mosaico de América del Norte", en http://www.cec.org/pubs_docs/documents/index.cfm? varlan=espanol\&ID=629

168 Cfr. Anglés Hernández, Marisol, Instrumentos de política ambiental sobre residuos peligrosos, México, Porrúa, 2004, p. 51. Además de ello, hay quienes opinan que el mandato de la CCA debe ampliarse a fin de lograr mejores resultados, $c f r$. Newcomb, John, "Why exactly does the NAFTA CEC (Commission for Environmental Cooperation) exist?", International Rivers and Lakes Newsletter, New York, núm. 33, June 2000, p. 6.

169 Cfr. Carmona Lara, María del Carmen, "El Tratado de Libre Comercio y el Ambiente", en Witker, Jorge (coord.), El Tratado de Libre Comercio de América del Norte. Análisis, Diagnóstico y Propuestas Jurídicos, México, UNAM, Instituto de Investigaciones Jurídicas, t. II, 1993, p. 308.

170 Sobre el tema véase Benjamin, Antonio Herman V., "O Estado teatral e a implementação do direito ambiental", en Benjamin, Antonio Herman (ed.), Direito, Água e Vida, São Paulo, Procuradoria Geral de Justiça-Instituto O Direito por um Planeta Verde, 2003, vol. 1, pp. 335-366. 
La Comisión de Cooperación Ecológica Fronteriza (Cocef), creada en el marco del ACA del TLCAN; es un organismo internacional cuya finalidad radica en identificar las necesidades de infraestructura en materia de agua potable, alcantarillado, saneamiento; así como manejo y disposición de residuos sólidos municipales para desarrollar proyectos binacionales, entre México y los EUA. ${ }^{171}$ Los proyectos, una vez que han sido evaluados, y en su caso aprobados, son financiados por el Banco de Desarrollo de América del Norte (Bandan), o por otra fuente de financiamiento.

Cabe señalar que la Cocef ha recibido soporte financiero de la $E P A$, con el que se pudo instrumentar el Programa de Apoyo al Desarrollo de Proyectos relacionados con agua potable, alcantarillado, saneamiento y asistencia técnica. La estructura de la Cocef se ha consolidado y la coordinación con las distintas instituciones de los tres niveles de gobierno de los dos países se ha fortalecido, así como la participación pública en la frontera, particularmente del lado mexicano. ${ }^{172}$

El acuerdo Frontera XXI, firmado por los gobiernos de México y los EUA el 7 de octubre de 1996, representó una nueva fase de planeación binacional basada en la experiencia reunida por el PIAF. Su estrategia central contempló tres ejes fundamentales: asegurar la participación pública en el desarrollo e implementación del programa; fortalecer la capacidad de las instituciones locales y estatales, así como descentralizar la gestión ambiental. ${ }^{173}$

Gracias a los esfuerzos de la Cocef y al apoyo del Bandan, se ha progresado en los proyectos de certificación y financiamiento para las co-

171 Wilder, Margaret, "Border farmers, water contamination, and the NAAEC environmental side accord to NAFTA", Natural Resources Journal, Albuquerque, New Mexico, vol. 40, núm. 4, fall, 2000, pp. 873-875.

172 Los avances puntuales logrados tanto por la Cocef como por el Bandan pueden encontrarse en Carter, Nicole, "Border Environment Policy, Part III: State of Binational Cooperation Today, Prospects for the Future", Borderlines 74, New Mexico, vol. 9, núm. 1, January 2001, pp. 7-10. La importancia de la participación pública en relación con la conservación y aprovechamiento de los cursos de agua compartidos en ambos lados de la frontera, ha empezado a reconocerse e impulsarse de manera directa, ejemplo de ello es la Recomendación sobre el particular hecha en la Conferencia de Oportunidades y Desafíos del Agua Binacional, $c f r$. United Nations, "Mexico-USA: Binational Water Challenges and Opportunities Conference Recommendations", International Rivers and Lakes Newsletter, New York, núm. 32, December 1999, p. 14.

173 Cfr. Kourous, George, "Still planning to plan?, The Border XXI Program: An Overview", Borderlines 55, New Mexico, vol. 7, núm. 4, April 1999, p. 4. 
munidades fronterizas. ${ }^{174}$ Indiscutiblemente, la Cocef es un modelo institucional, caracterizado por la transparencia y la participación del público en materia de agua y aguas residuales que sirve como puntero para lograr las metas ambientales y sociales dentro del marco del desarrollo sostenible. ${ }^{175}$

Frontera XXI define objetivos ambientales de mediano plazo (cinco años), así como los mecanismos de implementación. Como parte de la estrategia global y los esfuerzos de planeación de la región fronteriza, ambos gobiernos reconocen la importancia de instaurar mecanismos de evaluación del programa. En concordancia con lo anterior, se trata de vincular los procesos presupuestales y la gestión programática con los resultados específicos de las acciones del programa, a través de indicadores de desempeño ambiental. ${ }^{176}$

El éxito de Frontera XXI depende de la amplia participación de ambos países en los tres niveles de gobierno; así como de instituciones internacionales, organizaciones no gubernamentales, sector académico y sector social. Pues actualmente, los ciudadanos que abogan por el desarrollo sostenible son actores influyentes dentro de la comunidad que determina cómo se aprovecha el agua en la frontera. Estos grupos quieren que el agua se utilice de una manera diferente, y conciben usos más eficientes de los recursos hídricos, una mejor conservación del agua, previsiones de largo plazo y prevención de contingencias y, reasignaciones que den prioridad a las necesidades urbanas o a proyectos no tradicionales. ${ }^{177}$

Ambos gobiernos federales procuran fomentar la participación pública dentro de Frontera XXI a través de sus respectivos consejos: el Consejo Consultivo para el Desarrollo Sustentable Región 1, por parte de Mé-

174 Aunque el financiamiento del Bandan es similar a las instituciones que ofrecen préstamos de bajo interés, el banco apoya sus concesiones y garantías en tarifas de mercado; por lo que en algunos casos la contratación del préstamo implica costos elevados. Véase Mumme, Stephen, “Despite shortcomings...", cit., pp. 7 y 8.

175 Idem.

176 Kourous, George, "Política ambiental en la frontera: la situación actual. Parte II: La reciente evolución de los esfuerzos y recomendaciones para futuras políticas", Borderlines 73, New Mexico, vol. 8, núm. 11, December 2000, p. 8.

177 La influencia ejercida por estos nuevos actores se reflejó en la agenda de la CILA durante los años noventa, cuando ocuparon un lugar prominente en problemáticas tales como las medidas contra las sequías, el ordenamiento de aguas subterráneas y la conservación ecológica, $c f r$. Mumme, Stephen P., "La reinvención de la comisión...", cit., p. 7. 
xico, y el Good Neighbor Environmental Board (Comité Ambiental del Buen Vecino-CABV), por parte de los EUA.

La implementación de Frontera XXI se lleva a cabo a través de nueve grupos de trabajo binacionales, seis fueron constituidos en el marco del Convenio de La Paz (agua, aire, suelo, residuos sólidos y peligrosos, prevención de la contaminación, y prevención de contingencias y respuesta a emergencias) y los tres restantes se crearon en el seno de Frontera XXI: recursos de información ambiental, recursos naturales y salud ambiental, cuya meta es tratar al medio ambiente desde una perspectiva integral.

Con el fin de verificar el cumplimiento de los objetivos del programa, ambos gobiernos acordaron generar reportes bienales. Para asegurar la aportación pública a través de este proceso de evaluación, tanto los reportes bienales de avance como los programas anuales de trabajo deben estar a disposición del público. Para ello, en los ámbitos internos, la EPA y la Semarnat han trabajado en el establecimiento de sus páginas web para permitir el acceso a la información pública medioambiental. ${ }^{178}$

Entre los resultados del Grupo de Trabajo del Agua, podemos mencionar los proyectos integrales de saneamiento de las ciudades de Mexicali, Reynosa y Ciudad Juárez; así como las obras paralelas de saneamiento de Tijuana y proyectos de Nogales y Naco; la construcción, en marzo de 1996, de la Planta de Tratamiento de Aguas Residuales de Nuevo Laredo, y en abril de 1997, la Planta Internacional de Tratamiento de Aguas Residuales Tijuana-San Diego; así como las estructuras complementarias entre ambas ciudades, lo que permite, hoy día, mejorar la recolección, tratamiento y disposición final de una gran parte de las aguas residuales generadas en la ciudad de Tijuana.

Por lo que al Grupo de Trabajo de Calidad del Aire corresponde, su logro más relevante, en el marco de participación ciudadana, fue la creación, en mayo de 1996, del Comité Consultivo Conjunto para el Manejo de la Calidad del Aire en la Cuenca Atmosférica de Ciudad Juárez-El Paso y el Condado de Doña Ana, cuyo objeto es mejorar la calidad del aire en la zona. ${ }^{179}$

178 Aunque en la práctica la posibilidad de poner a disposición del público la información no ha sido completamente exitosa. Cfr. Kourous, George, "Still planning..., cit., p. 6.

179 Véase Dávila, Guillermo H., "Air pollution control...”, cit., pp. 546-550. Un análisis sobre la cuenca atmosférica El Paso/Ciudad Juárez y los resultados alcanzados a través de la cooperación binacional puede consultarse en Rincón, Carlos y Emerson, Peter, "Binationally Managing Air Qual- 
El Comité Ambiental del Buen Vecino (CABV) puso especial énfasis en las siguientes recomendaciones en materia de agua - tema en el que centró su atención-, para ser tomadas en cuenta en la elaboración del futuro programa binacional fronterizo:

a) Institucionalizar un enfoque de cuencas hidrológicas a lo largo de la frontera para iniciar en las cuencas hidrológicas prioritarias clave y luego expandir el esfuerzo; b) Apoyar la recolección y el análisis de datos que generen un panorama claro de las cuencas hidrológicas de la frontera; c) Hacer sobresalir y apoyar las prácticas de administración de los recursos del agua a lo largo de la frontera, que estén basadas en un enfoque de cuencas hidrológicas; d) Fomentar la participación plena de las organizaciones binacionales, gobiernos federales, estatales y locales, y otros grupos fronterizos, en el desarrollo e implementación de un enfoque de cuencas hidrológicas; e) Proveer un apoyo presupuestal federal continuo para las acciones y programas que sean coherentes con los temas y propósitos de un enfoque de cuencas hidrológicas para la región fronteriza, y f) Apoyar con un presupuesto pleno los compromisos binacionales para abordar los asuntos ambientales fronterizos dentro del contexto de un enfoque de cuencas hidrológicas. ${ }^{180}$

Hacia la conclusión del Programa Frontera XXI, y a fin de mejorar los esfuerzos binacionales de planificación ambiental, se elaboró el Programa Frontera 2012, cuya misión es proteger el medio ambiente y la salud pública en la región fronteriza México-EUA de manera acorde a los principios del desarrollo sostenible, durante un período de diez años.

Entre sus objetivos sobresale la reducción de la contaminación del agua, del aire y del suelo a través de mejorar la infraestructura para el manejo de residuos peligrosos; la evaluación de los sistemas de rastreo de residuos peligrosos de ambos países a fin de consolidar su enlace; implementar una política binacional de limpieza y restauración de los sitios abandonados contaminados con residuos peligrosos, y el incentivar el

ity in the U.S.-Mexico Borderlands: A Case Study”, Borderlines 63, New Mexico, vol. 8, núm. 1, January 2000, pp. 5-15.

180 Véase Kourous, George, "Border Environment Policy: Where Do Things Stand?, Part II: New Developments Related to Ongoing Efforts and Recommendations for Future Policy", Borderlines 73, New Mexico, vol. 8, núm. 11, December 2000, pp. 8-9. El texto completo del Cuarto Informe de la Junta Ambiental del Buen Vecino para el Presidente y el Congreso de los Estados Unidos se encuentra disponible en línea en $h t t p: / / w w w . e p a . g o v / o c e m / g n e b-p a g e . h t m$ 
cumplimiento de la ley a través de programas voluntarios y/o realización de auditorías internas. ${ }^{181}$

Aunque existen muchas críticas respecto de todos estos acuerdos y programas bilaterales encaminados a atender la problemática ambiental fronteriza, todos ellos han representado una opción para el cambio en la gestión ambiental; 182 evidentemente, sus resultados han estado muy alejados de las expectativas creadas con la adopción de cada uno de ellos y, aunque no debemos desdeñar el esfuerzo que han representado; ${ }^{183}$ la realidad y los hechos recientes muestran aún su insuficiencia. La franja fronteriza continúa desarrollándose, sin que hasta la fecha haya un control efectivo de las sustancias y los residuos peligrosos. La falta de recursos, tanto materiales como económicos, ha impedido la ejecución de planes de limpieza y sanidad; así como de control y vigilancia, principalmente en México.

Paralelamente, dos proyectos binacionales han iniciado, el primero trata el desarrollo de un plan binacional de largo plazo de manejo de sequías para la cuenca del río Bravo solicitado al Centro Nacional de Mitigación de Sequías de la Universidad de Nebraska y el segundo es un plan de emergencia para responder a la sequía actual, encargado a expertos del Departamento de Ingeniería Civil y Ambiental de la Universidad de Washington, en Seattle. ${ }^{184}$ No obstante, nada garantiza que los resultados de ellos sean favorables para México.

Por último, aunque no ha podido materializarse en la práctica, debemos destacar la preparación de la Convención sobre Aguas Subterráneas Internacionales, conocida como "Tratado de Bellagio", de febrero de $1989,{ }^{185}$ ya que este instrumento proporciona el marco legal, los mecanismos institucionales y las medidas y programas considerados esenciales para que las cuencas de aguas subterráneas internacionales sean admi-

181 Cfr. Environmental Protection Agency, "Programa Ambiental México-Estados Unidos 2012", http://www.epa.gov/usmexicoborder/index_esp.htm\#principles.

182 Una reseña puntual de las críticas referidas a estos intrumentos puede consultarse en Mumme, Stephen P., "New directions in United States-Mexican transboundary environmental management: A critique of current proposals", Natural Resources Journal, Albuquerque, New Mexico, vol. 32, núm. 3, summer 1992, pp. 546-562.

183 Johnstone, Nick, "International trade, transfrontier pollution, and environmental cooperation: A case study of the Mexican-American border region", Natural Resources Journal, Albuquerque, New Mexico, vol. 35, núm. 1, winter 1995, p. 55.

184 Kourous, George, "Las aguas turbulentas...", cit.

185 Entre los antecedentes inmediatos de este tratado encontramos a las Reglas de Helsinki, de 1966 y las Reglas de Seúl, de 1986. 
nistradas por acuerdo mutuo en las zonas consideradas críticas, ya sea porque las extracciones superan la recarga o porque la contaminación pone en peligro la calidad del agua subterránea; en lugar de ser objeto de extracciones unilaterales; a fin de evitar los graves y prolongados conflictos en estos tiempos de presiones crecientes sobre el inapreciable recurso. ${ }^{186}$

El artículo XII de este acuerdo está destinado a la planificación para la sequía mediante un plan de manejo para ser puesto en marcha en la región fronteriza, o en parte de ella, previa aprobación de los gobiernos involucrados. Para ello, el tratado define, a la "sequía" como el estado de escasez anormal de agua en un área específica, debido a condiciones naturales (artículo 1.8).

Este plan deberá especificar las condiciones hidrometeorológicas previas a la declaración de una alerta o emergencia de sequía, y en concordancia con ella, las medidas de conservación que han de ser observadas por todos los usuarios del agua dentro de la región fronteriza. El plan de manejo puede designar y reservar ciertos acuíferos transfronterizos o pozos específicos para que se usen en tiempo de sequía; así como disponer, mientras dure la sequía: a) El manejo conjunto del abastecimiento de aguas subterráneas $y$ superficiales que estén dentro, o bien que se hayan puesto a disposición, de la región fronteriza gobernada por la declaración; $b$ ) Incrementos o reducciones en las extracciones normales permisibles, que sean distintas de las asignaciones hechas durante un Plan de Manejo Global para un Área de Conservación de Agua Subterránea Transfronteriza, o por acuerdos previos entre las partes, manteniendo hasta donde sea practicable los porcentajes de extracción convenidos entre las partes y un balance equitativo de todas las obligaciones de emergencia; y c) La autorización de usar aguas subterráneas designadas y reservadas dentro de la región fronteriza. ${ }^{187}$

Los Estados deben tomar las medidas individuales y en conjunto para prevenir, reducir y controlar la contaminación que pueda causar daño apreciable a los cursos de agua de otros Estados o a su medio am-

186 Véase el texto completo del proyecto en Hayton, Robert D. y Utton, Albert E., "Aguas subterráneas transfronterizas: Anteproyecto de Tratado Bellagio", trad. de Carmen L. de Campoy y Raquel L. de Barbuzza, Natural Resources Journal, Albuquerque, New Mexico, vol. 32, núm. 2, spring 1992, pp. 345-414.

187 Cfr. Hayton, Robert D. y Utton, Albert E., "The Model Agreement on Transboundary Groundwaters", en http://uttoncenter.unm.edu/pdfs/Bellagio_Draft_Treaty_S.pdf 
biente, incluyendo daño a la salud humana o seguridad para el uso de las aguas para cualquier propósito benéfico o para los recursos vivos del curso de agua internacional. En este sentido, los Estados deben armonizar sus políticas y elaborar una lista de sustancias que no pueden ser introducidas en el sistema del curso de agua. Asimismo, deben desarrollar planes de contingencia conjuntos para atender las emergencias (artículos 26 y 27$)$.

Independientemente de lo anterior, consideramos como una tarea insoslayable, trabajar en la elaboración de un verdadero Tratado Ambiental para la Región de América del Norte, ${ }^{188}$ pues aunque existen esfuerzos entre Canadá y los EUA y entre este último y México, lo óptimo sería proteger el medio ambiente desde una perspectiva holística, que considere al medio ambiente como un sistema ${ }^{189} \mathrm{y}$, en ese sentido, atienda su tutela ya no desde la perspectiva política, sino medioambiental, pues ha quedado demostrado que los recursos naturales no respetan fronteras, las cuencas de agua superficiales y subterráneas rebasan el territorio de un Estado y qué decir de las cuencas atmosféricas, de las cadenas montañosas y de la biodiversidad.

\section{REFLEXIONES FINALES}

La gestión integral de los acuíferos debe reconocer que éstos son parte de un sistema ambiental complejo y como tal, tienen interrelación e interdependencia con otros elementos ambientales. El agua es un recurso natural, pero también es un bien económico cuya disponibilidad está cada vez más reducida. Por ello, debemos trabajar en la búsqueda de su protección y preservación, para poder realizar un uso y aprovechamiento sostenibles, que consideren la reducción del consumo y pongan énfasis en la supervisión del cumplimiento de su marco normativo.

188 Véase la propuesta de Székely, Alberto, "Establishing a Region for Ecological Cooperation in North America”, Natural Resources Journal, Albuquerque, New Mexico, vol. 32, núm. 3, summer 1992, pp. 571-572 y 595-596.

189 Brañes concibe al medio ambiente "como un sistema, vale decir, como un conjunto de elementos que interactúan entre sí, pero con la precisión de que estas interacciones provocan la aparición de nuevas propiedades globales, no inherentes a los elementos aislados, que constituyen el sistema", cfr. Brañes, Raúl, Manual de Derecho Ambiental Mexicano, 2a. ed., México, Fundación Mexicana para la Educación Ambiental-Fondo de Cultura Económica, 2000, p. 20. 
Si consideramos que las relaciones bilaterales entre México y los EUA están determinadas, entre otros, por los acuíferos compartidos, y a ello agregamos que la contaminación no identifica fronteras, resulta fundamental fortalecer las políticas regionales en materia de tratamiento de aguas residuales municipales e industriales, instalación de servicios de alcantarillado y manejo adecuado de sustancias y residuos peligrosos, a fin de frenar el deterioro de las cuencas y, poco a poco, recuperar la calidad del agua.

Las condiciones actuales de sequía prevalecientes en la región de América del Norte están íntimamente relacionadas con el incumplimiento del Tratado de Aguas de 1944 por parte de México, debido, fundamentalmente, a la reducción significativa de la disponibilidad del recurso. Por ello, resulta imperativo iniciar una renegociación del Tratado de Aguas respaldada en los principios de derecho ambiental internacional, así como en la jurisprudencia y doctrina internacionales aplicables al caso, que permita el desarrollo sostenible de ambas naciones y respete los intereses de los demás Estados del orbe y de las generaciones futuras; pues, de lo contrario, México constantemente se verá en la imposibilidad de cumplir con sus obligaciones y esto, a la larga, puede dar lugar a conflictos bilaterales con serias implicaciones políticas, económicas y sociales que a ninguno de los dos países convendría.

Otro punto muy importante para la atención de la problemática concerniente al Tratado de Aguas requiere el desarrollo de un marco conceptual que defina lo que debe entenderse por sequía, sequía extrema, accidente en los sistemas hidráulicos y accidente en los sistemas de irrigación, así como de una estrecha coordinación y cooperación internacional que considere los aspectos científicos, sociales, culturales, económicos y políticos implicados.

Ante las deficiencias e inequidades del Tratado de Aguas, el desempeño de la CILA ha sido trascendental para la atención y solución de las diferencias presentadas a causa de las aguas superficiales transfronterizas. Su actividad ha evitado reclamar el incumplimiento o violación de las cláusulas del tratado, por cada una de las partes, como un delito internacional y, en su lugar, ha trabajado en la negociación pacífica, lo que ha dado lugar a la creación de normas específicas para la región, mismas que han enriquecido nuestras relaciones bilaterales y al propio derecho internacional fluvial. 
Sin embargo, no podemos pasar por alto que los efectos ambientales negativos resultado del uso y abuso de los recursos naturales por parte de todas las naciones del mundo exigen que éstas asuman su responsabilidad; en este sentido, la gestión del cambio climático debe efectuarse mediante un régimen internacional equitativo y solidario, como lo es el Protocolo de Kyoto y, los EUA tienen el deber de asumirlo.

Otra cuestión ineludible es el fortalecimiento del mecanismo de acceso a la información en la zona fronteriza, ya que una sociedad informada podrá participar de manera adecuada en los procesos de toma de decisión y, sobre todo, en la verificación del cumplimiento de la normatividad y, en su caso, en la denuncia de las irregularidades.

Como se advierte, el camino por andar para alcanzar la correcta comprensión, administración y aprovechamiento de las aguas a lo largo de la frontera México-EUA es aún muy largo, así es que ambos países deben hacer frente a este reto y tomar en cuenta los esfuerzos realizados en la preparación del Tratado de Bellagio, que alude a las aguas subterráneas, para dar inicio a una negociación bilateral que permita la conservación de los acuíferos y, a partir de ella, pueda realizarse su aprovechamiento de manera equitativa.

Finalmente, creemos que es fundamental enfocar los esfuerzos de los países de América del Norte para desarrollar un tratado ambiental para la región, que incluya a los ecosistemas transfronterizos de la zona, entre los que se encuentran cuencas atmosféricas y de agua, tanto superficiales como subterráneas, cadenas montañosas y una importante biodiversidad, en muchos casos de carácter endémico o en peligro de extinción, lo anterior redundará en beneficios no sólo regionales, sino globales.

\section{BIBLIOHEMEROGRAFÍA}

ADEDE, Andrónico O., Digesto de derecho internacional ambiental, trad. de Diana L. Ponce Nava, México, Secretaría de Relaciones Exteriores, 1995.

AgUILAR, Ricardo, "Los ríos: ¿patrimonio de la humanidad?", en http:// www.guaso.com/rios_ara_jornadas00_mesa3_01.htm

AlBRIGHT, Madelene, "An Alliance for Global Water Security in the 21 st Century", International Rivers and Lakes Newsletter, New York, núm. 33, June 2000. 
ANDERSON, Kirsten J., "A History and interpretation of The Water Treaty of 1944", Natural Resources Journal, Albuquerque, New Mexico, vol. 12, núm. 4, October, 1972.

ANDRASSY, Juraj, "Les Relations Internationales de Voisinage", Recueil des Cours, Leyde, t. 79, vol. II, 1951.

ANGLÉS HeRnÁnDEZ, Marisol, "Hacia la consolidación del Protocolo de Kioto y el control de los gases de efecto invernadero", Anuario Mexicano de Derecho Internacional, México, vol. II, 2002.

- Instrumentos de política ambiental sobre residuos peligrosos, México, Porrúa, 2004.

Anuario de la Comisión de Derecho Internacional, 1974, New York, Naciones Unidas, 1976, vol. 2, 2a. parte.

Anuario de la Comisión de Derecho Internacional, 1981, New York, Naciones Unidas, 1983, vol. 2, 1a. parte.

APPLEGATE, Howard G., "Transboundary air quality: Problems and prospects from El Paso to Brownsville", Natural Resources Journal, Albuquerque, New Mexico, vol. 22, núm. 4, October, 1982.

ARNAUD, Vicente Guillermo, Derecho internacional ambiental. La contaminación de los ríos en el derecho internacional público, Buenos Aires, Centro de Tecnología del Agua, 1975.

BECERRA RAMíreZ, Manuel, "Nota introductoria al Tratado sobre Distribución de Aguas Internacionales entre los Estados Unidos Mexicanos y los Estados Unidos de América", Anuario Mexicano de Derecho Internacional, México, vol. III, 2003.

BENJAMÍN, Antonio Herman V., "O Estado teatral e a implementação do direito ambiental", en id. (ed.), Direito, Água e Vida, São Paulo, Procuradoria Geral de Justiça-Instituto O Direito por um Planeta Verde, 2003, vol. 1.

BENNETT, Vivienne y HERZOG, Lawrence A., "U.S.-Mexico borderland water conflicts and institutional change: A commentary", Natural Resources Journal, Albuquerque, New Mexico, vol. 40, núm. 4, fall 2000.

BESNÉ MAÑERO, Rosario, El crimen internacional; nuevos aspectos de la responsabilidad internacional de los Estados, Bilbao, Universidad de Deusto, 1999.

BogDANOVIC, Slavko (ed.), International Law of Water Resources: Contribution of the International Law Association (1954-2000), The Netherlands, Kluwer Law International, 2001. 
Bosch GARCíA, Carlos, "1819-1836: la expansión norteamericana”, Secuencia, México, núm. 20, mayo-agosto, 1991.

BRañes, Raúl, Manual de Derecho Ambiental Mexicano, 2a. ed., México, Fundación Mexicana para la Educación Ambiental-Fondo de Cultura Económica, 2000.

BRown, Christopher P. y MuMME, Stephen, "Applied and theoretical aspects of Binational Watershed Councils (Consejos de Cuencas) in the U.S.-Mexico Borderlands," Natural Resources Journal, Albuquerque, New Mexico, vol. 40, núm. 4, fall, 2000.

CAMPOS DÍAZ BARRIGA, Mercedes, La responsabilidad civil por daños al medio ambiente. El caso del agua en México, México, UNAM, Instituto de Investigaciones Jurídicas, 2000.

Carbonell, Miguel (coord.), Constitución Politica de los Estados Unidos Mexicanos. Comentada y concordada, México, Porrúa-UNAM, Instituto de Investigaciones Jurídicas, 2003, t. I.

CARMOnA LARA, María del Carmen, "El Tratado de Libre Comercio y el Ambiente", en WITKER, Jorge (coord.), El Tratado de Libre Comercio de América del Norte. Análisis, Diagnóstico y Propuestas Jurídicos, México, UNAM, Instituto de Investigaciones Jurídicas, t. II, 1993.

CARTER, Nicole, "Border Environment Policy, Part III: State of Binational Cooperation Today, Prospects for the Future", Borderlines 74, New Mexico, vol. 9, núm. 1, January 2001.

CARROLL, John E. (ed.), International environmental diplomacy. The management and resolution of transfrontier environmental problems, Cambridge, Cambridge University Press, 1990.

CASAsús, Joaquín D., El Chamizal. Demanda, réplica, alegato e informes ante el Tribunal de Arbitraje y sentencia, México, Eusebio Gómez de la Puente, 1911.

CHÁvez, Octavio E., "The 1994-95 drought, what did we learnt from it?: The Mexican perspective", Natural Resources Journal, Albuquerque, New Mexico, vol. 39, núm. 1, winter 1999.

Comisión de Cooperación Ambiental, "El mosaico de América del Norte", en http://www.cec.org/pubs_docs/documents/index.cfm? varlan $=$ espanol\&ID $=629$

Comisión Nacional del Agua, "NOM-011-CNA-2000. Conservación del recurso agua. Establece las especificaciones y el método para 
determinar la disponibilidad media anual de las aguas nacionales", Diario Oficial de la Federación, México, 17 de abril de 2002.

—_, "Programa de Modernización de Organismos Operadores de Agua", en http://www.cna.gob.mx/portal/publica/doctos/publica ciones/promma/promagua.pdf

-, Estadísticas del Agua en México, México, CNA, 2003.

- Programa Nacional Hidráulico 2001-2006, México, CNA, 2000.

Convención de Viena sobre el Derecho de los Tratados de 1969, México, Secretaría de Relaciones Exteriores, 1976.

Convenio entre los Estados Unidos Mexicanos y los Estados Unidos de América sobre Cooperación para la Protección del Medio Ambiente en la Zona Fronteriza, Diario Oficial de la Federación, México, 22 de marzo de 1984.

Cortinas de Nava, Cristina y Vega Gleason, Sylvia, Residuos peligrosos en el mundo y México, México, Secretaría de Desarrollo Social-Instituto Nacional de Ecología, 1993.

CRUz Miramontes, Rodolfo, "Comentarios al Acta 218 de la Comisión Internacional de Límites y Aguas", Lecturas Jurídicas, Chihuahua, México, núm. 27, abril-junio, 1966.

- "El problema limítrofe fluvial entre México y los Estados Unidos; la Doctrina Harmon, el Tratado de Aguas de 1944 y algunos problemas derivados de su aplicación", Revista de Derecho Público, Santiago, Chile, núm. 4, septiembre, 1965.

—_ "La administración y solución de conflictos de las cuencas fluviales internacionales: Experiencia actual de México en su frontera norte", Anuario Jurídico, México, vol. XV, 1988.

— , "El conflicto de las aguas del río Colorado", Lecturas Jurídicas, Chihuahua, México, núm. 10, 1962.

_ , "Las comisiones fluviales internacionales y la Comisión Internacional de Límites y Aguas", Natural Resources Journal, Albuquerque, New Mexico, vol. 18, núm. 1, January 1978.

DÁVILA, Guillermo H., "Air pollution control on the United States-Mexico Border: International considerations", Natural Resources Journal, Albuquerque, New Mexico, vol. 12, núm. 4, October, 1972.

DiEgo-FernándeZ, Salvador, Los pactos de Bucareli. El Tratado de la Mesilla, México, Editorial Polis, 1937. 
DuMARS, Charles T., "The New Federal Regulatory Water Rights and the Future of River Management: The Example of New Mexico", Utton Center Report, Albuquerque, New Mexico, vol. 1, núm. 1, spring, 2002.

ENRÍQUEZ, Ernesto, "Defensa del Tratado México-Norteamericano sobre Ríos Internacionales", Revista de la Escuela Nacional de Jurisprudencia, México, t. VIII, núm. 30, abril-junio, 1946.

ENRÍQUEZ, Bill, "International legal implications of industrial development along the Mexican-U.S. border", Natural Resources Journal, Albuquerque, New Mexico, vol. 12, núm. 4, October, 1972.

Environmental Protection Agency, "Cuarto Informe de la Junta Ambiental del Buen Vecino", en http://www.epa.gov/ocem/gnevpage.htm

—_ "Programa Ambiental México-Estados Unidos 2012", http:// www.epa.gov/usmexicoborder/index_esp.htm\#principles

Escolero, O., Panorámica del agua subterránea en México. El agua recurso vital, Oaxaca, Universidad Tecnológica de la Mixteca, 1993.

FILHO, Armando Gallo Yahn, "Aspectos jurídico-ambientais da utilização dos cursos d'água internacionais", en BENJAMín, Antonio Herman (ed.), Direito, Água e Vida, São Paulo, Procuradoria Geral de Justiça do Estado de São Paulo-Instituto O Direito por um Planeta Verde, 2003, vol. 2.

Food Agriculture Organization, "Sistema de Información sobre el Uso del Agua en la Agricultura y el Medio Rural de la FAO; Estado del Agua en México", en http://www.fao.org/landandwater/aglw/ aquastat/countries/mexico/

Gallardo, Sofía C., "El debate sobre el Acuerdo de Cooperación Ambiental", Estados Unidos, México, vol. III, núm. 4, invierno de 1993.

GANTZ, David A., "United States approaches to the salinity problem on the Colorado River", Natural Resources Journal, Albuquerque, New Mexico, vol. 12, núm. 4, October, 1972.

GARCÍA-ACEVEDO, María Rosa, "Agua: cooperación y conflicto en la frontera México-Estados Unidos", Cuadernos Americanos, nueva época, vol. 3, núm. 87, mayo-junio del 2001.

, "The confluence of water, patterns of settlement, and constructions of the border in the Imperial and the Mexicali Valleys (1990-1999)", en BlatTER, Joachim e INGRAM, Helen (eds.), Re- 
flections on water: New approaches to transboundary conflicts and cooperation, Cambridge, The MIT Press, 2001.

GARCÍA, G. et al., "El impacto del revestimiento del canal "Todo americano" sobre la calidad del agua del acuífero y el rendimiento de los cultivos del Valle de Mexicali”, en SÁNCHEZ Munguía, Vicente (coord.), El revestimiento del Canal Todo Americano. ¿Competencia o cooperación por el agua en la frontera México Estados Unidos?, México, El Colegio de la Frontera Norte-Plaza y Valdés, 2004.

GARCÍA LÓPEZ, Tania, Quien contamina paga; principio regulador del derecho ambiental, México, Porrúa, 2001.

GARCÍA Moreno, Víctor Carlos, "Derecho internacional, ecología, desechos peligrosos y otros temas", Lex; Difusión y Análisis, México, 3a. época, año II, núm. 10, abril 1996.

GASCA ZAMORA, José, "Desarrollo regional y medio ambiente en la frontera de México-Estados Unidos", en Delgadillo MACÍAS, Javier (coord.), Los terrenos de la política ambiental en México, México, UNAM, Instituto de Investigaciones Económicas-Miguel Ángel Porrúa, Librero-Editor, 2001.

GAINE, Sanford E., "The polluter pays principe: From economic equity to environmental ethos", Texas International Law Journal, Austin, vol. 26, núm. 3, 1991.

GLEICK, Peter H., "La importancia de cada molécula", Investigación Cientifica, Madrid, núm. 295, abril 2001.

GómEZ-Robledo VerduzCO, Alonso, Responsabilidad internacional por daños transfronterizos, México, UNAM, Instituto de Investigaciones Jurídicas, 1983.

GONZÁlEZ ANINAT, Raimundo, "Principios generales del derecho ambiental internacional", Revista de Derecho, Chile, año LX, núm. 191, enero-junio, 1992.

GONZÁLEZ, Ana Karina, La OCDE y el medio ambiente; La OMC y el medio ambiente, México, Centro Mexicano de Derecho Ambiental-National Wildlife Federation, 1998.

GotTLIEB, Robert y Fitz SimMONS, Margaret, Thirst for growth: Water agencies as hidden government in California, Tucson, University of Arizona Press, 1991.

GuTIÉRREZ BAYLÓN, Juan de Dios, "El septentrión fluvial y marítimo de México en el derecho internacional general", Anuario Mexicano de Derecho Internacional, México, vol. III, 2003. 
HaYton, Robert D. y UtTon, Albert E., "The Model Agreement on Transboundary Groundwaters", en http://uttoncenter.unm.edu/pdfs/ Bellagio_Draft_Treaty_S.pdf

_ , "Aguas subterráneas transfronterizas: Anteproyecto de Tratado "Bellagio", trad. de Carmen L. de Campoy y Raquel L. de Barbuzza, Natural Resources Journal, Albuquerque, New Mexico, vol. 32, núm. 2, spring 1992.

HERNÁNDEZ, John W., "Analysis of the drought of 1996 in the Middle Río Grande Valle of New Mexico", Natural Resources Journal, Albuquerque, New Mexico, vol. 39, núm. 1, winter 1999.

Herrera RAmos, M. J. (ed.), Desarrollo regional e infraestructura, México, Fundación Mexicana Cambio XXI, 1994.

Hohmann, Harald, Precautionary Legal Duties and Principles of Modern International Environmental Law. The Precautionary Principle: International Environmental Law between Exploitation and Protection, London, Graham \& Trotman, 1994.

Houston Advanced Research Center, "Water and Sustainable Development in the Binacional Lower Rio Grande", en http://www.harc.edu/ mitchellcenter/mexico/downloads.html

Instituto Nacional de Estadística, Geografía e Informática, Industria maquiladora de exportación, México, INEGI, 2003.

International Court of Justice, "Legality of the Threat or Use of Nuclear Weapons, Advisory Opinion of 8 July 1996", en http://www.icj-cij. org/icjwww/icases/iunan/iunanframe.htm

—_ Case concerning Gabcíkovo-Nagymaros Project (Hungary/ Slovakia), Judgment of 25 September 1997, The Netherlands, ICJ, 1997.

JAQUENOD DE ZsÖGÖN, Silvia, El derecho ambiental y sus principios rectores, Madrid, Dykinson, 1991.

JOHNSTONE, Nick, "International trade, transfrontier pollution, and environmental cooperation: A case study of the Mexican-American border region", Natural Resources Journal, Albuquerque, New Mexico, vol. 35, núm. 1, winter 1995.

JORDANO FRAGA, Jesús, La protección del derecho a un medio ambiente adecuado, Barcelona, Bosch, 1995.

Juste RuIZ, José, Derecho internacional del medio ambiente, Madrid, McGraw-Hill, 1999 
KELLY, Mary E., "The drought in Texas: Its impact and consequences", Natural Resources Journal, Albuquerque, New Mexico, vol. 39, núm. 1, winter 1999.

- et al., "The Border's Troubled Waters", Borderlines 83, New Mexico, vol. 9, núm. 10, November 2001.

KISS, Alexandre, Droit International de l'Environnement, Paris, Pedone, 1989.

- y SHELTON, Dinah, International environmental law, New York, Transnational Publishers, Inc., 1991.

Kourous, George, "Availability of Information on the Border Environment: An Introductory Assessment", Borderlines 59, New Mexico, vol. 7, núm. 8, September 1999.

, "Política ambiental en la frontera: la situación actual. Parte II: la reciente evolución de los esfuerzos y recomendaciones para futuras políticas", Borderlines 73, New Mexico, vol. 8, núm. 11, December 2000.

, "Still planning to plan?, The Border XXI Program: An Overview”, Borderlines 55, New Mexico, vol. 7, núm. 4, April 1999.

- "The Border's Troubled Waters, Second in a two-part series", Borderlines 84, New Mexico, vol. 9, núm. 11, December 2001.

LINARES, Mireille, "La sequía en la cuenca del río Bravo: principios de política", Gaceta Ecológica, México, núm. 70, 2004.

LOPERENA RoTA, Demetrio, El derecho al medio ambiente adecuado, reimp., Madrid, Civitas, 1998.

LÓPEZ, Todd M., "A look at climate change and the evolution of the Kyoto Protocol", Natural Resources Journal, Albuquerque, New Mexico, vol. 43, núm. 1, winter 2003.

MARÍN, Carlos, "Mexican water debt coming due", International Rivers and Lakes Newsletter, New York, núm. 35, June 2001.

MARTÍN MATEO, Ramón, "Cultura y tecnología del agua", Revista Española de Derecho Administrativo, Madrid, núm. 62, 1988.

- Tratado de Derecho Ambiental, Madrid, Trivium, 1991, vol. 2.

MAZARI HIRIART, Marisa, "El agua como recurso", ¿Cómo ves?, México, año 5, núm. 54, mayo 2003.

—_ "El potencial de contaminación del agua subterránea", Gaceta Ecológica, México, nueva época, núm. 36, septiembre, 1995.

MCGEe, Henry W. y ORTIZ NAGLE, Luz Estella, "TLC y el control de residuos tóxicos en la guerra contra la contaminación transfron- 
teriza”, Revista de Derecho Puertorriqueño, Ponce, vol. 35, núm. 1, 1996.

Mumme, Stephen P., "La Comisión Internacional de Límites y Aguas, los Estados Unidos y México. La protección del ambiente en la frontera entre los Estados Unidos y México", Revista de la Facultad de Derecho de México, México, t. XXXV, núms. 142-144, julio-diciembre 1985.

, "La reinvención de la Comisión Internacional de Límites y Aguas", Borderlines 79, New Mexico, vol. 9, núm. 6, June 2001.

, "Minute 242 and beyond: Challenges and opportunities for managing transboundary groundwater on the Mexico-U.S. border", Natural Resources Journal, Albuquerque, New Mexico, vol. 40, núm. 2, spring 2000.

, "Strengthening Binational Drought Management", Utton Center Report, Albuquerque, New Mexico, vol. 2, núm. 1, winter 2003, p. 7.

"Despite shortcomings, promising potential for improved protection NAFTA's Environmental Side Agreement: Almost Green?", Borderlines 60, New Mexico, vol. 7, núm. 9, October 1999.

, "Managing acute water scarcity on the U.S.-Mexico border: Institutional issues raised by the 1990's drought", Natural Resources Journal, Albuquerque, New Mexico, vol. 39, núm. 1, winter 1999.

-, "New directions in United States-Mexican transboundary environmental management: A critique of current proposals", Natural Resources Journal, Albuquerque, New Mexico, vol. 32, núm. 3, summer 1992.

Naciones Unidas, Asamblea General, Convención Internacional sobre el Derecho de los Usos de los Cursos de Agua Internacionales para Fines Distintos de la Navegación, A/RES/51/229, 21 de mayo de 1997.

, "Carta de las Naciones Unidas", 26 de junio de 1945, disponible en http://www.un.org/spanish/aboutun/charter.htm

NEWCOMB, John, "Why exactly does the NAFTA CEC (Commission for Environmental Cooperation) exist?", International Rivers and Lakes Newsletter, New York, núm. 33, June 2000.

NOM-001-Semarnat-1996 que establece los límites máximos permisibles de contaminantes en las descargas de aguas residuales en aguas y 
bienes nacionales, Diario Oficial de la Federación, México, 6 de enero de 1997.

OJEDA, Ramón y LoperenA, Demetrio (eds.), Cases and materials on international and comparative environmental law, México, Editora Laguna, 2001.

Organisation for Economic Co-operation and Development, Declaration on Environmental Policy, C/M(74)26, disponible en http://web dominol.oecd.org/horizontal/oecdacts.nsf/Display/C5E33AAD694 E04E0C1257052007C6AC9?OpenDocument

ORTIZ RENDÓN, Gustavo, "Aspectos relevantes de la política del agua en México en el marco del desarrollo sustentable", en http://www.oieau. fr/ciedd/contributions/at2/contribution/rendon.htm

PEACH, James y WiLliams, James, "Borderlands Demographic Trends", Borderlines 58, New Mexico, vol. 7, núm. 7, August 1999.

PEÑALVER, Eduardo M., "Acts of god or toxic torts? Applying tort principles to the problem of climate change", Natural Resources Journal, Albuquerque, New Mexico, vol. 38, núm. 4, fall, 1998.

PIÑERO, Daniel (comp.), La ecología, las ciencias ambientales y la situación ambiental en México, México, Secretaría Ejecutiva del Consejo Consultivo de Ciencias, Presidencia de la República, 1994.

PITT, Jennifer et al., "Two nations, One river: Managing ecosystem conservation in the Colorado River Delta", Natural Resources Journal, Albuquerque, New Mexico, vol. 40, núm. 4, fall, 2000.

Plascencia Rodríguez, José Francisco, "Principios de tributación ambiental", Trimestre Fiscal, Guadalajara, Jal., México, año 17, núm. 55, julio-septiembre de 1996.

PosTEL, Sandra, "Aprovechamiento agrícola del agua", Investigación y Ciencia, Madrid, núm. 295, abril 2001.

Presidencia de la República, "Plan Nacional de Desarrollo", en pnd. presidencia.gob.mx/pdf/2003/pag_234-246.pdf

Real Academia Española, Diccionario de la lengua española, 20a. ed., Madrid, Espasa-Calpe, 1984, t. II, H-Z.

Recomendaciones de la Conferencia de las Naciones Unidas sobre Aguas Internacionales, en SZÉKELY, Alberto, Instrumentos fundamentales de derecho internacional público, México, UNAM, Instituto de Investigaciones Jurídicas, 1990, t. V.

Resolución sobre Cooperación en el Campo del Medio Ambiente en Materia de Recursos Naturales Compartidos por Dos o Más Estados, 
Asamblea General de la ONU, 13 de diciembre de 1973, en SzÉKELY, Alberto, Instrumentos fundamentales de derecho internacional público, México, UNAM, Instituto de Investigaciones Jurídicas, 1990, t. V.

REYNOLDS, S. E., "The water quality problem on the Colorado River", Natural Resources Journal, Albuquerque, New Mexico, vol. 12, núm. 4, October, 1972.

RINCÓN, Carlos y EMERSON, Peter, "Binationally Managing Air Quality in the U.S.-Mexico Borderlands: A Case Study", Borderlines 63, New Mexico, vol. 8, núm. 1, January 2000.

Rogers, Ann Berkley y UTTON, Albert E., "The Ixtapa Draft Agreement relating to the Use of Transboundary Ground waters", Natural Resources Journal, Albuquerque, New Mexico, vol. 25, núm. 3, July 1985.

ROMERO LANKAO, Patricia, "Uso social y gestión gubernamental del agua en México", en BARBA PIREZ, Regina (coord.), La guía ambiental, México, Unión de Grupos Ambientalistas, 1998.

SÁNCHEZ, Roberto A., "Health and environmental risk of the maquiladora in Mexicali", Natural Resources Journal, Albuquerque, New Mexico, vol. 30, núm. 1, winter 1990.

SÁnCHEZ, Vicente, CASTILleJos, Margarita y RoJAS BRACHO, Leonora, Población, recursos y medio ambiente en México, México, Fundación Universo Veintiuno, 1989.

SAUSER-HALL, George, "L'utilisation industrielle des fleuves internationaux", Recueil des Cours, Leyde, t. 83, vol. II, 1953.

Secretaría de Comercio y Fomento Industrial, "Tratado de Libre Comercio de América del Norte", Diario Oficial de la Federación, México, 21 de diciembre de 1993.

— - Tratado de Libre Comercio de América del Norte. Acuerdos Paralelos. Conclusión de las Negociaciones, México, Secofi-Miguel Ángel Porrúa, 1993.

Secretaría de Economía, "Sistema de Información de la Industria Maquiladora", en http://www.siem.gob.mx/siem2000/spyme/maquila_/ intranet.asp

Secretaría de Medio Ambiente y Recursos Naturales, "Decreto por el que se reforman, adicionan y derogan diversas disposiciones de la Ley de Aguas Nacionales", Diario Oficial de la Federación, México, 29 de abril de 2004. 
Centro de Educación y Capacitación para el Desarrollo Sustentable, "Programa para la Frontera Norte", en http://cecadesu. semarnat.gob.mx/programa_fronteranorte/index.shtml\# ftn 1

Secretaría de Recursos Hidráulicos, Salinidad del Río Colorado (Recopilación), México, SRH, 1975.

Secretaría de Relaciones Exteriores, "Comisión Internacional de Límites y Aguas entre México y los Estados Unidos", en http://www.sre. gob.mx/cila

Algunos documentos sobre el Tratado de Guadalupe y la situación de México durante la invasión americana, México, SRE, Archivo Histórico Mexicano, 1930.

- Comisión Internacional de Límites y Aguas entre México y los Estados Unidos, Sección Mexicana, "Salinidad de las Aguas que Recibe México del Río Colorado en el Valle de Mexicali, B. C.", en http://www.sre.gob.mx/cila

- Convenio con Estados Unidos acerca de la salinidad de las aguas del río Colorado que se entregan a México, México, SRE, 1965.

- Declaración del Gobierno de los Estados Unidos Mexicanos sobre la Aceptación de sus Obligaciones como miembro de la Organización para la Cooperación y el Desarrollo Económico, México, SRE, 1994.

-, El Tratado de Aguas Internacionales celebrado entre México y los Estados Unidos el 3 de febrero de 1944, México, SRE, Oficina de Límites y Aguas Internacionales, 1947.

-, Tratados y convenciones vigentes entre los Estados Unidos Mexicanos y otros países, t. VI: Tratados y convenciones bilaterales, México, SRE, 1938.

SEPÚlvedA, César, "Historia y problemas de los límites de México; I. La frontera Norte", Historia Mexicana, México, vol. VIII, núm. 1, julio-septiembre 1958.

-, "Instituciones para la solución de problemas de aguas de superficie entre México y los Estados Unidos", Natural Resources Journal, Albuquerque, New Mexico, vol. 18, núm. 1, January 1978.

-, "La contaminación de los ríos internacionales y el derecho; El conflicto México-Estados Unidos sobre el río Colorado 1961-1973 y sus lecciones", Anuario de Derecho Internacional, Pamplona, núm. $1,1974$. 
, "Los recursos hidráulicos en la zona fronteriza México-Estados

Unidos. Perspectiva de la problemática hacia el 2000; Algunas recomendaciones", Natural Resources Journal, Albuquerque, New Mexico, vol. 22, núm. 4, October, 1982.

_- "Mexican-American International Water Quality Problems: Prospects and Perspectives", Natural Resources Journal, Albuquerque, New Mexico, vol. 12, núm. 4, October, 1972.

$\longrightarrow$, Derecho Internacional, 18a. ed., actualizada, México, Porrúa, 1997.

SoARes, Guido Fernando da Silva, Direito Internacional do Meio Ambiente, São Paulo, Atlas, 2001.

SoBARzO, Alejandro, "Salinity in the Colorado: An interpretation of the Mexican-American Treaty of 1944", Natural Resources Journal, Albuquerque, New Mexico, vol. 12, núm. 4, October 1972.

SZÉKELY, Alberto, Instrumentos fundamentales de derecho internacional público, México, UNAM, Instituto de Investigaciones Jurídicas, 1990, t. V.

—_, "Establishing a Region for Ecological Cooperation in North America", Natural Resources Journal, Albuquerque, New Mexico, vol. 32, núm. 3, summer 1992.

, "International law of natural resources and the environment: A selected bibliography", Natural Resources Journal, Albuquerque, New Mexico, vol. 30, núm. 4, fall 1990.

, "International law of natural resources and the environment: A selected bibliography. Part 2", Natural Resources Journal, Albuquerque, New Mexico, vol. 31, núm. 2, spring 1991.

_- "Emerging boundary environmental challenges and institutional issues: Mexico and the United States", Natural Resources Journal, Albuquerque, New Mexico, vol. 33, núm. 1, winter 1993

TAPIA HERNÁNDEZ, Silverio (comp.), Principales Declaraciones y Tratados Internacionales de Derechos Humanos Ratificados por México, México, Comisión Nacional de Derechos Humanos, 1999.

TOLIVIA, Enrique, "Problemas y perspectivas de la calidad del aire en la frontera", Natural Resources Journal, Albuquerque, New Mexico, vol. 22, núm. 4, October, 1982.

United Nations, "April rains reduce Mexico water debt to Texas", International Rivers and Lakes Newsletter, New York, núm. 1, June 2004. 
, "Mexican desert state and US farmers fight for water", International Rivers and Lakes Newsletter, New York, núm. 36, December 2001.

, "Mexico-USA: Binational Water Challenges and Opportunities Conference Recommendations", International Rivers and Lakes Newsletter, New York, núm. 32, December 1999.

, "The United Nations Framework Convention on Climate Change", en http://unfccc.int/essential_background/kyoto_protocol/status_of_ratification/items/2613.php

-, Summaries of Judgments, Advisory Opinions and Orders of the International Court of Justice, 1992-1996, New York, United Nations, 1998.

-, Department of Economic and Social Affairs, Division for Sustainable Development, "Programme 21", en http://www.un.org/esa/ sustdev/documents/agenda21/spanish

, General Assembly, Resolución 34/186, Cooperación en el campo del medio ambiente en materia de recursos naturales compartidos por dos o más Estados", en http://www.un.org/spanish/documents/ ga/res/34/ares34.htm

, International Year of Freshwater 2003, "El derecho al agua como derecho humano", en http://www.wateryear2003.org/es/ev.php $-U R L \_I D=4087 \& U R L \_D O=D O \_T O P I C \& U R L \_S E C T I O N=201$. html

, Yearbook of the International Law Commission, 1990, Summary Records of the Meetings of the Forty-Second Session, 1 May 1-20 July 1990, New York, United Nations, 1993, vol. II, part 2.

, Department of Economic and Social Affairs, "Declaración de Johannesburgo sobre el Desarrollo Sostenible", en http://www.un. org/esa/sustdev/documents/WSSD_POI_PD/Spanish/WSSDsp_PD. htm

UTTON, Albert E., "An assessment of the management of U. S.-Mexican water resources: Ancicipating the year 2000", Natural Resources Journal, Albuquerque, New Mexico, vol. 22, núm. 4, October, 1982.

, "Doping with drought on an International River under stress: The case of the Río Grande-Río Bravo", Natural Resources Journal, Albuquerque, New Mexico, vol. 39, núm. 1, winter 1999.

, "Problems and successes of international water agreements: The example of the United States and Mexico", en CARROLL, John E. 
(ed.), International environmental diplomacy; The management and resolution of transfrontier environmental problems, Cambridge, Cambridge University Press, 1990.

VICTORIA MASCORRO, Edmundo, "Características del desarrollo económico de la franja fronteriza norte de México", Natural Resources Journal, Albuquerque, New Mexico, vol. 22, núm. 4, October, 1982. WILDER, Margaret, "Border farmers, water contamination, and the NAAEC environmental side accord to NAFTA", Natural Resources Journal, Albuquerque, New Mexico, vol. 40, núm. 4, fall, 2000.

World Water Council, "Indicadores de disponibilidad, acceso y calidad del agua", en http://www.worldwaterforum.net 